Imitação de expressões faciais para aprendizado de emoções em robótica social

Valéria de Carvalho Santos 



\title{
Imitação de expressões faciais para aprendizado de emoções em robótica social
}

\author{
Valéria de Carvalho Santos
}

Orientadora: Profa. Dra. Roseli Aparecida Francelin Romero

Dissertação apresentada ao Instituto de Ciências Matemáticas e de Computação - ICMC-USP, como parte dos requisitos para obtenção do título de Mestre em Ciências - Ciências de Computação e Matemática Computacional. VERSÃO REVISADA 
Ficha catalográfica elaborada pela Biblioteca Prof. Achille Bassi e Seção Técnica de Informática, ICMC/USP, com os dados fornecidos pelo(a) autor(a)

d231i de Carvalho Santos, Valéria
Imitação de expressões faciais para aprendizado de
emoçóes em robótica social / Valéria de Carvalho
Santos; orientadora Roseli Aparecida Francelin
Romero. -- São Carlos, 2012.
85 p.
Dissertação (Mestrado - Programa de Pós-Graduação en
Ciências de Computação e Matemática Computacional) --
Instituto de Ciências Matemáticas e de Computação,
Universidade de São Paulo, 2012.
1. Robótica Social. 2. Aprendizado por Imitação. 3.
Redes Neurais Artificiais. 4. Emoção Artificial. I.
Aparecida Francelin Romero, Roseli, orient. II.
Título.


"Entrega o teu caminho ao Senhor, confia Nele e o mais Ele fará"

(Salmo 37,5) 



\section{Agradecimentos}

Conquistei mais uma vitória na minha vida e gostaria de agradecer a todos que colaboraram comigo nessa fase, pois sozinha eu não teria conseguido.

Acima de tudo, agradeço a Deus, que sempre me ilumina e me dá forças para vencer. "Tudo posso Naquele que me fortalece".

Aos meus pais, Arlene e Moacir, que sempre apoiam minhas decisões e não medem esforços para me ajudar a atingir meus objetivos. Aos meus irmãos, Camilo e Clarisse pelo carinho e compreensão. Apesar da distância, que só nós sabemos o quanto é difícil enfrentar, o amor de vocês me deu forças para superar as dificuldades.

À minha orientadora Roseli, pela oportunidade e confiança no meu trabalho.

Aos professores da Universidade Federal de Sergipe que me incentivaram a fazer o mestrado. Em especial, agradeço a Hendrik, que me inspirou a seguir a linha de pesquisa que escolhi, e à Leila, que além de todo apoio, acompanhou minha trajetória durante todo esse tempo e tornou-se uma grande amiga. Muito obrigada pelas tradicionais tardes de lanche, conversa e conselhos nas minhas idas a Aracaju.

Aos amigos do Biocomp/LAR pela convivência diária. Gostaria de agradecer em especial aos amigos Rodrigo Calvo, Bruno, Renato, André, Fernando Zuher, Luiz Coletta e Thiago Cupertino. Muito obrigada pelas conversas, conselhos, orientações e momentos de descontração.

À minha companheira de moradia, Gabriela, com quem divido momentos de alegria e de dificuldade. Obrigada pela amizade construída nesses anos.

À amiga Laura pelo companheirismo, confiança e disposição para me ajudar sempre que preciso.

À minha amiga Chris pela paciência em me ouvir nos momentos de desespero e por sua alegria e otimismo cativante.

Ao Sergio, que além de ajudar muito no desenvolvimento do meu trabalho, tornou-se um grande amigo. Sempre vou lembrar com carinho e saudades do tempo que você passou aqui.

Ao amigo Thiago Reis e sua esposa Aline pela amizade mantida por tantos anos e, principalmente, pelo apoio nos meus primeiros meses sozinha em São Carlos.

Agradeço a todos amigos que conheci no ICMC durante o curso das 
disciplinas, nas festas e nas pausas para o café. O apoio dos amigos foi essencial para minha adaptação em São Carlos e motivação para nunca pensar em desistir. Em especial, gostaria de citar os amigos Alceu, Nathalie, Fernando Alva, Pedro, Silvana e Fredy.

Aos meus amigos e familiares de Aracaju, que mesmo longe torcem para o meu sucesso.

Agradeço à Carnegie Melon University, por ter cedido o robô virtual, e ao Jason Saragih, por ter cedido seu sistema de detecção de pontos da face, usados nesta pesquisa.

Por fim, agradeço aos funcionários do ICMC/USP pela dedicação ao trabalho e ao CNPq e à Fapesp pelo apoio financeiro. 


\title{
Resumo
}

\begin{abstract}
Robôs sociáveis devem ser capazes de interagir, se uma maneira natural. Embora diversos robôs sociáveis tenham sido desenvofidos com sucesso, ainda existem muitas limitações a serem superadas. São necessários importantes avanços no desenvolvimento de mecanismos que possibilitem interações mais realísticas, bem como regulem o relacionamento entre robôs e humanos. Um forma de tornar mais realísticas as interações é através de expressões faciais de emoção. Nesse contexto, este trabalho fornece capacidade de imitação de expressão facial de emoções a uma cabeça robótica virtual, com o objetivo de permitir interações mais realísticas e duradouras com o ser humano. Para isso, é incorporado à mesma aprendizado por imitação, no qual a cabeça robótica imita expressões faciais apresentadas por um usuário durante a interação social. O aprendizado por imitação foi realizado atráves de redes neurais artificiais. As expressões faciais consideradas neste trabalho são: neutra, alegria, raiva, surpresa e tristeza. Os resultados experimentais são apresentados, os quais mostram o bom desempenho do sistema de imitação proposto.
\end{abstract}





\title{
Abstract
}

\begin{abstract}
ociable robots must be able to interact, communicate, understand and relate to humans in a natural way. Although many social robots have been developed successfully, there are still many limitations to overcome. Important advances are needed in the development of mechanisms that allow more realistic interactions and that regulate the relationship between robots and humans. One way to make more realistic interactions is through facial expressions of emotion. In this context, this project provides ability for imitation of facial expressions of emotion to a virtual robotic head, in order to allow more realistic and lasting interactions with humans. For such, learning by imitation is used, in which the robotic head mimics facial expressions made by a user during social interaction. The imitation learning was performed by artificial neural networks. Facial expressions considered in this work are: neutral, happiness, anger, surprise and sadness. Experimental results are presented which show the good performance of the proposed system imitation.
\end{abstract}





\section{Sumário}

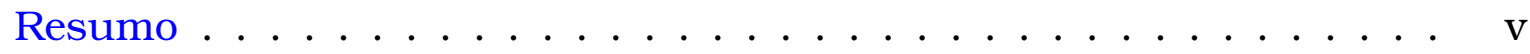

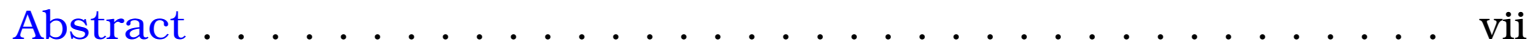

Sumário .................... ix

1 Introdução 1

1.1 Objetivo ..................... 2

1.2 Organização..................... 3

2 Robótica Social 5

2.1 Aspectos para o Desenvolvimento de Robôs Sociais . . . . . . . . 5

2.2 Considerações Finais . . . . . . . . . . . . . . . . . . . 12

3 Aprendizado por Imitação 15

3.1 Trabalhos Relacionados ao Aprendizado por Imitação . . . . . . . 15

3.2 Considerações Finais . . . . . . . . . . . . . . . . . 30

4 Redes Neurais Artificiais $\quad 31$

4.1 Conceito . . . . . . . . . . . . . . . . . . 32

4.2 Funções de Ativação . . . . . . . . . . . . . . . . . . . . . 33

4.3 Aprendizado Supervisionado . . . . . . . . . . . . . . . . . 34

4.4 Topologias de Redes Neurais Artificiais . . . . . . . . . . . . . . . 39

4.5 Considerações Finais . . . . . . . . . . . . . . . . . 42

5 Sistema de Imitação de Expressões Faciais de Emoção 45

5.1 Módulo de Extração Automática de Características da Face . . . . 46

5.1 .1 Sistema I . . . . . . . . . . . . . . . . . . 46

5.1 .2 Sistema II . . . . . . . . . . . . . . . . . 50

5.2 Módulo de Reconhecimento e Geração de Expressões Faciais de

Emoção . . . . . . . . . . . . . . . . . . . . . 51

5.2 .1 Cabeça Robótica Virtual . . . . . . . . . . . . . . . . . . 52

5.2.2 Rede de Jordan com a Utilização do Sistema I . . . . . . . . 53

5.2 .3 Rede TLFN com a Utilização do Sistema I . . . . . . . . . . . 54

5.2.4 Rede MLP e TLFN com a Utilização do Sistema II . . . . . . 55

5.3 Considerações Finais . . . . . . . . . . . . . . . . . 58 
6 Avaliação Experimental 59

6.1 Rede TLFN com a Utilização do Sistema I . . . . . . . . . . . . . 59

6.2 Rede MLP e TLFN com a Utilização do Sistema II . . . . . . . . . . 60

6.3 Considerações Finais . . . . . . . . . . . . . 73

7 Conclusão e Trabalhos Futuros 75

7.1 Conclusão . . . . . . . . . . . . . . . 75

7.2 Trabalhos Futuros . . . . . . . . . . . . 76

$\begin{array}{ll}\text { Referências Bibliográficas } & 85\end{array}$ 


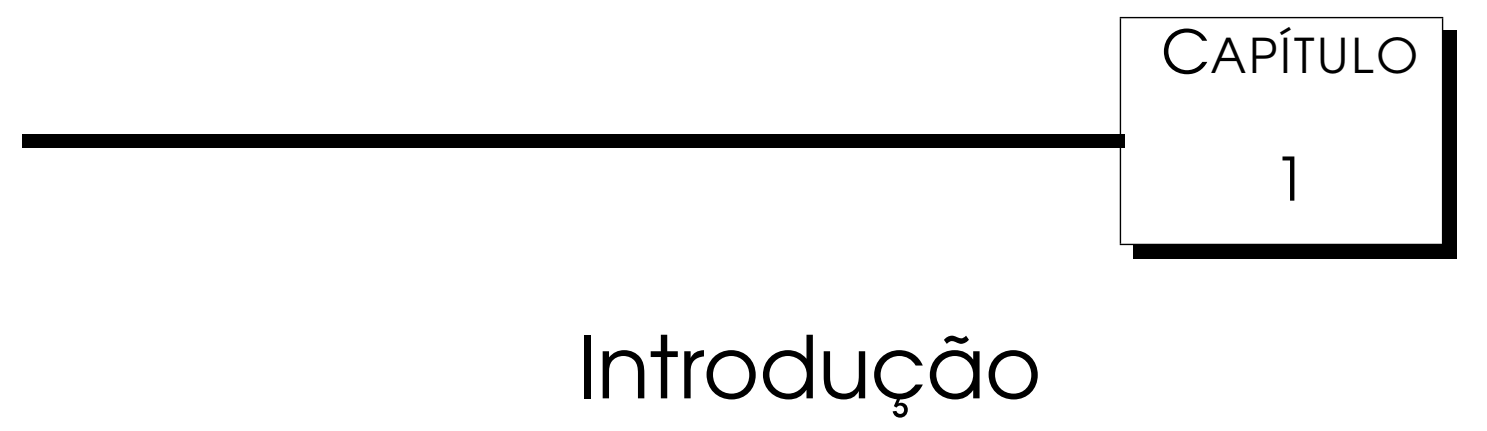

$\mathcal{R}$

obôs sociais são agentes que fazem parte de um grupo heterogêneo, uma sociedade de robôs ou humanos. Estes robôs não devem ser confundidos com sistemas multi-robôs, nos quais diversos robôs devem interagir para a execução de tarefas específicas. Eles devem ser capazes de reconhecer outros robôs ou seres humanos e realizar interações sociais. Para isso, devem possuir percepções, conseguir interpretar o ambiente no qual estão inseridos, além de se comunicar, aprender e se relacionar com seres humanos de uma maneira natural (Breazeal, 2002).

Existem motivações científicas e práticas para o desenvolvimento de robôs sociais. De uma perspectiva científica, pode-se aprender muito sobre a natureza social dos seres humanos com o processo de desenvolvimento de robôs socialmente inteligentes (Breazeal, 2002; Webb, 2000). De uma perspectiva prática, com o progresso das pesquisas sobre robôs sociais e o potencial que esses robôs oferecem, espera-se o aumento da utilização deles no auxílio aos seres humanos em um número cada vez maior de tarefas. Esses robôs são particularmente importantes em domínios de problema nos quais devem interagir com os seres humanos para resolver tarefas específicas, ou em domínios nos quais possam ser utilizados como máquina persuasiva. Neste contexto, alguns pesquisadores têm empregado robôs sociais como ferramentas de ensino ou como mediadores de interações em terapias com crianças autistas (Robins et al., 2004; Bjoorne e Balkenius, 2005). 
Uma abordagem recentemente empregada para o desenvolvimento de robôs sociais é a biologicamente inspirada, na qual o objetivo é criar robôs que imitam ou simulam o comportamento social ou inteligente encontrado nas criaturas vivas. Projetos biologicamente inspirados são baseados em teorias da neurociência e ciências biológicas, incluindo antropologia, psicologia, etiologia, sociologia, entre outras. Estas teorias têm sido largamente empregadas para direcionar o projeto dos sistemas motivacional, motor, cognitivo e comportamental dos robôs (Breazeal, 2000; Dautenhahn et al., 2002).

Humanos e animais usam imitação como um mecanismo para adquirir conhecimento. O aprendizado baseado em imitação é explorado para capacitar um agente inexperiente a aprender tarefas simplesmente observando o desempenho de um agente experiente. Essa abordagem pode ser vista como um aprendizado colaborativo baseado na interação entre o humano e o agente (Bombini et al., 2009).

\subsection{Objetivo}

A maioria dos robôs sociais existentes possui habilidades limitadas de percepção, cognição e comportamento em comparação com os seres humanos. O desenvolvimento de robôs que possuam a noção de socialização, ou seja, robôs que possam desenvolver habilidades sociais além de mostrar empatia e entendimento do mundo real, é uma tarefa complexa. Uma forma de contribuir com a socialização dos robôs é fornecer capacidade de expressão facial de emoções, tornando a interação com os humanos mais realísticas. Dessa forma, o principal objetivo deste trabalho é fornecer capacidade de imitação de expressão facial de emoções a uma cabeça robótica virtual, a partir de expressões fornecidas por um humano. Essa cabeça robótica foi obtida através de um projeto em conjunto existente entre a Carnegie Mellon University e o Laboratório de Aprendizado de Robôs (LAR), do Instituto de Ciências de Computação e Matemática Computacional (ICMC/USP). Cada expressão facial imitada será associada a uma das cinco emoções básicas (aversão, medo, alegria, tristeza e surpresa) apresentadas na literatura. 


\subsection{Organização}

Este documento está organizado da seguinte maneira:

Capítulo 2: é introduzido o tema a cerca de robótica social assim como os aspectos mais relevantes para o desenvolvimento de robôs sociais, a saber: voz, gestos e expressões faciais. Uma revisão de trabalhos a respeito destes aspectos é apresentado para contextualizar o tema do presente projeto.

Capítulo 3: aborda-se a contraposição de modelos de aprendizagem por imitação sobre modelos matemáticos e uma revisão de trabalhos relacionados focando o tema de aprendizagem por imitação considerado nesta dissertação.

Capítulo 4: são apresentados os conceitos básicos que envolvem a teoria de Redes Neurais Artificiais, salientando suas propriedades. O modelo de aprendizagem e topologia da rede adotados no sistema propostos neste capítulo

Capítulo 5: é descrito o sistema proposto de imitação de expressões faciais de emoção. Inicialmente, apresenta-se dois módulos de extração de características da face. Um foi desenvolvido no LAR enquanto que o outro foi cedido. Por meio desse módulos, informações são extraídas de expressões faciais e transmitidas para o módulo de reconhecimento e geração de expressões faciais de emoção. Tal modelo consiste no objetivo principal deste projeto.

Capítulo 6: são apresentados os experimentos utilizando ambos os sistemas de extração facial. Além disso, é fornecida uma análise experimental para avaliar o desempenho do sistema proposto.

Capítulo 7: são apresentadas as conclusões do trabalho e sugestões para futuras investigações. 



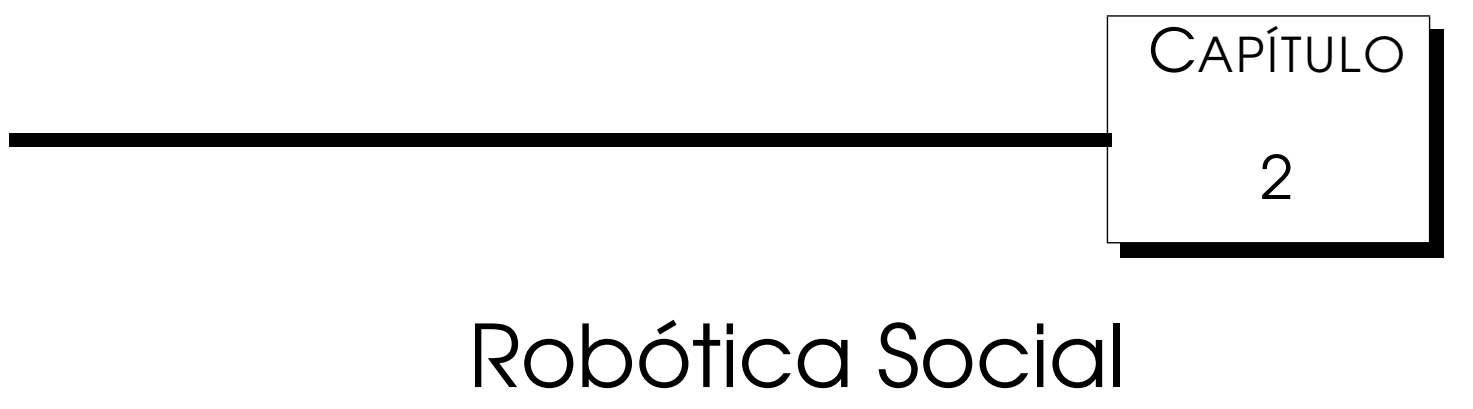

A intenção do desenvolvimento de robôs sociais é permitir que os robôs sejam capazes de interagir de forma natural com os seres humanos. Um dos aspectos que colaboram para tornar natural essa interação está relacionado à expressão de emoções. Em particular, na Seção 2.1 são apresentados os principais aspectos para o desenvolvimento de robôs sociais e alguns trabalhos direcionados a esse tema e na Seção 2.2 são apresentadas as considerações finais desse capítulo.

\subsection{Aspectos para o Desenvolvimento de Robôs Sociais}

O conceito de robô social é discutido por Duffy et al. (1999). Os autores afirmam que sociabilidade implica a existência de relacionamentos interativos. Um agente que apresenta comportamento interativo e comunicativo é considerado social. Nesse trabalho, o termo "robô social" é proposto como uma representação genérica para interação multi-robô, que engloba colaboração, comunicação, cooperação, coordenação, comunidades, entidade e relacionamentos com modelos comportamentais reativos e pró-ativos. Também é proposta uma arquitetura robótica social, composta por quatro camadas: física, reativa, deliberativa e social. A camada física considera que robôs devem assumir a forma de uma entidade física. $\mathrm{Na}$ camada reativa é implementada uma série de comportamentos reflexivos 
fundamentais. Na camada deliberativa, o processo de percepção converte eventos do agente em crenças e os adiciona ao conjunto de crenças. $\mathrm{Na}$ camada social, os agentes interagem através de uma linguagem de comunicação entre agentes. $\mathrm{O}$ autor desse trabalho acredita que essa arquitetura é escalável e pesquisas futuras visam demonstrar sua aplicabilidade em domínios de problemas diferentes do mundo real.

Os robôs sociais precisam perceber e entender o comportamento humano para interagir com estes (Sidner et al., 2005). Eles devem ser capazes de rastrear características humanas, interpretar a fala, além de incorporar mecanismos para o reconhecimento de expressões faciais, gestos e atividades humanas (Breazeal, 2002; Kanda et al., 2004; Salichs et al., 2006). Outra importante característica dos robôs sociais é a capacidade de integrar as percepções visuais e auditivas, a partir de interfaces multimodais, para a formação de conceitos e complemento das informações, uma vez que os seres humanos frequentemente utilizam gestos para complementar a fala e para compactar informações geométricas (localização, direção de movimento) (Policastro et al., 2008). Isso demanda o desenvolvimento de interfaces multimodais que permitam a interação do robô em tempo real, direcionando seus recursos computacionais para o processamento dos estímulos mais relevantes do ambiente. Pode-se citar, como exemplos, o robô Maggie (Salichs et al., 2006) e o robô Grace (Gockley et al., 2007) que integram interfaces com visão, voz e personificação corporal. A figura 2.1 ilustra o robô Maggie e a figura 2.2 ilustra o robô Grace. À esquerda, o robô Grace está seguindo uma pessoa e à direita é apresentada sua face gráfica em um monitor LCD.

Uma arquitetura robótica que integra um sistema de visão computacional e um sistema de reconhecimento de voz foi desenvolvida por Policastro et al. (2007, 2008). Esta arquitetura foi modularizada para permitir a inserção de diferentes sistemas periféricos como, por exemplo, diferentes sistemas motores para manipulação de robôs. Ela foi utilizada com sucesso para manipular uma cabeça robótica interativa. A Figura 2.3 apresenta a arquitetura robótica. O módulo de visão computacional é composto por um módulo de reconhecimento de faces humanas, capaz de estimar a pose da cabeça de um ser humano, e por um módulo de detecção de objetos, capaz de identificar cores. O módulo de reconhecimento de voz permite a interação entre robô e usuário do sistema por meio da fala. Esse módulo é capaz de reconhecer frases completas em português. A arquitetura robótica permite o aprendizado por meio da interação social. Valendo-se de um conjunto de 


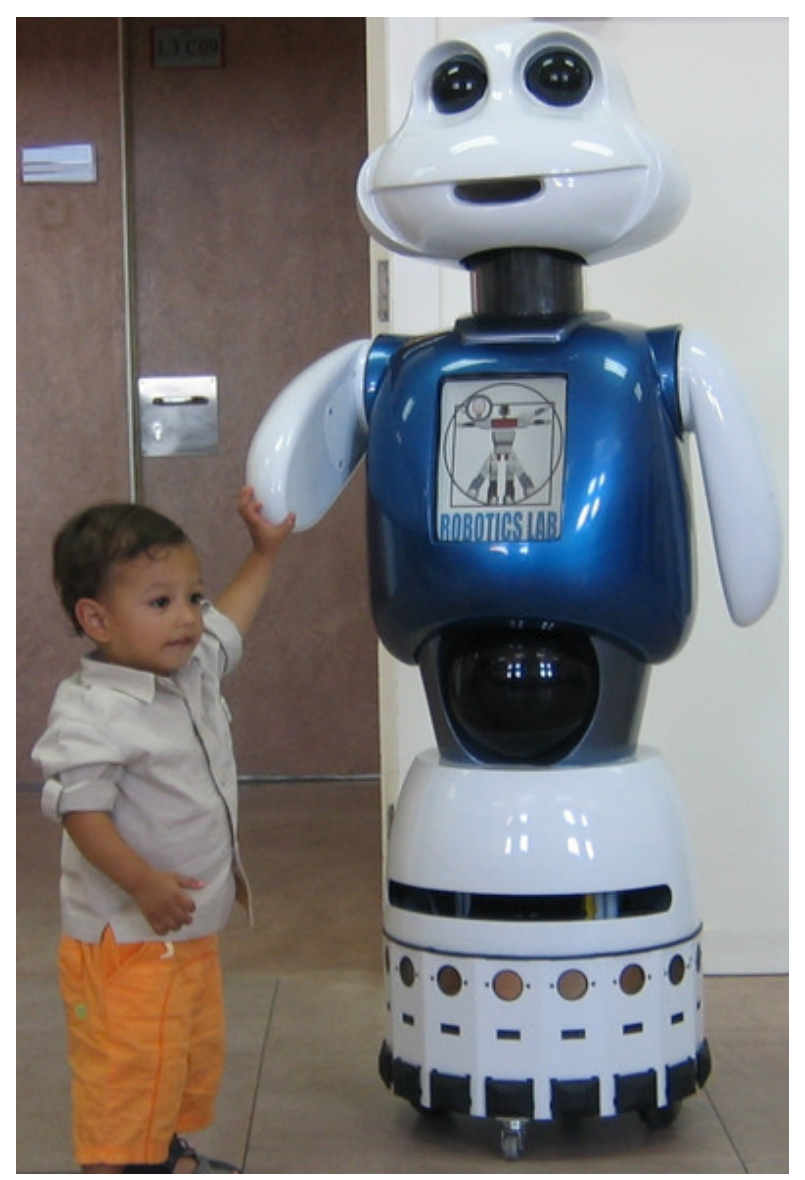

Figura 2.1: O robô Maggie (Salichs et al., 2006)

comportamentos iniciais simples aprendidos durante a interação social com o usuário, ela é capaz de produzir comportamentos mais complexos utilizando os vários comportamentos simples existentes. Três módulos principais constituem essa arquitetura robótica: percepção de estímulos, emissão de respostas e controle de conseqüências. O módulo de percepção de estímulos suporta a conexão de diversos módulos externos de percepção (sistema de visão computacional, sistema de reconhecimento de voz e algoritmos de aquisição de dados), dependendo do domínio da aplicação para o qual se está desenvolvendo o robô. Este módulo é responsável por detectar o estado do ambiente e codificá-lo, empregando uma representação apropriada. O módulo de emissão de respostas é composto por um mecanismo de aprendizado responsável por modificar os comportamentos do modelo computacional, por meio da interação social. O módulo de controle de consequências é composto por um sistema motivacional, responsável por simular as necessidades internas de um indivíduo e detectar os reforços recebidos do ambiente. O objetivo desse módulo é conferir pró-atividade ao 

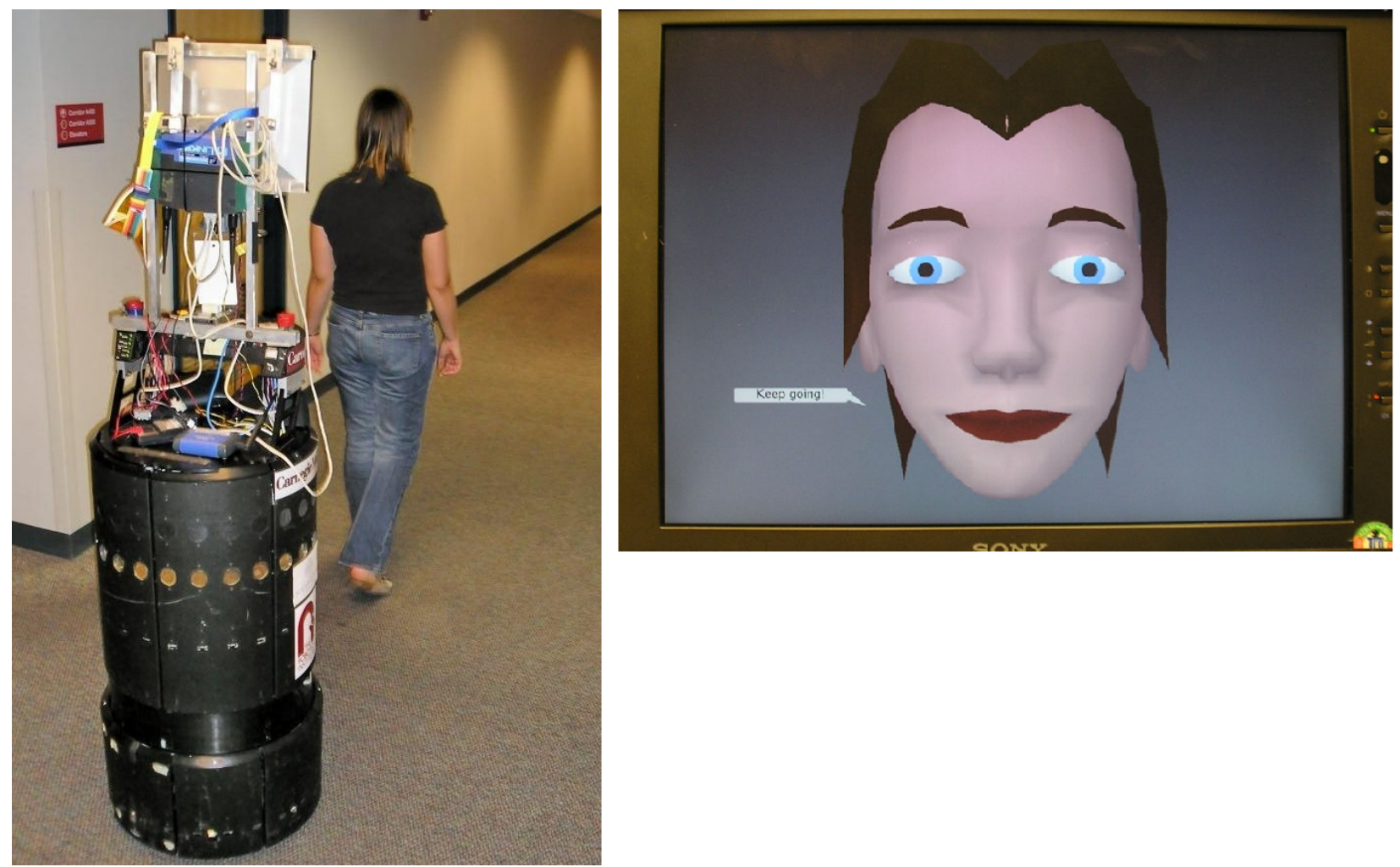

Figura 2.2: À direita, o robô Grace seguindo uma pessoa e à esquerda, sua face gráfica em um monitor LCD (Gockley et al., 2007).

robô nas interações com o ambiente. A arquitetura robótica também utiliza uma memória de trabalho para trocar informações entre seus três módulos principais. Esta memória é usada para manter informações sobre estímulos, últimas respostas emitidas, necessidades internas ativas, reforços detectados, além de possuir um contador que confere a noção de tempo.

As interações sociais não se dão apenas através da fala. Os sinais não-verbais podem contribuir de maneira mais significativa para essas interações. Segundo Frith (2009), entre os sinais não-verbais, as expressões facias têm maior parte nas interações sociais. Por isso, é desejável que um robô social reconheça e imite expressões faciais. Experimentos em imitação de gestos durante conversações mostram que as pessoas imitadas se sentem mais amigáveis para outro locutor e, consequentemente, se comportam de uma maneira mais pró-social (Frith, 2009; Ge et al., 2008).

As emoções possuem um papel muito importante no comportamento e na comunicação humanos, assim como no convivio em sociedade. Elas influenciam também os processos cognitivos, particularmente nos processos que envolvem tomada de decisão e resolução de problemas (Damasio, 1994). Por esses motivos, nas pesquisas mais recentes, tem aumentado sua 


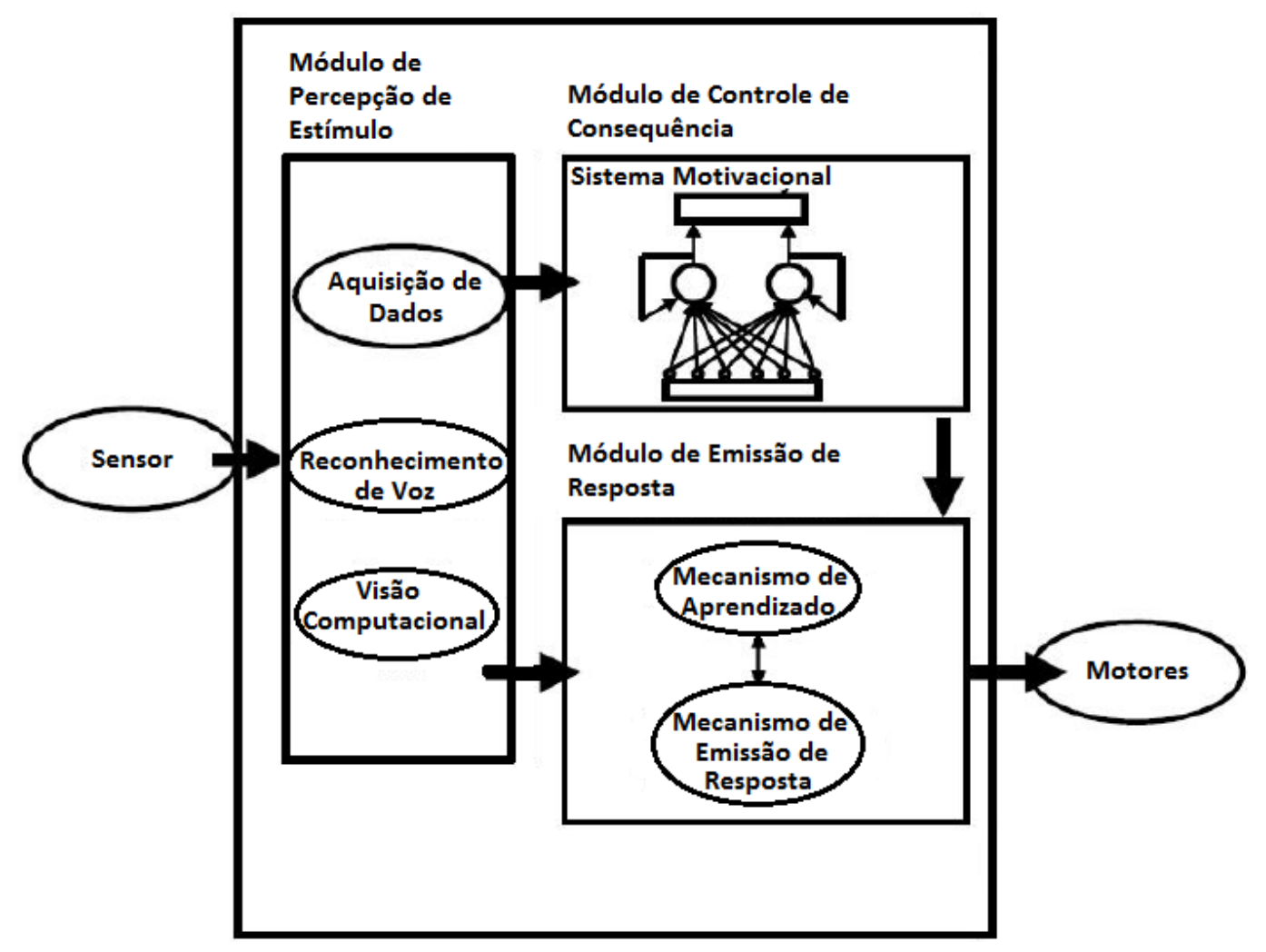

Figura 2.3: Arquitetura robótica de Policastro et al. $(2007,2008)$.

utilização em robôs sociais, seguindo a ideia de que as pessoas costumam tratar as máquinas como tratam outras pessoas (Salichs et al., 2006).

Há muitas definições de emoção na literatura. Segundo James (1884), emoção é a percepção de mudanças no corpo. O autor diz que a maneira natural de pensar sobre emoções é que a percepção mental de algum fato excita a afeição mental chamada emoção, e esse último estado de espírito dá origem à expressão corporal. Sua tese é que ocorre o contrário. Mudanças no corpo seguem diretamente a percepção do fato excitante, e o que sentimos dessas mudanças, como elas ocorrem, é a emoção. Oatley et al. (1996) diz que emoção é aquilo que normalmente é produzido por uma pessoa que avalia um evento, consciente ou inconscientemente, no sentido que resulta relevante para um objetivo ou meta; uma emoção dá prioridade a uma linha de atuação, interrompendo outros processos mentais, às vezes seguida de mudanças corporais, expressões, ações. De forma semelhante, para Casacuberta (2000) uma emoção simples é um estado mental, gerado automaticamente de um sistema cognitivo, que avalia um evento, conscientemente ou não, de acordo com os objetivos do sistema. Pode ser um facilitador - emoção positiva, um obstáculo - emoção negativa, ou um 
modificador. Segundo Casacuberta (2000) as funções emocionais são: comunicar ao próprio sistema cognitivo a avaliação do evento por meio de mudanças fisiológicas; disparar ou preparar ações como uma resposta ao evento e; comunicar o estado emocional aos outros sistemas, por meio de mudanças ou ações físicas.

Segundo Michaud et al. (2000), conceito de emoção artificial é usado principalmente para fazer com que robôs respondam emocionalmente a situações vividas no mundo ou a interações com humanos. Um dos objetivos é ajudar a estabelecer a credibilidade de que um robô está realmente interagindo com o usuário e não simplesmente executando um programa. Outro objetivo é criar modelos computacionais de emoção, derivados de estudos psicológicos ou de pesquisas em neurociência. Também considera-se como a emoção pode influenciar o processo de aprendizado de agentes autônomos.

Um dos principais trabalhos que incorpora emoções em um robô, que é utilizado como referência para diversas pesquisas da área, foi desenvolvido por Breazeal (2002, 003b). Nele, é apresentado o robô Kismet (figura 2.4), que é capaz de interagir face-a-face com pessoas. O robô é formado por uma cabeça com aproximadamente 1,5 vezes o tamanho de uma cabeça de uma pessoa adulta e possui 21 graus de liberdade: três para direcionar o olhar, outros três para controlar a orientação de sua cabeça, e os 15 restantes controlam suas expressões faciais (pálpebras, sobrancelhas, lábios e orelhas). Para visualizar e detectar as pessoas com quem ele interage, Kismet é equipado com um total de quatro câmeras coloridas, duas câmeras com campo estreito de visão localizadas em seus olhos e duas câmeras com visão panorâmica situadas entre os olhos. Além disso, Kismet possui dois pequenos microfones, localizados um em cada orelha, além de um terceiro microfone que é usado pela pessoa que está interagindo com o robô para processar suas vocalizações. Mais detalhes desse trabalho são apresentados na seção a seguir.

Um robô com aparência semelhante ao robô Kismet, denominado Arisco, é apresentado em (Dominguez et al., 2006). A figura 2.5 ilustra o robô. Este robô possui 17 graus de liberdade para movimentar seu pescoço e face, e é equipado com duas câmeras esféricas em seus olhos, dois microfones (um em cada orelha), um sensor de presença e um sensor de proximidade. Na Figura 3.4 esse robô é apresentado. Três micro-controladores são utilizados para controlar a cabeça, interfacear os sensores e detectar a origem do som. 


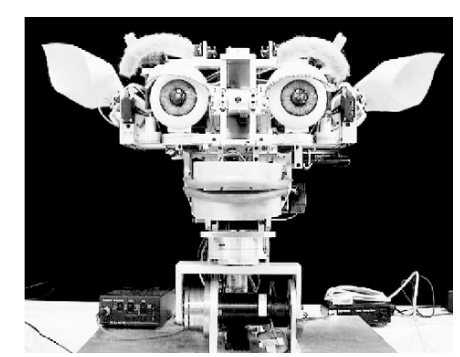

Figura 2.4: O robô sociável Kismet (Breazeal, 2003)

Os micro-controladores e as câmeras são conectados a um laptop por meio de uma porta USB. Esse computador é o responsável por controlar todas as funcionalidades do robô, como planejar o comportamento, fazer o reconhecimento de voz e o processamento visual. Essa cabeça robótica possui a habilidade de expressar comportamentos emocionais por meio de expressões faciais, reconhecer comandos de voz, localizar a direção do som, detectar faces humanas e regiões coloridas, além de detectar movimentos. Existe também um sistema de atenção compartilhada para garantir uma melhor interação com o usuário, auxiliando o robô a aprender informações sobre novos objetos e eventos. Dessa forma, Arisco desenvolve novas crenças e cria associações por meio das interações sociais. As novas experiências adquiridas servem para que novos comportamentos possam ser aprendidos e utilizados em interações futuras.

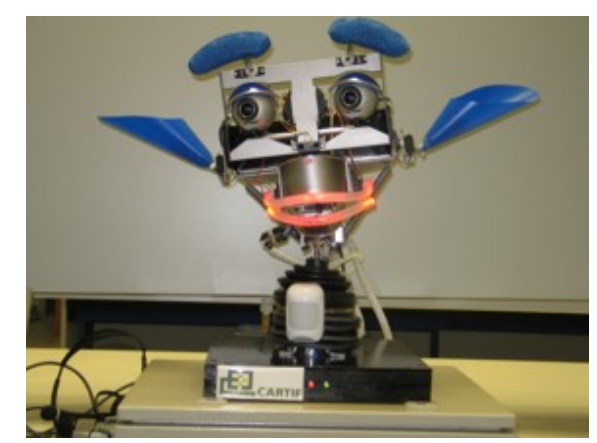

Figura 2.5: O robô Arisco (Dominguez et al., 2006)

No trabalho de Kirby et al. (2010) foi desenvolvido um modelo afetivo para robôs sociais. Este modelo generativo tenta criar afeto natural, como em um ser humano, e incluir distinções entre respostas emocionais imediatas, o humor total do robô, e atitudes de longo prazo para cada visitante do robô, com o objetivo de desenvolver relações mais duradouras entre o humano e o robô Roboceptionist. A base mecânica do robô é um RWI B21r com uma cabeça LCD que rotaciona para ficar de frente aos visitantes. Um teclado e 
um pequeno monitor permitem a entrada de humanos com feedback visual. Reconhecimento de fala não é usado devido ao alto ruído no ambiente. A cabeça de LCD mostra uma face gráfica altamente expressiva, que pode exibir uma grande variedade de expressões emocionais reconhecíveis. Os visitantes podem fazer perguntas ao robô sobre sua vida para ouvir a continuação da história, segundo a qual o Roboceptionist Valerie deixou o emprego para se tornar cantora e foi substituída por Tank, um paranóico ex-agente da CIA. Os robôs são mostrados na Figura 2.6. O objetivo dessas histórias é fornecer o interesse e incentivar a formação de relacionamentos de longo prazo com o robô. As emoções são apresentadas imediatamente depois de um evento, e por último a duração da resposta verbal do robô. Desta forma, as emoções são de curta duração, mas são exibidas o tempo suficiente para serem reconhecidas. As emoções não ocorrem simultaneamente nesse modelo, evitando assim a questão de como diferentes bases emocionais podem interagir ou misturar. Isso simplifica bastante a exibição das emoções. Desde que as emoções sejam de curta duração, várias emoções podem ser exibidas em seqüência.
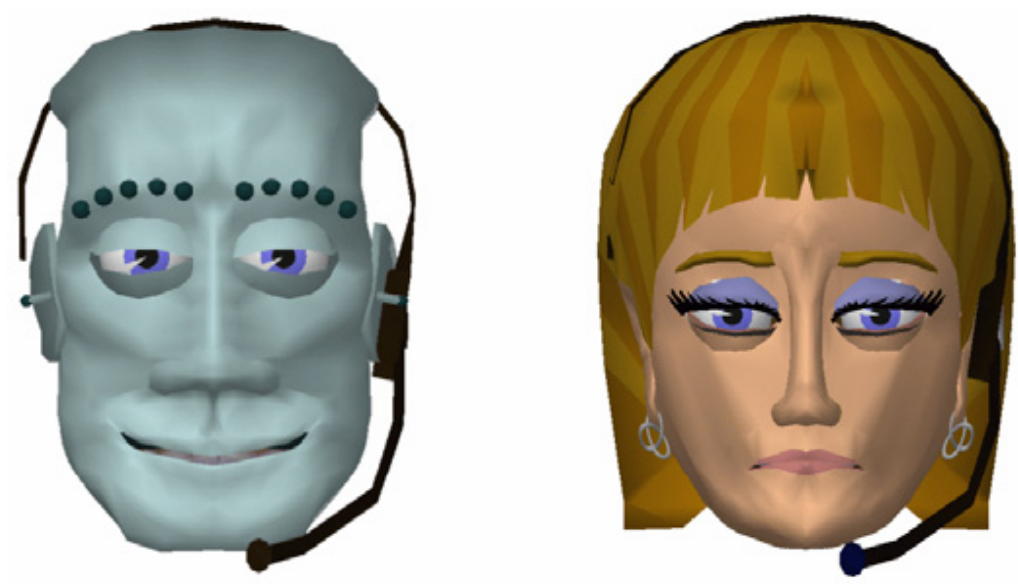

Figura 2.6: Faces gráficas usadas no Roboceptionist. Na esquerda é o Tank, mostrando felicidade e na direita é a Valerie, mostrando tristeza.

\subsection{Considerações Finais}

Nesse capítulo foi apresentada uma introdução à robótica social, bem como os principais aspectos a serem considerados na interação entre robôs e humanos. Vários aspectos contribuem para tornar natural essa interação, como gestos e expressões faciais. Pelo que foi apresentado, pode-se dizer que 
o objetivo da robótica social é que tarefas sejam executadas através da colaboração de seres humanos e robôs. 



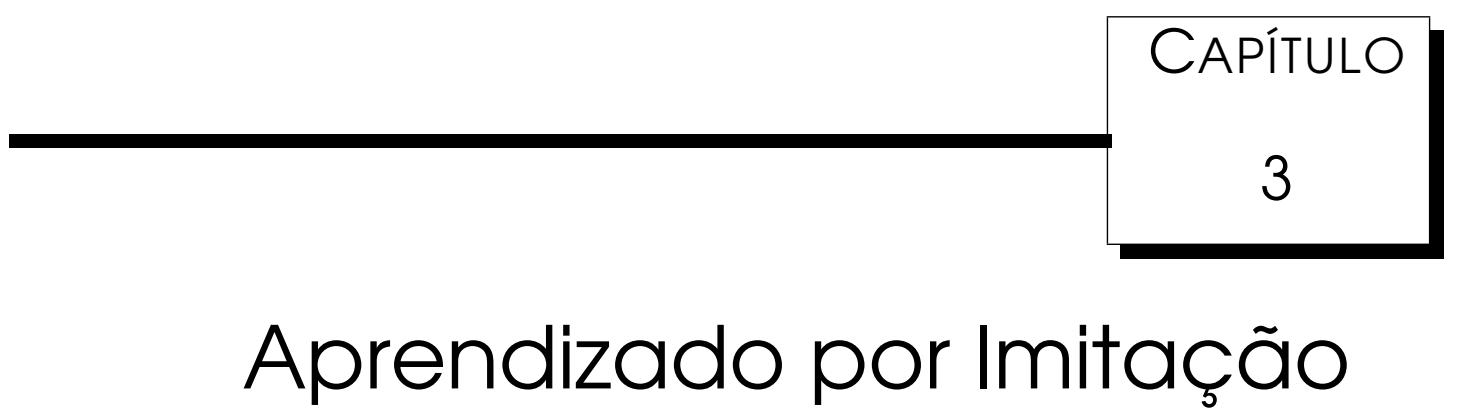

Nesse capítulo é apresentada uma introdução ao aprendizado por imitação e aos trabalhos existentes na literatura que tratam dessa abordagem. Em particular, na Seção 3.1 são apresentados os trabalhos relacionados ao Aprendizado por Imitação e na Seção 3.2 são apresentadas as considerações finais desse capítulo.

\subsection{Trabalhos Relacionados ao Aprendizado por Imitação}

A Programação de Robôs por Demonstração (Robot Programming by Demonstration - $\mathrm{PbD}$ ) engloba meios pelos quais um robô aprende novas habilidades através de orientações humanas. A PbD se inspira na maneira como humanos aprendem novas habilidades por imitação e, assim, desenvolve métodos pelos quais novas habilidades possam ser transmitidas a um robô (Calinon, 2009). De acordo com Calinon e Billard (2005), o objetivo do mecanismo de imitação é reproduzir precisamente um subconjunto pré-definido de tarefas e, assim, aprender por meio de exemplos.

Há abordagens tradicionais para o controle do modelo de domínio dinâmico do robô e para derivar políticas matematicamente baseadas. Embora teoricamente bem fundamentadas, essas abordagens dependem fortemente da precisão do modelo de mundo. Esse modelo não só exige considerável conhecimento para ser desenvolvido, mas aproximações, como 
linearização, são frequentemente introduzidas para tratabilidade computacional, degradando o desempenho. Outras abordagens, tais como aprendizagem por reforço, orientam as políticas de aprendizagem ao fornecer um retorno de recompensa sobre a conveniência de visitar determinados estados. Definir uma função para fornecer a recompensa, no entanto, é conhecido por ser difícil, além de exigir considerável experiência para resolver. A demonstração também tem a característica prática de focalizar o conjunto de dados para as áreas do espaço de estado realmente encontrados durante a execução da tarefa. (Argall et al., 2009).

Atualmente, é possivel utilizar sistemas computacionais sem conhecimento sobre programação ou sobre o funcionamento detalhado do sistema. Entretanto, em sistemas robóticos os passos para alcançar esse nível avançam lentamente. O aprendizado de demonstração contribui nesse sentido por não exigir conhecimento especializado do domínio, facilitando o desenvolvimento de políticas para leigos em robótica e eliminando fragilidades resultantes de simplificações do modelo. Além disso, a demonstração tem o atrativo de ser um intuitivo meio de comunicação dos seres humanos, que já usam demonstração para ensinar outros seres humanos (Calinon, 2009).

Há uma variedade de denominações para as técnicas de aprendizado baseada em demonstração, como Aprendizado por Demonstração, Aprendizado de Demonstração, Programação por Demonstração, Aprendizado por Demonstrações Experimentadas, Aprendizado de Observação, Imitação, entre outros. Há também muitos critérios para subdividir a pesquisa em aprendizado de demonstração. Uma categorização considera "o que imitar”, que consiste em determinar as características relevantes da tarefa a ser imitada, "como imitar", que consiste em adaptar seu programa motor a produzir uma imitação ótima e "quando imitar", que consiste em determinar o momento em que a imitação deve ser executada pelo agente. Outro critério adotado considera técnicas e formulações computacionais necessárias para implementar um sistema de aprendizado de demonstração (Argall et al., 2009; Billard et al., 2006).

O trabalho de Billard et al. (2004) apresenta uma política geral para determinar quais características de uma tarefa de manipulação são relevantes e devem ser imitadas, seguindo a tendência de definir uma formulação matemática para aprendizado por imitação. O estudo nesse trabalho foi restringido para imitação de tarefas manipulativas ou gestos. $\mathrm{O}$ 
processo de imitação é modelado como um sistema de otimização hierárquico, que minimiza a discrepância entre conjuntos de dados multidimensionais. Também foi proposta uma métrica de performance de imitação que determina a estratégia de imitação ótima, baseada em Modelos Ocultos de Markov (Alejandro e Govea, 2010), na qual a medida de probabilidade observa uma estratégia de manipulação particular. A métrica usa uma combinação linear de probabilidades para comparar os resultados de diferentes algoritmos para extração de características, aplicados a diferentes conjuntos de dados. O modelo foi aplicado com sucesso na reprodução de manipulação e tarefas de desenho em um simulador dinâmico e em um robô humanóide, usando dados cinemáticos de movimento humano.

Em seu trabalho posterior, Billard et al. (2006) tenta explorar o problema de "como imitar" no controle da manipulação uni-manual e bi-manual de objetos, utilizando um par de mãos robóticas. Segundo o autor, a tarefa "como imitar" não é tão simples quanto parece, porque o demonstrador e o imitador devem diferir significativamente em sua personificação. Isso acontece quando há transferência de informação de um humano para um robô, mesmo quando o robô tem a forma humanóide. Nesse sistema maior, que inclui "o que" e "como" imitar, o autor define as seguintes etapas:

- Pré-processamento: no qual os sinais irrelevantes e com variabilidade muito alta são descartados;

- Codificação de dados probabilísticos: nessa etapa, os sinais restantes da etapa anterior são codificados em um completo Modelo Oculto de Markov para encontrar uma representação probabilística ótima da tarefa;

- Determinação das restrições da tarefa: cada variável possui uma medida que descreve sua relativa importância no conjunto de dados. Essa medida é usada para determinar a função custo com relação às restrições do corpo do robô.

- Geração da trajetória ótima: nessa etapa, a trajetória que otimiza a função custo com relação às restriçõs do corpo do robô é calculada.

O autor considera esse sistema genérico, no sentido de que não faz nenhum pressuposto da configuração do robô. Além disso, produz trajetórias suaves, mesmo nos limites da área de trabalho do robô, o que o torna um controlador de robô adequado. 
Uma proposta de imitação como um mecanismo genérico para aprendizado rápido em robôs é encontrada no trabalho de Grimes e Rao (2009). Nesse trabalho, afirma-se que há dois principais obstáculos que impediram que a inteligência cerebral fosse implementada em máquinas. $O$ primeiro é a falta de mecanismos para o aprendizado rápido de novos comportamentos que permitem que a máquina se adapte ao ambiente. $\mathrm{O}$ segundo é a falta de capacidade para lidar com incerteza devido ao ruído de ambiguidade, de insumos e o conhecimento completo do ambiente. Assim, o problema da incerteza é tratado pela utilização de modelos bayesianos que mantém completamente as distribuições de probabilidade sobre os estados sensoriais e motores. Essas distribuições e seus parâmetros são atualizados de modo bayesiano, baseado no retorno sensorial. Segundo o autor, há uma crescente evidência de estudos físico-químicos e neurobiológicos que o cérebro deve depender de princípios bayesianos para pecepção e ação. Dessa forma, o modelo proposto para imitação robótica é inspirado por estes modelos bayesianos da função do cérebro e pela capacidade dos humanos para aprender novas habilidades simplesmente observando outro ser humano. Pelos resultados obtidos, um robô humanóide com 25 graus de liberdade pode aprender de forma dinamicamente estável movimentos completamente imitativos, simplesmente observando um demonstrador humano.

Muitos neurocientistas vêem imitação como mediada por neurônios-espelho em humanos. Modelos conceituais atuais atribuem funções de alto nível como entendimento de ação, imitação, e linguagem aos neurônios-espelho (Oztop et al., 2006). Um modelo de rede neural dinâmica de um sistema de espelhos foi implementado em um robô humanóide baseado no modelo de rede neural recorrente com bias paramétrico (Recurrent Neural Network Model with Parametric Bias - RNNPB) por Ito e Tani (2004). O robô humanóide GRIO (SDR-4X II) da Sony foi utlizado como plataforma experimental. Apenas movimentos padrões dos braços foram considerados. A tarefa do robô consiste de duas fases: aprendizado e interação. Na fase de aprendizado, um conjunto de movimentos padrões com diferentes perfis é aprendido e associado aos correspondentes movimentos padrões visualmente percebidos das mãos do usuário. Na fase de interação, o robô percebe visualmente os movimentos padrões da mão do usuário e gera seus movimentos padrões correspondentes. O fluxo do sistema nas fases de aprendizado e interação é apresentado nas Figuras 3.1 e 3.2, 
respectivamente.

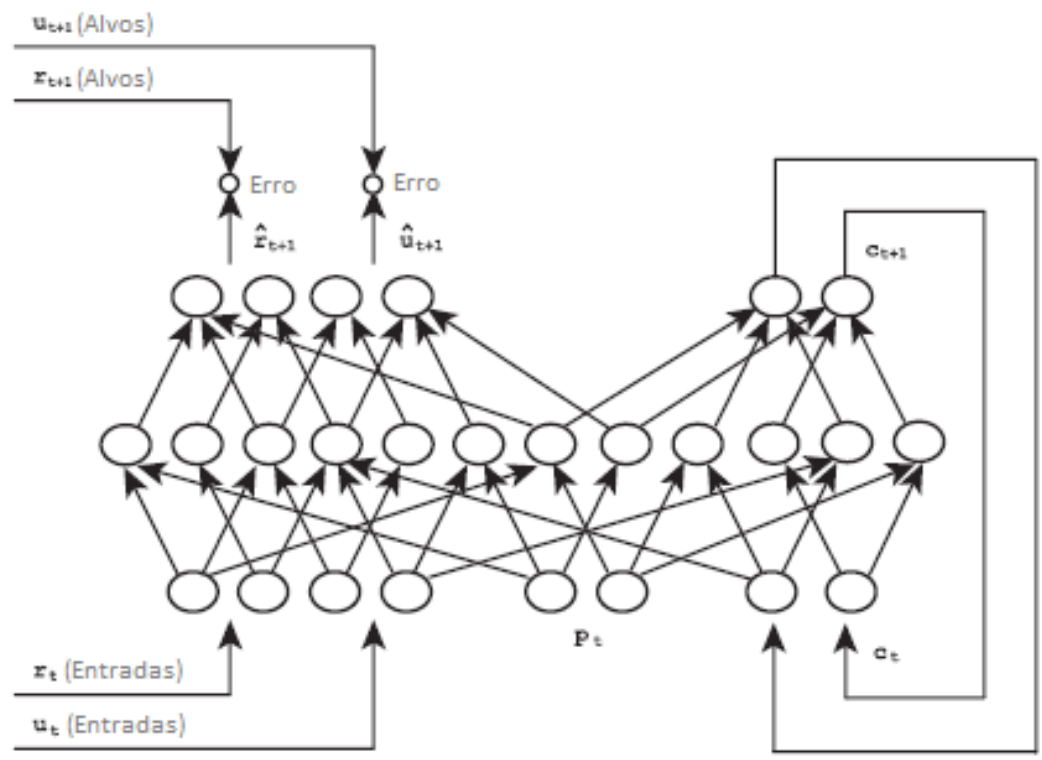

Figura 3.1: Fluxo do sistema da RNNPB na fase de aprendizado (Ito e Tani, 2004).

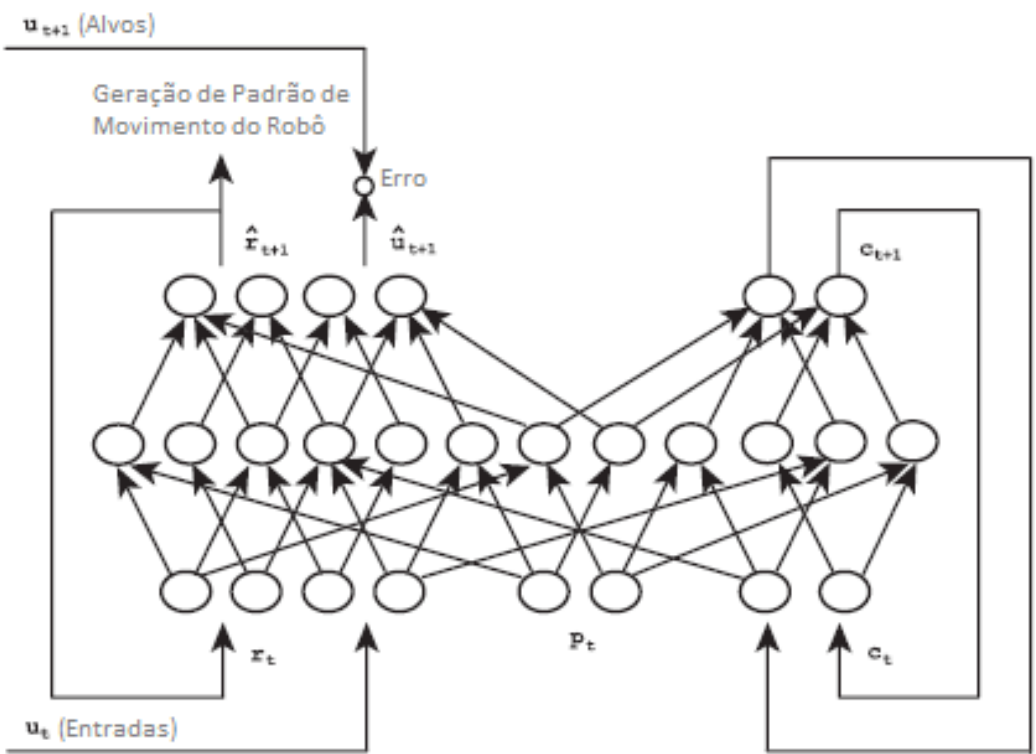

Figura 3.2: Fluxo do sistema da RNNPB na fase de interação (Ito e Tani, 2004).

O aprendizado da RNNPB é conduzido pelas sequências-alvo das articulações do robô $r_{t}$ e as posições da mão do usuário $u_{t}$, que são as entradas da rede. Com essas entradas, a rede prediz seus valores na próxima iteração na camada de saída como $\hat{r}_{t+1}$ e $\hat{u}_{t+1}$. Então, as saídas são comparadas com seus valores alvo $r_{t+1}$ e $u_{t+1}$ e o erro gerado é retropropagado 
para atualizar os pesos sinápticos e os valores dos bias paramétricos (PB). $c_{t}$ representa as unidades de contexto, onde o laço de retro-alimentação é estabelecido de $c_{t+1}$ na camada de saída para $c_{t}$ na camada de entrada. As ativações da unidade de contexto representam o estado interno da rede. Na fase de interação, a rede pré-treinada é utilizada sem atualizar os pesos sinápticos. Enquanto a dinâmica para frente da rede gera a predição de sequências sensorial-motoras, os valores de $\mathrm{PB}$ são inversamente computados por utilizar a informação de erro obtida entre a predição sensorial e a consequência. A RNNPB quando recebe $u_{t}$ tenta predizer seu próximo valor $\hat{u}_{t+1}$ na saída. O erro de predição gerado do valor alvo $u_{t+1}$ na saída é retropropagado para as unidades $\mathrm{PB}$ e os valores de $\mathrm{PB}$ são atualizados na direção de minimizar o erro. Então, a rede é capaz de gerar os padrões motores associados $\hat{r}_{t+1}$, como anteriormente aprendidos. Os padrões de movimento do robô são gerados com base nos valores PB, enquanto esses valores são adaptados ao perceberem os padrões de movimento da mão. A equação de atualização do bias paramétrico é dada por:

$$
\begin{gathered}
\delta \rho_{t}^{i}=k_{b p} \cdot \sum_{s t e p=t-l / 2}^{t+l / 2} \delta_{s t e p}^{b p^{i}}+k_{n b}\left(\rho_{t+1}^{i}-2 \rho_{t}^{i}+\rho_{t-1}^{i}\right) \\
\Delta \rho_{t}^{i}=\epsilon \cdot \delta \rho_{t}^{i}+\eta \cdot \Delta \rho_{t-1} \\
\rho_{t}^{i}=\operatorname{sigmoid}\left(\rho_{t}\right)
\end{gathered}
$$

O componente $\delta \rho_{t}$ é obtido pela soma de dois termos. O primeiro termo representa a soma do erro delta. O segundo termo faz o papel de um filtro passa baixa frequência, através do qual as mudanças rápidas do bias paramétrico são inibidas. Uma característica interessante desse modelo é que a geração e a percepção são executadas simultaneamente em sistema dinâmico neural. Os experimentos mostraram que interações dinâmicas diversas podem emergir na forma de coerência ou incoerência entre o robô e o usuário. O robô pode seguir os padrões de movimento do usuário sincronicamente, gerando estados dinâmicos coerentes. Ele não pode seguir novos padrões, mas responde a eles de várias maneiras com estados dinâmicos incoerentes.

O problema de aprender gestos de braços por imitação em robôs humanóides é tratado no trabalho de Thobbi e Sheng (2010). Nesse trabalho 
é apresentada uma plataforma para implementar e avaliar um framework de aprendizado por imitação que capacita um robô humanóide a aprender gestos demonstrados por humanos. Esse trabalho se baseia na ideia de que para aprender um gesto particular, várias demonstrações do mesmo gesto devem ser executadas. Isso é necessário para extrair as características essenciais do gesto e aprendê-lo, ao invés de simplesmente copiá-lo. A plataforma utiliza um sistema de captura de movimento e o robô humanóide NAO, desenvolvido pela Aldebaran Robotics. A metodologia de aprendizado por imitação proposta envolve modelagem do braço humano, aquisição de dados, análise de dados, aplicação de Dynamic Time Warping (Sakoe e Chiba, 1978) e média ponderada. A anatomia do braço humano é modelada pela articulação do ombro e do cotovelo. Na aquisição dos dados, a captura de movimento é feita pelo uso de quatro marcadores colocados no corpo do humano e, assim, são extraídos os ângulos articulares do braço humano. A análise dos dados é realizada em relação ao ruído e à variação nos dados (toda trajetória difere de outras em fase). Dynamic Time Warping é um algoritmo de normalização de tempo baseado em programação dinâmica que dá um efeito de normalização de tempo não-linear entre dois sinais. Assim, ele é utilizado para alinhar as trajetórias no tempo. Depois que as trajetórias são alinhadas otimamente no tempo, sua representação geral deve ser obtida. Para obtê-la, simplesmente foi aplicada a média ponderada, reduzindo as distorções na trajetória média por causa de possíveis outliers. Pelos experimentos realizados, o algoritmo funciona bem para vários gestos.

O trabalho de Richert et al. (2009) investiga a combinação de Aprendizado por Reforço e imitação em cenários onde a imitação é apenas esporadicamente possível. A arquitetura multi-camada ESLAS (Evolving Societies of Learning Autonomous Systems), de um trabalho anterior do autor, foi estendida para ser usada para imitação em cenários multi-robô. Essa arquitetura é baseada em três camadas de abstração. No nível mais alto, uma camada de motivação fornece uma função de motivação para o algoritmo de aprendizado, sendo o objetivo global do robô. Essa função determina a qual objetivo é mais vantajoso chegar em cada momento. Na camada do meio está o algoritmo de Aprendizado por Reforço. Ele recebe a entrada da interface e decide que habilidade será executada. Uma habilidade é descrita por uma função objetivo e é tratada na camada mais baixa. Usando essa função, uma habilidade é capaz de reconhecer se uma habilidade similar a ela própria foi executada nas observações. O processo de 
reconhecimento do comportamento observado é inspirado pelo algoritmo de Viterbi que é frequentemente aplicado para sintetizar comportamento usando Modelos Ocultos de Markov anteriormente aprendidos. Depois que o comportamento é reconhecido, chega o momento de aprendê-lo. Para se beneficiar da imitação, o robô que está imitando primeiro observa o estado do robô observado em um determinado período de tempo. A sequência de observação é projetada por uma função de mapeamento do ponto de vista do demonstrador para o ponto de vista do imitador. No estado projetado, o imitador parece estar na posição do próprio demonstrador. Com essa abordagem, o robô pode melhorar suas estratégias observando qualquer robô que está ao seu redor, apenas requerendo que ele expresse seu estado global.

Lee e Nakamura (2010) propõem um novo esquema de imitação para observações parciais, consistindo de duas estratégias: entender o movimento de observações parciais e gerar o movimento condicionado por observação. $O$ esquema capacita um robô humanóide a imitar padrões de movimento completos de observações incompletas. Através do esquema de geração de movimento proposto, o conjunto de padrões de movimento do humanóide é enriquecido, comparado com a repetição possuindo proto-símbolos. O robô pode imitar um novo padrão de movimento rápido, encontrando o melhor casamento para o proto-símbolo e remodelando-o para a observação atual, em comparação com o aprendizado do movimento, e gerando-o. O modelo de imitação é desenvolvido como um modelo matemático inspirado pelo sistema de neurônio-espelho e está baseado em Modelos Ocultos de Markov. O algoritmo de Viterbi faz um importante papel, no sentido de gerar um movimento próximo à observação. Os fatores de avaliação, como herança coordenada e casamento de erro, são introduzidos para avaliar a performance de imitação. A viabilidade do esquema proposto é demonstrada pela avaliação de um robô humanóide com 20 graus de liberdade. Três experimentos detalhados foram realizados: imitação de um movimento conhecido, imitação de um movimento desconhecido e imitação de um movimento completo a partir de um movimento incompleto. Do primeiro experimento, encontrou-se que o movimento gerado está próximo à observação e foi herdado do conhecimento prévio e da observação. O segundo experimento mostra que um movimento não treinado também pode imitado por aplicar pro-símbolo similar. O terceiro experimento mostra uma extensão para a imitação do movimento completo a partir de dados de observação incompleta. 
Quanto mais as pessoas tendem a imitar os outros, mais elas tendem a ser empáticas e preocupadas com o estado emocional. Isto sugere que o circuito central possa interagir com o sistema límbico (o sistema neural relacionado com emoções) durante o espelhamento social (Iacoboni, 2005).

O trabalho de Breazeal (2003) foca no papel da emoção e comportamento expressivo na interação social entre humanos e robôs. Seu trabalho apresenta os modelos computacionais de emoção de Kismet, um robô humanóide expressivo, como ele expressa seu estado emotivo e como os robôs usam esses sistemas em conjunto com seus sistemas perceptuais e comportamentais, para regular sua interação com pessoas. Nesse projeto foram implementados três drives que estabelecem os objetivos de nível superior do robô: envolver pessoas, envolver brinquedos e, ocasionalmente, envolver o resto. Os drives de Kismet servem para vários propósitos. Influenciam a seleção de comportamento por diretamente e preferencialmente passar ativação para alguns comportamentos sobre outros. Eles também fornecem um contexto funcional que organiza o contexto e a percepção. Além disso, eles influenciam o estado afetivo do robô por contribuir diretamente com a valência e as medidas de estímulo. O sistema emocional, em relação aos drives, é projetado para ser um sistema flexível que fica entre a simulação interna e ambiental, para extrair uma resposta comportamental adaptativa que serve às funções sociais ou de auto-manutenção. As emoções são disparadas por vários eventos que são avaliados como sendo de importância para o bem-estar do robô. Uma vez disparada, cada emoção serve a um conjunto particular de funções para estabelecer uma relação desejada entre o robô e seu ambiente. Eles motivaram o robô a entrar em contato com coisas que promovem seu bem-estar e para evitar as que não promovem. Em geral, essa implementação é fortemente inspirada por modelos etológicos (modelos de comportamento animal) para percepção, motivação e comportamento. A avaliação das expressões do robô é realizada primeiro isoladamente. Nessa primeira avaliação, o reconhecimento médio de expressões emocionais para imagens estáticas foi de $70,9 \%$ e para vídeo foi de $77,6 \%$ que é melhor comparado com um trabalho anterior. Depois é avaliado o comportamento emotivo geral do robô no relacionamento social direto com os seres humanos. As interações resultantes são bastante envolventes, porque o comportamento expressivo do robô é oportuno e adequadamente sincronizado com o comportamento humano em escalas de tempo de granulação fina. 
No trabalho de Monceaux et al. (2009) apresenta-se uma introdução do primeiro trabalho realizado pela Aldebaran Robotics para obter uma biblioteca comportamental dedicada à expressão de emoções pelo robô NAO (Gouaillier et al., 2009). Os comportamentos expressivos usam movimentos articulares, o sistema de luz e som. A técnica utilizada envolve imitação por observação direta, o isolamento das principais etapas para alcançá-la e o ajuste de cada um desses elementos para a morfologia do NAO e pelo contato humano. O autor deixa claro que nesse trabalho não há uma tentativa de construir um sistema emocional, mas sim fornecer aos projetistas de comportamento uma biblioteca com um simulador de emoções que possa ser usada. O autor também explica que o trabalho não envolve a interação do robô com um humano, mas pretende lidar com isso futuramente.

Um sistema para imitar as expressões faciais foi construído em Ge et al. (2008). O sistema proposto é composto por quatro módulos chave: detecção de face, extração de características, classificação e geração de emoção artificial. O módulo de detecção de face segmenta as regiões da face de uma sequência de vídeo ou uma imagem e localiza as posições da sobrancelha, olhos, nariz e boca. As posições podem ser representadas por alguns pontos conduzidos com propriedades matemáticas especiais. São utilizados vinte e dois músculos que são considerados relevantes para expressões humanas. Cada músculo facial é representado por um par de pontos-chave, rotulados como ponto dirigido e ponto fixo. Do ponto de vista do modelo de músculo facial, uma expressão facial pode ser considerada como uma combinação de diferentes movimentos dos pontos dirigidos em diferentes expressões faciais. O módulo de extração de características é usado para rastrear os pontos conduzidos durante a expressão facial e computar seus deslocamentos sequenciais comparados aos seus correspondentes pontos fixos. Esses pontos fixos não podem ser movidos durante a expressão facial. Dadas as saídas da extração de características e um conjunto pré-definido de expressões faciais (felicidade, surpresa, tristeza, nojo, medo e raiva), o módulo de classificação classifica um vídeo ou uma imagem em uma classe correspondente às expressões faciais, utilizando SVM como classificador. No módulo de geração de emoção artificial foi desenvolvida uma metodologia para copiar o movimento facial. A ideia é obter o modelo de face alvo com a expressão copiada da face fonte. Em linhas gerais, o vetor de características faciais do demonstrador é subtraído da expressão fonte. Assim, a cabeça robótica é capaz de mostrar suas emoções através de um vetor de 
características situado na sua parte frontal. Os experimentos mostraram que o robô pode imitar seis tipos de expressões faciais efetivamente.

Um novo robô, chamado Ifbot, que pode se comunicar por meio de uma conversação agradável e expressão facial emocional foi desenvolvido por um projeto de pesquisa conjunto entre universidade e indústria (Masayoshi Kanoh, 2004; Kato et al., 2004). Esse robô pode conversar com uma pessoa por um motor de síntese e reconhecimento de voz fundamental. Também é capaz de se comunicar com uma pessoa transmitindo suas emoções através de mecanismos de gestos e expressões faciais. O trabalho de Gotoh et al. (2007) tentar aprender o mapeamento de expressão facial entre um humano e um robô Ifbot, pelo qual o robô pode imitar uma expressão facial arbitrária. Para isso, foi utilizado o FACS (Facial Action Coding System) (Ekman e Friesen, 1978), um dos mais conhecidos e usado sistema para medir movimento facial em termos de ações de músculos observáveis parcialmente, e para sistematicamente categorizar as expressões físicas de emoções. Com FACS, um observador humano decompõe uma expressão facial observada em uma ou mais de 44 unidades de ação, que representa a atividade muscular que produz mudanças momentâneas na aparência facial. Dessa forma, o trabalho de Gotoh et al. (2007) utilizou uma rede neural perceptron com três camadas, que tem performance de mapeamento não-linear, para mapear expressões faciais entre um humano e o Ifbot. As entradas da redes são os parâmetros das unidades de ação de faces humanas, decompostas pelo FACS. A rede é treinada com aprendizado supervisionado por retropropagação de erro, usando erro entre os dados de saída da rede e os parâmetros de expressão facial do Ifbot. Foram definidas 16, 48 e 16 unidades para a primeira, segunda e terceira camada respectivamente. Para o treinamento da rede foram usadas quatro imagens faciais expressivas (raiva, satisfação, tristeza e surpresa) e uma neutra de quatro pessoas e as correspondentes expressões faciais do Ifbot. Para avaliar o método, foram apresentadas à rede imagens de três pessoas. As imagens de saída da rede, que mostram as expressões do Ifbot, foram fotografadas por uma câmera digital e colocadas em um questionário em ordem aleatória, juntamente com as imagens faciais de humanos utilizadas como entrada. $\mathrm{O}$ questionário foi respondido por vinte estudantes, que tentaram associar as imagens correspondentes em relação às expressões. No pior caso, o sistema apresentou taxa de acurácia média de 51\%, mostrando que o sistema é capaz de fazer um mapeamento válido entre expressõs faciais de humanos e o Ifbot. 
No trabalho de Boucenna et al. (2010) foram realizados uma série de experimentos mostrando que um simples modelo de rede neural pode controlar uma cabeça robótica e aprender de forma online a reconhecer expressões faciais que lhe são apresentadas. A cabeça robótica utilizada possui expressividade muito simples e foi desenvolvida como uma ferramenta para pesquisadores em ciências cognitivas, envolvendo experimentos psicológicos e modelagem computacional. O objetivo desses experimentos é entender como os bebês aprendem a reconhecer expressões faciais sem ter um sinal de ensino, permitindo associar, por exemplo, a visão de uma face feliz com seu próprio estado emocional de felicidade. Nos experimentos, o robô é considerado um bebê e um humano, o seu pai. Originalmente, o robô conhece nada sobre o ambiente, mas ele começa a aprender à medida que interage com ele. Uma arquitetura de rede neural (figura 3.3) foi desenvolvida para reconhecer características visuais de pessoas que interagem com a cabeça robótica e para aprender se essas características são correlacionadas com sua própria expressão facial.

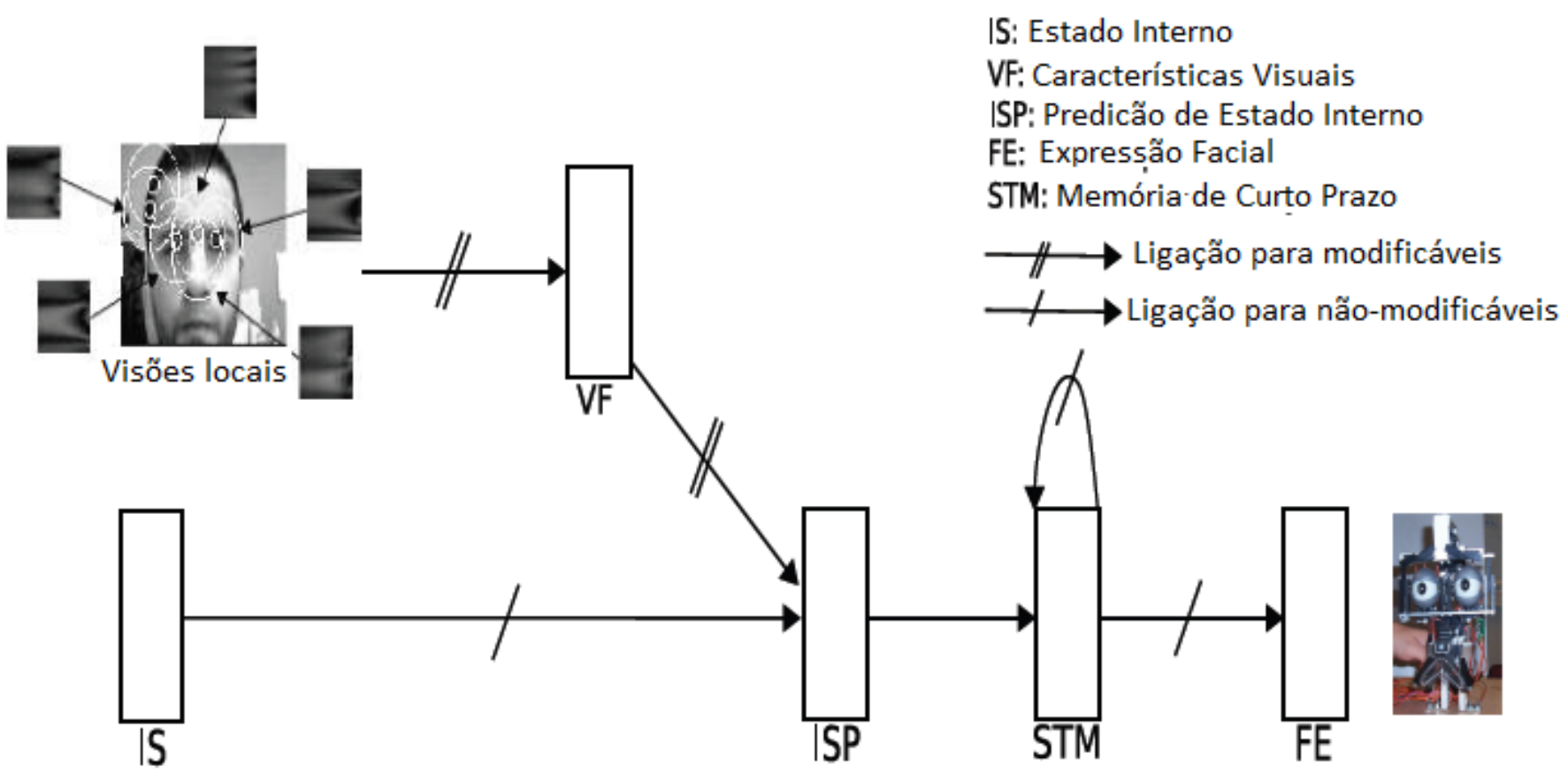

Figura 3.3: Arquitetura global para reconhecer e imitar expressões faciais (Boucenna et al., 2010).

O seguinte protocolo experimental foi adotado: em uma primeira fase de interação, o robô produz uma expressão facial aleatória e depois retorna à face neutra. Em seguida, o humano é convidado a imitar a cabeça robótica. 
Se a rede neural aprendeu corretamente, o robô deve ser capaz de imitar a expressão facial do humano. O grupo VF de características visuais aprende as visões locais. A predição de estado interno (ISP) aprende a associação entre o estado interno (IS) e VF. STM é uma memória de curto prazo para fornecer mais robustez. IS, ISP, STM e FE (expressão facial) são grupos de neurônios que contêm cinco neurônios correspondendo a quatro expressões faciais mais a expressão neutra. O conjunto de visões locais é aprendido pelo recrutamento de novos neurônios no grupo (VF), usando um variante do $k$ means, permitindo funções de aprendizado online e em tempo real:

$$
\begin{gathered}
V F_{j}=\text { net }_{j} \cdot H_{\max \left(\gamma, \overline{n e t}+\sigma_{n e t}\right)}\left(\text { net }_{j}\right) \\
\text { net }_{j}=1-\frac{1}{N} \sum_{i=1}^{N}\left|W_{i j}-I_{i}\right|
\end{gathered}
$$

$V F_{j}$ é a atividade do neurônio $j$ no grupo $V F$. I é uma entrada visual. $H_{\theta}(x)$ é a função Heaviside descrita por:

$$
H_{\theta}(x)= \begin{cases}1, & \theta<x \\ 0, & \text { caso contrário }\end{cases}
$$

$\gamma$ é a vigilância (limiar de reconhecimento, se o reconhecimento protótipo está abaixo de $\gamma$, então um novo neurônio é recrutado). $\overline{n e t}$ é a média da saída, $\sigma_{n e t}$ é o desvio padrão. A regra de aprendizado permite tanto um aprendizado instantâneo quanto de longa duração, em média. O ajuste dos pesos é realizado da seguinte forma:

$$
\Delta W_{i j}=\delta_{j}^{k}\left(a_{j}(t) I_{i}+\epsilon\left(I_{i}-W_{i j}\right)\left(1-V F_{j}\right)\right)
$$

onde $k=\operatorname{ArgMax}\left(a_{j}\right), a_{j}(t)=1$ apenas quando um novo neurônio é recrutado, caso contrário, $a_{j}(t)=0 . \delta_{j}^{k}$ é o símbolo de Kronecker e $\epsilon$ é a constante para a média dos protótipos. O símbolo de Kronecker é:

$$
\delta_{j}^{k}= \begin{cases}1, & j=k \\ 0, & \text { caso contrário }\end{cases}
$$

Quando um novo neurônio é recrutado, os pesos são modificados para casar com a entrada (termo $a_{j}(t) I_{i}$ ). A outra parte da regra de aprendizado, $\epsilon\left(I_{i}-W_{i j}\right)\left(1-V F_{j}\right)$ pondera os protótipos já aprendidos. Quanto mais a entrada se aproxima dos pesos, menos os pesos são modificados. De forma 
recíproca, quanto menos as entradas se aproximam dos pesos, mais eles são ponderados. Se $\epsilon$ for bem pequeno, causará pouco impacto. Reciprocamente, se $\epsilon$ for muito grande, os protótipos aprendidos anteriormente podem ser desaprendidos. Graças a essa regra de aprendizado, os neurônios no grupo $V F$ aprender a mediar protótipos de características da face. ISP associa a atividade de $V F$ com o IS atual do robô, através da seguinte regra (usando o mecanismo de erro mínimo quadrado):

$$
\Delta w_{i j}=\epsilon \cdot V F_{i} \cdot\left(I S_{j}-I S P_{j}\right)
$$

STM é usada para somar e filtrar em um curto período os estados emocionais $I S P_{i}(t)$ associado com cada visão local explorada:

$$
S T M_{i} t+1=\frac{1}{N} \cdot \operatorname{ISP}(t+1)+\frac{N-1}{N} S T M_{i}(t)
$$

onde $i$ é o índice de neurônios. Por exemplo, $I S P_{i}$ corresponde ao $i^{\text {th }}$ estado emocional. O robô reconhece á capaz de reconhecer as expressões faciais mesmo quando a distância é considerável, em torno de $2 \mathrm{~m}$. Esse modelo apresenta algumas dificuldades em relação a um sistema de processamento de imagens clássico, entretanto, possui capacidade de adaptação graças à rede neural e ao aprendizado online.

Um modelo de agente adaptativo com capacidade para interpretar emoções de outros agentes é apresentado no trabalho de Bosse et al. (2009). Esse modelo é baseado em recentes avanços no contexto neurológico. O modelo de agente é baseado na ideia de neurônios-espelho e um recursivo ciclo do corpo: um ciclo de feedback positivo convergente, baseado em causalidade recíproca entre as ativações dos neurônios-espelho e ativações dos neurônios subjacentes às emoções sentidas. Esse modelo de agente neural se refere a estados de ativação de neurônios e o corpo. O modelo é apresentado na figura 3.4.

Cada nó está para um grupo de um ou mais neurônios, ou para um efetor, estado de sensor ou corpo. $R N(s, f)$ é o neurônio que representa que o estímulo $s$ induz o sentimento $f$. Assim, no estado de ativação neural de $R N(s, f)$, a emoção experimentada $\mathrm{f}$ está relacionada ao estímulo $s$, que dispara o processo de geração de emoção. Quanto mais o neurônio está fortemente relacionado ao neurônio de representação sensorial para $s$, $S R N(s)$, mais ele deve ser considerado para representar um nível de sensibilização de que causa o sentimento $f$; isso deve estar relacionado ao 


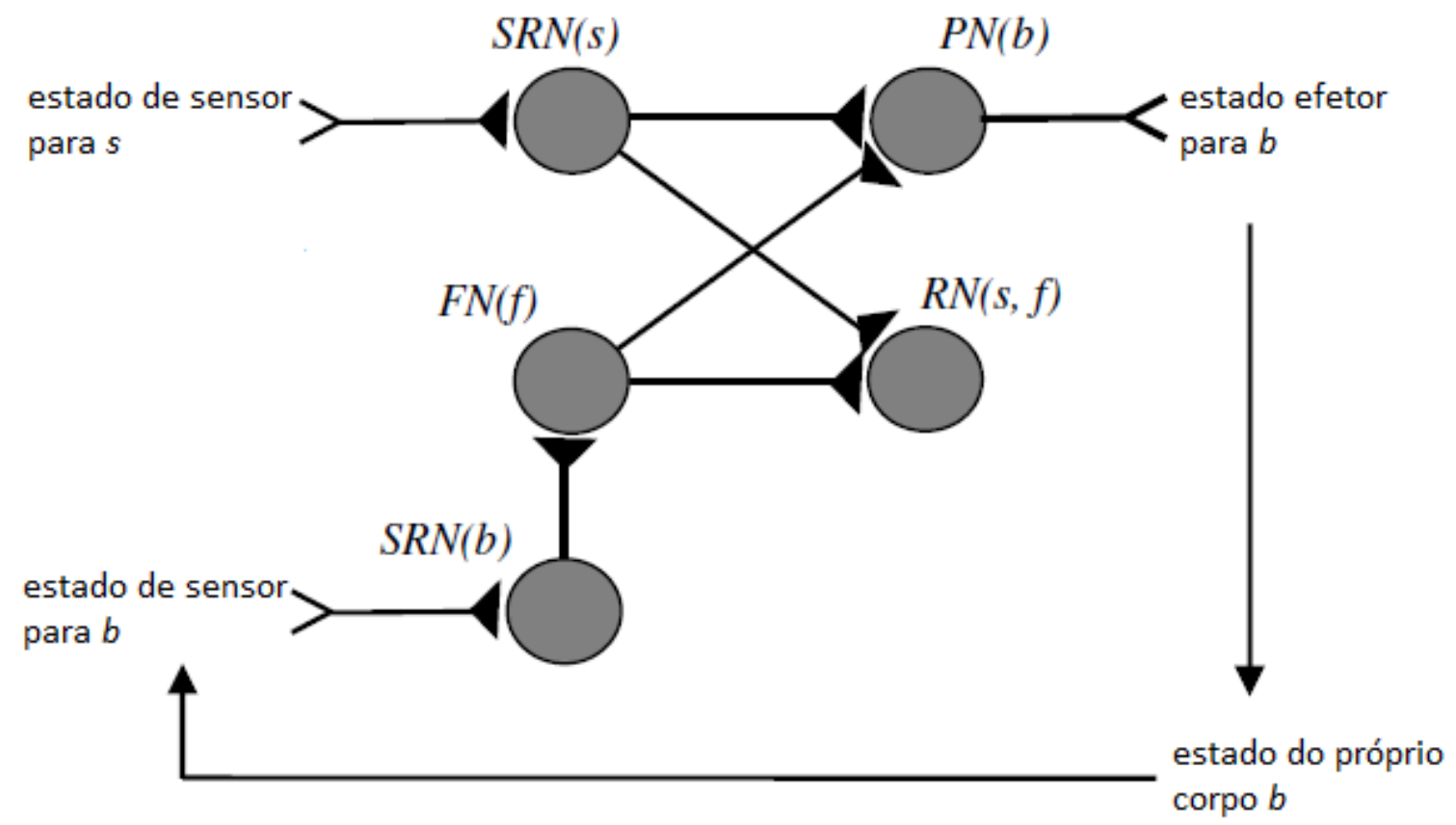

Figura 3.4: Estrutura de rede neural do modelo de agente com ciclo do corpo (Bosse et al., 2009).

que é chamado por um estado de sentimento consciente. Esse estado que relaciona uma emoção sentida $f$ a qualquer desencadeamento do estímulo $s$, pode fazer um papel importante na atribuição consciente do sentimento para qualquer estímulo $s$. $\mathrm{O}$ modelo de rede neural introduzido pode ser especializado em uma maneira simples para habilitar leitura de emoção. O principal passo é que o estímulo $s$ que dispara o processo emocional, que até agora foi deixado em aberto, é instanciado com o estado do corpo b' do outro agente, por exemplo, uma expressão facial de outro agente. Ao invés disso, mais e mais evidência mostra que, como um exemplo do funcionamento de um sistema de neurônios-espelho, sentir a expressão facial de alguém leva a preparar para mostrar a mesma expressão facial. Isso leva à ativação do estado de preparação, $P N(b)$, onde $b$ é o próprio estado do corpo, correspondente ao estado do corpo $b$ ' de outro agente. Esse padrão mostra como esse estado de preparação $P N(b)$ funciona como um neurônio-espelho. Depois, via o laço do corpo recursivo, gradualmente mais e mais níveis de ativação do próprio estado de sentimento $f$ são gerados. Além disso, esse modelo de agente foi estendido para um modelo de agente neural baseado em aprendizado Hebbiano, onde neurônios que são frequentemente ativados simultaneamente reforçam sua sinapse de conexão. Baseado nesse modelo de agente adaptativo, uma conexão direta entre um estímulo sentido e o 
reconhecimento da emoção pode ser reforçado. O modelo de agente consiste de apenas dois tipos de regras: uma para propagação dos níveis de ativação entre os neurônios conectados e uma para fortalecimento das conexões entre neurônios que estão ativos simultaneamente. Essas regras são aplicadas a todos os nós na rede. As simulações realizadas indicaram que o modelo do agente é, de fato, suficientemente genérica para simular vários padrões de leitura de emoções adaptativas.

\subsection{Considerações Finais}

Nesse capítulo foi realizada uma breve introdução ao aprendizado por imitação e apresentados alguns trabalhos que utilizam essa abordagem. De acordo com esses trabalhos, o aprendizado por imitação é uma abordagem que tem sido muito utilizada para desenvolver aspectos que contribuem para a naturalidade na interação entre robôs sociais e humanos; inclusive, o próprio aprendizado por imitação se dá por meio dessa interação. 
CAPÍTULO

\section{Redes Neurais Artificiais}

Como visto no capítulo anterior, aplicações de diversas tarefas de imitação vêm aumentando, resultado de pesquisas e estudos em interação homem-robô. Modelos matématicos são capazes de promover o mecanismo de imitação a fim de reproduzir um determinado conjunto de tarefas, porém, tais modelos exigem conhecimento a priori preciso do modelo de mundo. Nesse sentido, as abordagens denominadas inteligentes são preferiveis para reproduzir o aprendizado por imitação, pois possuem capacidade de encontrar soluções eficientes para problemas complexos. O armazenamento de informação e sua recuperação, juntamente com a tomada de decisão, caracterizam a habilidade de uma abordagem inteligente. Entre as técnicas inteligentes dotadas das capacidades mencionadas, destaca-se Redes Neurais Artificiais, utlizada para a concepção do sistema de imitação proposto.

Esse capítulo é organizado como segue: Na Seção 4.1, descreve-se conceitos básicos de Redes Neurais Aritificais. Na Seção 4.2, apresentam-se os principais funções de ativação utilizadas em redes neurais. O métodos de aprendizado supervisioando é brevemente descrito na Seção 4.3. Na Seção 4.4, são apresentadas algumas topologias de redes neurais. Por fim, na Seção 4.5, as considerações finais são fornecidas. 


\subsection{Conceito}

A célula básica do sistema nervoso cerebral é o neurônio. Seu papel é conduzir impulsos sob determinadas condições de operação. Esse elemento biológico pode ser dividido em três partes principais: dendritos, corpo celular e axônio. A Figura 4.1 ilustra um neurônio. O corpo celular é responsável pelo processamento das informações vindas dos dendritos para produzir um potencial de ativação que indicará se o neurônio poderá disparar um impulso elétrico ao longo do seu axônio. O papel do axônio é conduzir os impulsos elétricos para outros neurônios conectores ou para aqueles que se conectam diretamente com o tecido muscular. A sua terminação também é formada por ramificações denominadas terminações sinápticas. As sinapses se configuram como as conexões que viabilizam a transferência de impulsos elétricos do axônio de um neurônio para os dendritos de outros (da Silva et al., 2010).

As redes neurais artificiais foram desenvolvidas a partir de modelos conhecidos de sistemas nervosos biológicos. O elemento computacional ou unidade processadora, denominada neurônio artificial, foi elaborado em 1943 por McCulloch e Pitts. O neurônio artificial é um modelo bem simplificado do neurônio biológico (da Silva et al., 2010). De acordo com o modelo da Figura 4.2 , o vetor $\mathbf{x}=\left[x_{1}, x_{2}, \ldots, x_{n}\right]$ corresponde às entradas ou estímulos externos apresentados ao neurônio. $\mathrm{O}$ vetor $\mathbf{w}=\left[w_{1}, w_{2}, \ldots, w_{n}\right]$ equivale aos pesos sinápticos, que correspondem à memória do neurônio. De acordo com Haykin (1999), são identificados três elementos básicos do modelo neuronal:

- um conjunto de sinapses, cada uma caracterizada por um peso. Especificamente, um sinal $x_{j}$ na entrada da sinapse $j$ conectada ao neurônio $k$ é multiplicado pelo peso sináptico $w_{k j}$;

- um somador, que soma os sinais de entrada, ponderados pelas respectivas sinapses do neurônio;

- uma função de ativação para restringir a amplitude da saída de um neurônio. Normalmente, o intervalo normalizado da amplitude da saída de um neurônio é escrito como o intervalo unitário fechado $[0,1]$ ou $[-1,1]$.

O bias $b_{k}$ tem o efeito de aumentar ou diminuir a entrada da função de ativação, dependendo se é positivo ou negativo, respectivamente. 


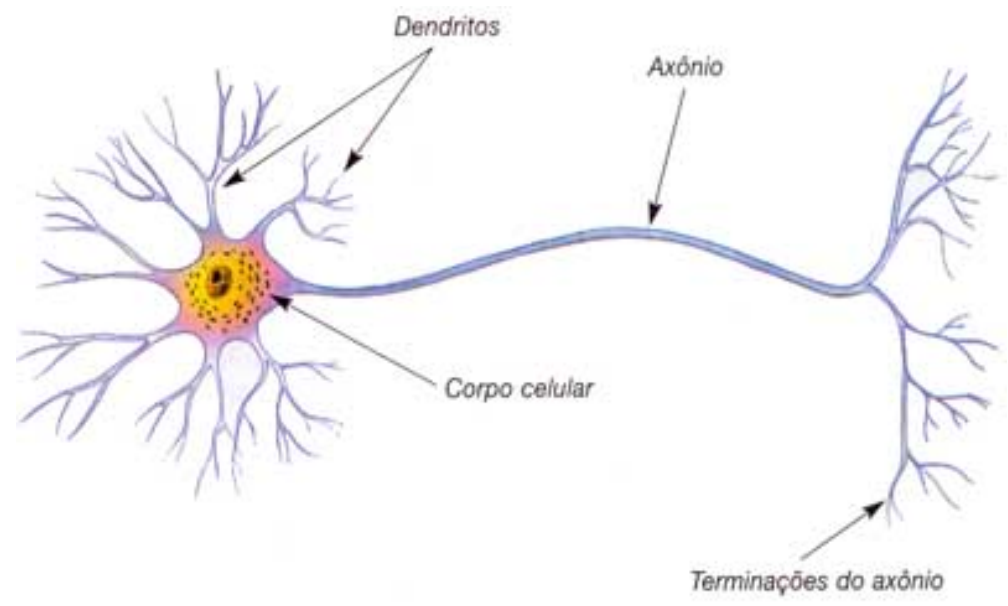

Figura 4.1: Neurônio Biológico

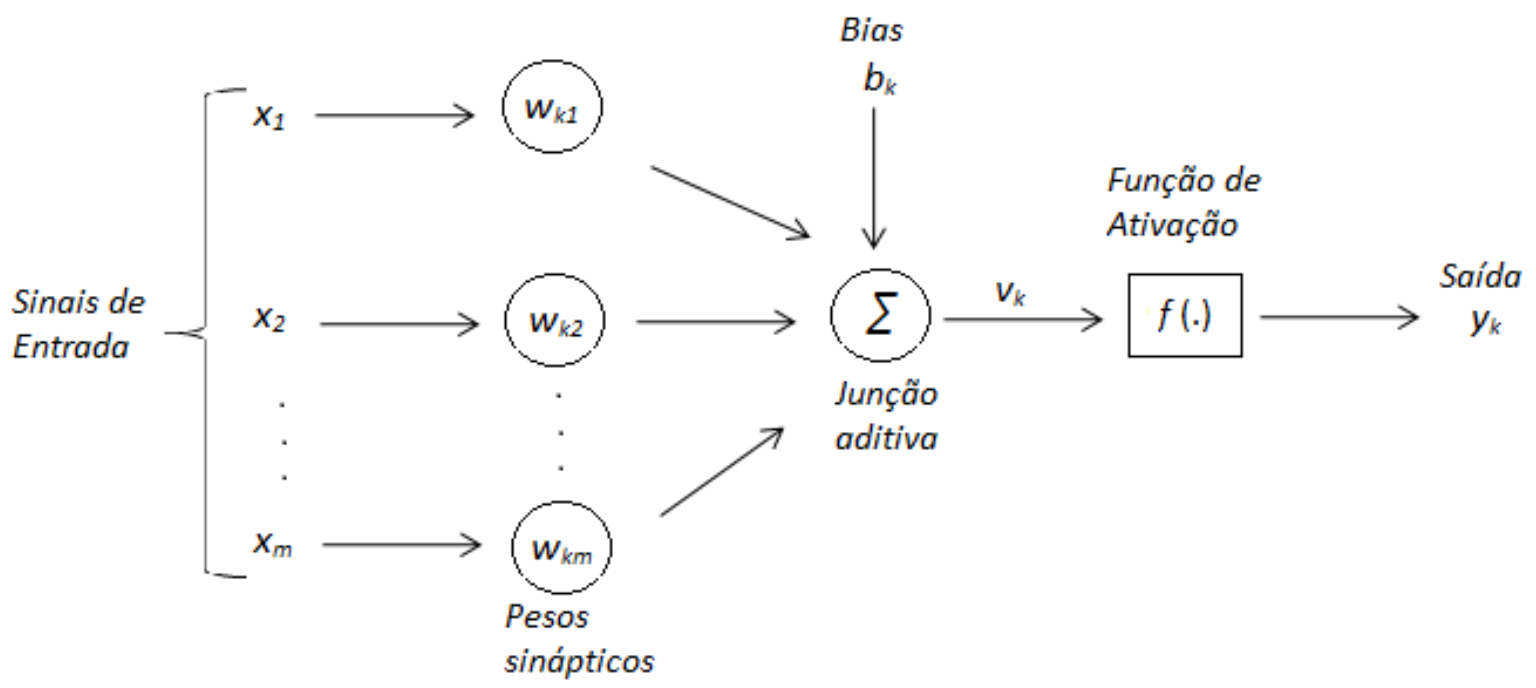

Figura 4.2: Neurônio Artificial

\subsection{Funções de Ativação}

Independente do modelo de rede neural, o mecanismo de como os sinais de entrada são processados na soma do neurônio é similar. O processamento neural ocorre quando o neurônio recebe os sinais de entrada (vetor $\mathbf{x}$ ), e juntamente com o vetor de pesos sinápticos w, aplica-se uma função que mede a similaridade entre os vetores. Uma medida de similaridade bastante utilizada é o produto interno entre os vetores $\mathbf{x}$ e w mostrada na Figura 4.2. Após a comparação dos vetores, a saída $y$ do neurônio é obtida através da aplicação de uma função de ativação $f($.$) ao resultado da comparação dos$ vetores. A função de ativação funciona através da aplicação de funções 
matemáticas, gerando um valor denominado valor de ativação. Tal valor, normalmente dentro do intervalo $[0,1]$, é propagado através das conexões sinápticas até os neurônios de saída, indicando com que grau de ativação cada neurônio vai disparar. Uma maneira utilizada pra determinar se o disparo do neurônio é significativo é estabelecer um limiar de ativação, que deve ser excedido pela função de ativação. Na Figura 4.3 são apresentadas graficamente quatro funções de ativação: função linear, função rampa, função degrau e função sigmóide.

A função linear, definida pela Equação 4.1, é especificada por um valor constante, que combina com a entrada do neurônio. Limitando a função linear em um intervalo específico, os valores da função para qualquer entrada pertencente ao universo de discurso são redefinidos por valores constantes. A restrição da função linear é denominada de função rampa definida na Equação 4.2. A função degrau (Equação 4.3) assume valores constantes para uma entrada menor que um limiar definido e outro valor constante quando a entrada é maior que esse limiar. A função sigmóide é limitada e monotônica, definida pela Equação 4.4.

$$
\begin{gathered}
f(x)=\alpha x \\
f(x)=\left\{\begin{array}{l}
0, \text { se } x<0 \\
x, \text { se } 0<x<1 \\
1, \text { se } x \geq 1
\end{array}\right. \\
f(x)=\left\{\begin{array}{l}
0, \text { se } x \leq 0 \\
1, \text { se } x>0
\end{array}\right. \\
f(x)=\frac{1}{\left(1+e^{-\beta x}\right)}
\end{gathered}
$$

em que $\alpha$ é um valor real que define a saída linear para os valores de entrada, $\beta$ determina a suavidade da curva da função sigmóide e $x$ é a entrada para as funções de ativação.

\subsection{Aprendizado Supervisionado}

Uma das mais importantes propriedades das redes neurais, herdada do sistema nervoso humano, é o aprendizado. As redes são capazes de adquirir 


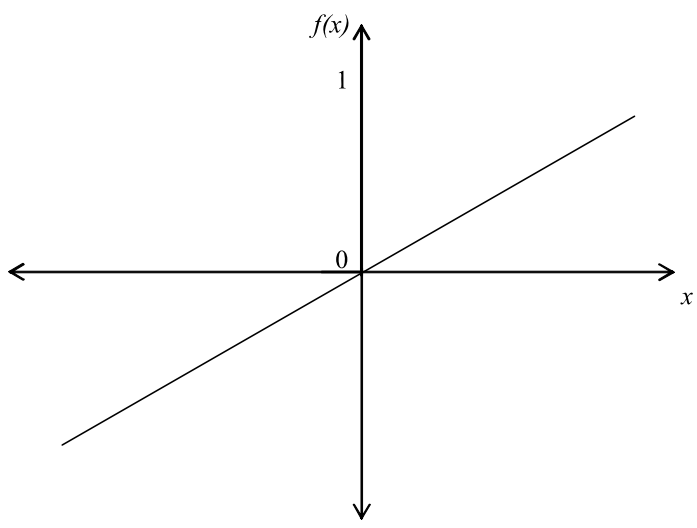

(a)

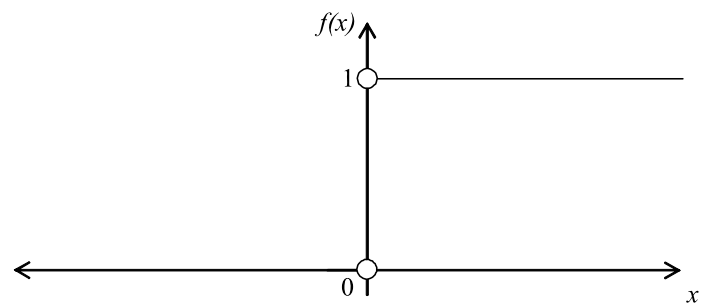

(c)

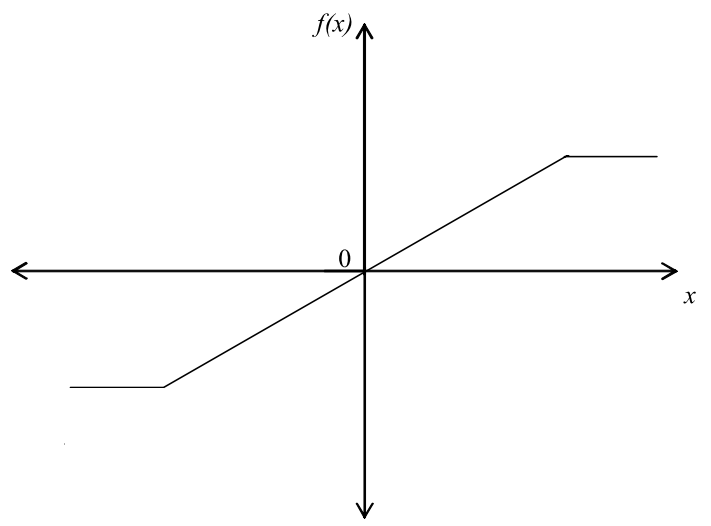

(b)

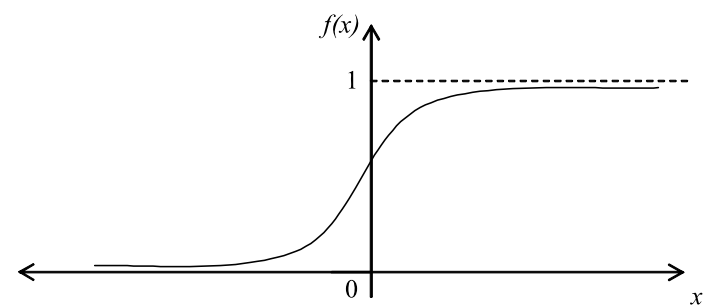

(d)

Figura 4.3: Funções de ativação não-lineares (a) função linear; (b) função rampa; (c) função degrau; (d) função sigmóide 
conhecimento a partir de experiências com o ambiente que as envolve, na tentativa de solucionar seus problemas. A partir dessas experiências, as sinapses são alteradas de modo a adaptar-se a inúmeras situações. As sucessivas alterações das sinapses e, consequentemente, a adaptação das redes neurais, caracterizam seu aprendizado, tornando-as capazes de generalização e reprodução do raciocínio aproximado.

O método de aprendizado supervisionado consiste na apresentação para a rede neural de um conjunto de exemplos, cada qual formado por um par entrada/saída. Para cada exemplo, a rede neural recebe a entrada e deve aprender a gerar a saída correspondente. No caso da rede neural não gerar a saída desejada, é encontrada a diferença (erro) entre a saída obtida e a saída desejada. A partir do valor dessa diferença, os pesos sinápticos dos neurônios são atualizados para que, nas próximas iterações a saída obtida se aproxime ao máximo da saída desejada. Portanto, não há necessidade de que a rede neural descubra quais saídas devem ser apresentadas como resposta às entradas. As saídas corretas são estabelecidas pelos exemplos de treinamento.

O método de aprendizado supervisionado denominado de retropropagação foi proposto por Rumelhart, Hinton e Willians Rumelhart et al. (1986a). Este é o modelo mais conhecido de treinamento supervisionado, sendo um dos principais responsáveis pelo ressurgimento do interesse em redes neurais artificiais. O algoritmo retropropagação é constituído por dois passos: passo para frente e passo para trás. O passo para frente consiste na propagação dos sinais aplicados à camada de entrada até a camada de saída da rede, passando pelas camadas intermediárias, gerando uma resposta. $\mathrm{O}$ erro encontrado entre a saída obtida pela rede e a saída desejada é propagado no sentido inverso (da camada de saída para a camada de entrada) para o ajuste dos pesos sinápticos. Tal propagação do sinal de erro determina o passo para trás do método de aprendizagem. Baseado na regra delta proposta por Widrow e Hoff Widrow e Hoff. (1960), este algoritmo apresenta uma forma de definir o erro dos neurônios das camadas intermediárias, possibilitando o ajuste de seus pesos. Estes ajustes são realizados utilizando-se o método do gradiente.

Os passos para frente e para trás são repetidos por diversas iterações com o objetivo de minimizar o erro, de acordo com a saída desejada. O sinal do erro $e$ da saída $y$ do neurônio $i$ é definido por:

$$
e_{i}(t)=d_{i}(t)-y_{i}(t)
$$


em que $d_{i}(t)$ é a saída desejada para o $i$-ésimo neurônio da camada de saída na iteração $t$.

O valor instantâneo $E(t)$ da energia total do erro é obtido somando-se os termos $\frac{1}{2} e_{i}^{2}(t)$ de todos os neurônios da camada de saída. Podemos assim escrever:

$$
E(t)=\frac{1}{2} \sum_{j \in C} e_{i}^{2}(t)
$$

em que o conjunto $C$ inclui todos os neurônios da camada de saída da rede.

Considerando que $N$ representa o número total de padrões do conjunto de treinamento, a energia média do erro quadrado é obtida somando-se os $E(t)$ para todo $t$, como mostrado por:

$$
E_{\text {med }}(t)=\frac{1}{N} \sum_{t=1}^{N} E(t)
$$

O método mais utilizado para o ajuste dos pesos sinápticos de uma rede neural multicamada é o do gradiente. Este método necessita da informação das derivadas parciais de primeira ordem de erro com relação aos pesos de cada neurônio e das funções de ativação dos neurônios da rede. Para as conexões entre a camada intermediária e a camada de saída, a regra do gradiente é definida por:

$$
\Delta_{w_{i j}}=-\eta \frac{\partial E\left(w_{i j}\right)}{\partial w_{i j}}=\eta \cdot \delta_{i} . y_{j}
$$

em que $w_{i j}$ é peso sináptico correspondente à sinapse $j$ do neurônio $i, \eta$ é a taxa de aprendizagem do algoritmo de retropropagação e $\delta_{i}$ é o gradiente local definido por:

$$
\delta_{i}=\varphi^{\prime}\left(c_{i}\right) \cdot\left(d_{i}-y_{i}\right),
$$

em que $c_{i}$ é o sinal de entrada dos pesos aplicado ao neurônio $y_{i}$ e $\varphi($.$) é a$ função de ativação do neurônio. As conexões $w_{i j}$ são ajustadas aplicando a Equação 4.10:

$$
w_{i j}(t+1)=w_{i j}(t)+\Delta_{w_{i j}}
$$

Para as sinapses entre a camada de entrada e a camada intermediária, a função erro é diferenciada com o respectivo peso $w_{j k}$ usando a regra da cadeia, 
definida por:

$$
\Delta_{w_{j k}}=-\eta \frac{\partial E\left(w_{j k}\right)}{\partial w_{j k}}=-\eta \cdot \sum \frac{\partial E\left(w_{j k}\right)}{\partial y_{j}} \cdot \frac{\partial y_{j}}{\partial w_{j k}}=\eta \cdot \delta_{j} \cdot x_{k},
$$

em que $w_{j k}$ corresponde à sinapse $k$ do neurônio $j$ e $\delta_{j}$ é o gradiente local em relação à $w_{j k}$ expresso por:

$$
\delta_{j}=\varphi^{\prime}\left(h_{i}\right) \sum w_{i j} . \delta_{j},
$$

em que $h_{i}$ é o peso do sinal de entrada aplicado ao neurônio $y_{j}$.

O ajuste dos pesos sinápticos $w_{j k}$ é definido pela seguinte equação:

$$
w_{j k}(t+1)=w_{j k}(t)+\Delta_{w_{j k}},
$$

A frequência de atualização dos pesos influencia o desempenho da rede durante o treinamento. Há duas abordagens que estabelecem os instantes de atualização dos pesos para o algoritmo de retropropagação: por padrão e por ciclo (batch). Na abordagem por padrão, os pesos sinápticos são ajustados após a apresentação de cada padrão de entrada para a rede durante o treinamento. Porém com taxas elevadas de aprendizagem para o ajuste dos pesos, a rede torna-se instável, pois os pesos sofrem um grande passo para minimizar o erro gerado pelo padrão de entrada corrente ocasionando na perda de generalidade quanto aos demais padrões. Dessa forma, esta abordagem requer taxa de aprendizagem baixa. A abordagem por padrão se sobressai sobre a abordagem por ciclo por demandar menos tempo e, principalmente, se o conjunto de treinamento for grande e redundante. Na abordagem por ciclo, o ajuste dos pesos sinápticos ocorre após a apresentação de todos os padrões de entrada pertencentes ao conjunto de treinamento. Assim, o erro propagado no passo para trás corresponde ao erro gerado por todos os padrões caracterizando a estabilidade da rede após a atualização dos pesos. Em contraste com a abordagem por padrão, esta técnica requer mais tempo caso o conjunto de treinamento seja grande e redundante.

Para o método de retropropagação, o processo de aprendizagem deve prosseguir até que o critério de parada seja alcançado. Tal critério implica o estabelecimento de um erro mínimo $\epsilon$. Ao longo do período de treinamento, deseja-se que o erro gerado pela rede seja reduzido. $O$ processo de aprendizagem é interrompido quando o erro gerado alcança $\epsilon$. Valores para o 
erro menores que $\epsilon$ são considerados admissíveis.

Deve ser observado que quando o treinamento se estende por um período muito longo, há o risco de a rede perder sua característica de generalização Geman et al. (1992) por se especializar somente nos padrões do conjunto de treinamento. Generalização é uma das mais importantes características das redes neurais artificais. O conjunto de treinamento da rede é o principal fator que determina sua capacidade de generalização. Tal conjunto, portanto, deve expressar as características gerais do Universo de Discurso. Isto implica, em dispor de vários padrões de cada classe a ser treinada, o que seria considerado o conjunto de treinamento ideal. A escolha dos padrões deve estar sempre bem fundamentada na caracterização do Universo de Discurso. A não generalização pode ser caracterizada pela escolha centrada de padrões particularizando o universo.

\subsection{Topologias de Redes Neurais Artificiais}

A topologia de uma RNA é um parâmetro importante na sua concepção, pois define o tipo de problema que pode ser tratado pela rede. As mais interessantes potencialidades das redes neurais não são factíveis a um único neurônio. É necessário um conjunto de neurônios convenientemente agrupados e conectados por meio de pesos sinápticos para que tais potencialidades possam ser empregadas. A decisão de como conectar os neurônios é uma das tarefas mais árduas na modelagem de uma rede neural.

O modelo Perceptron, proposto por (Rosemblatt, 1958), pode ser considerado uma rede simples, constituída por uma única camada com um neurônio. A entrada do neurônio equivale à entrada da rede, assim como a saída do neurônio equivale à saída da rede. Além dos estímulos externos, o perceptron recebe como entrada outro fator denominado bias. Este fator determina como o mecanismo de aprendizagem explora o espaço de busca dos parâmetros do neurônio ou da rede.

O modelo Perceptron Multicamadas (MLP, Multilayer Perceptron) de Rumelhart et al. (1986b), para sanar as limitações do perceptron, é composto por vários neurônios distribuídos em três tipos de camadas distintas: entrada - camada que recebe estímulos externos; intermediária (ou oculta) camada que recebe como entrada o sinal de saída dos neurônios da camada anterior, podendo ser a camada de entrada ou outra camada intermediária; saída - camada que recebe como entrada o sinal de saída dos neurônios da 
última camada intermediária e gera a saída da rede. Nesse modelo, o sinal da rede propaga de forma ascendente, ou seja, todos os neurônios de uma camada são conectados a todos os neurônios da camada seguinte. A Figura 4.4 ilustra o modelo MLP.

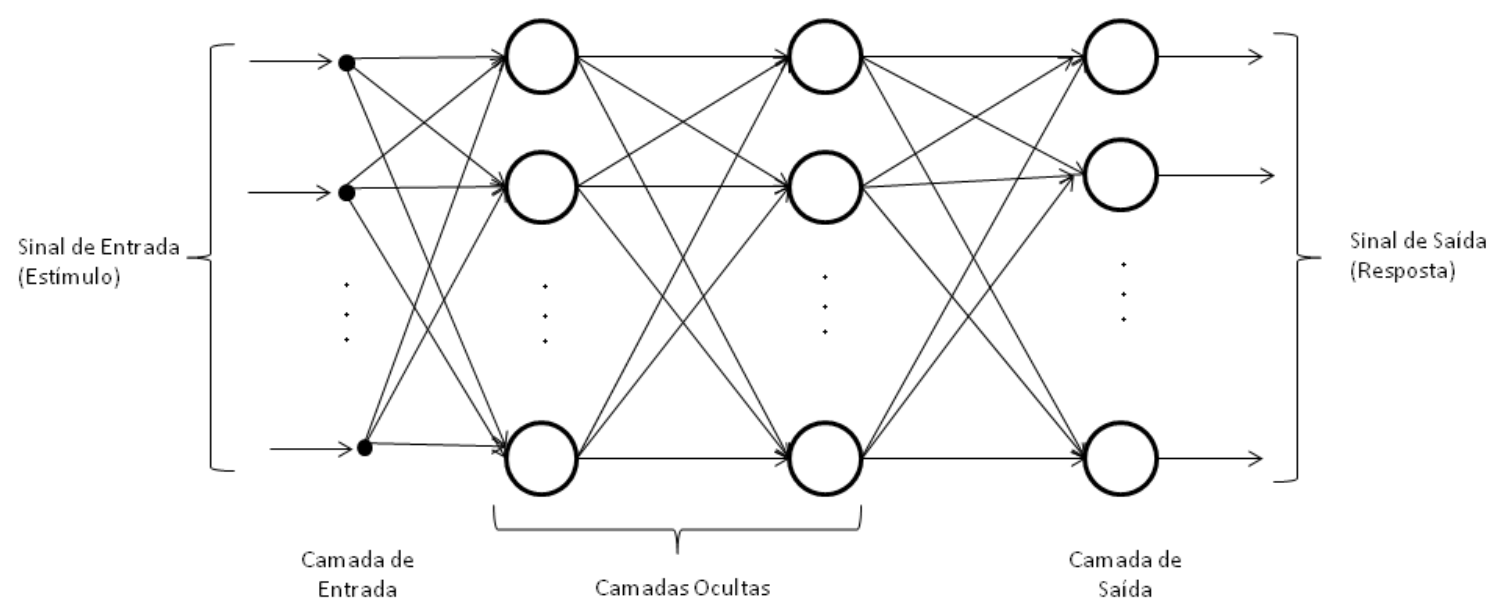

Figura 4.4: Modelo Perceptron Multicamadas

O tempo pode ser representado implicitamente na operação de uma rede neural, permitindo que uma rede neural estática (por exemplo, uma MLP), possua propriedades dinâmicas. Para que uma rede neural seja dinâmica, ela deve ter memória. A memória pode ser dividida em memória de curto prazo e de longo prazo. A memória de longo prazo é inserida na rede neural através de aprendizado supervisionado, pelo qual a informação do conjunto de dados de treinamento é mantido nos pesos sinápticos da rede. Entretanto, se a tarefa considerada tiver uma dimensão temporal, faz-se necessário alguma forma de memória de curto prazo para tornar a rede dinâmica. Uma forma simples de inserir memória de curto prazo na estrutura de uma rede neural é através de atrasos de tempo, que podem ser implementados a nível sináptico dentro da rede ou na camada de entrada da rede (Haykin, 1999).

Uma rede alimentada adiante focada atrasada no tempo (TLFN focada, 
focused time lagged feedforward network) é um exemplo de rede neural à qual é inserida memória de curto prazo, implementada na camada de entrada. Essa rede é capaz de realizar reconhecimento temporal de padrões, que requer o processamento de padrões que evoluem no tempo, sendo que a resposta em determinado instante depende não apenas do valor atual de entrada, mas também de seus valores passados. Uma rede TLFN focada consiste de uma memória de linha de atraso derivada de ordem $p$ e um perceptron de múltiplas camadas. Especificamente, o sinal de entrada, consistindo do valor atual $x(t)$ e de $p$ valores passados $x(t-1), \ldots, x(t-p)$ armazenados em uma memória de linha de atraso de ordem $p$, são propagados de forma ascendente para gerar a saída da rede neural (Haykin, 1999). A Figura 4.5 ilustra uma TLFN.

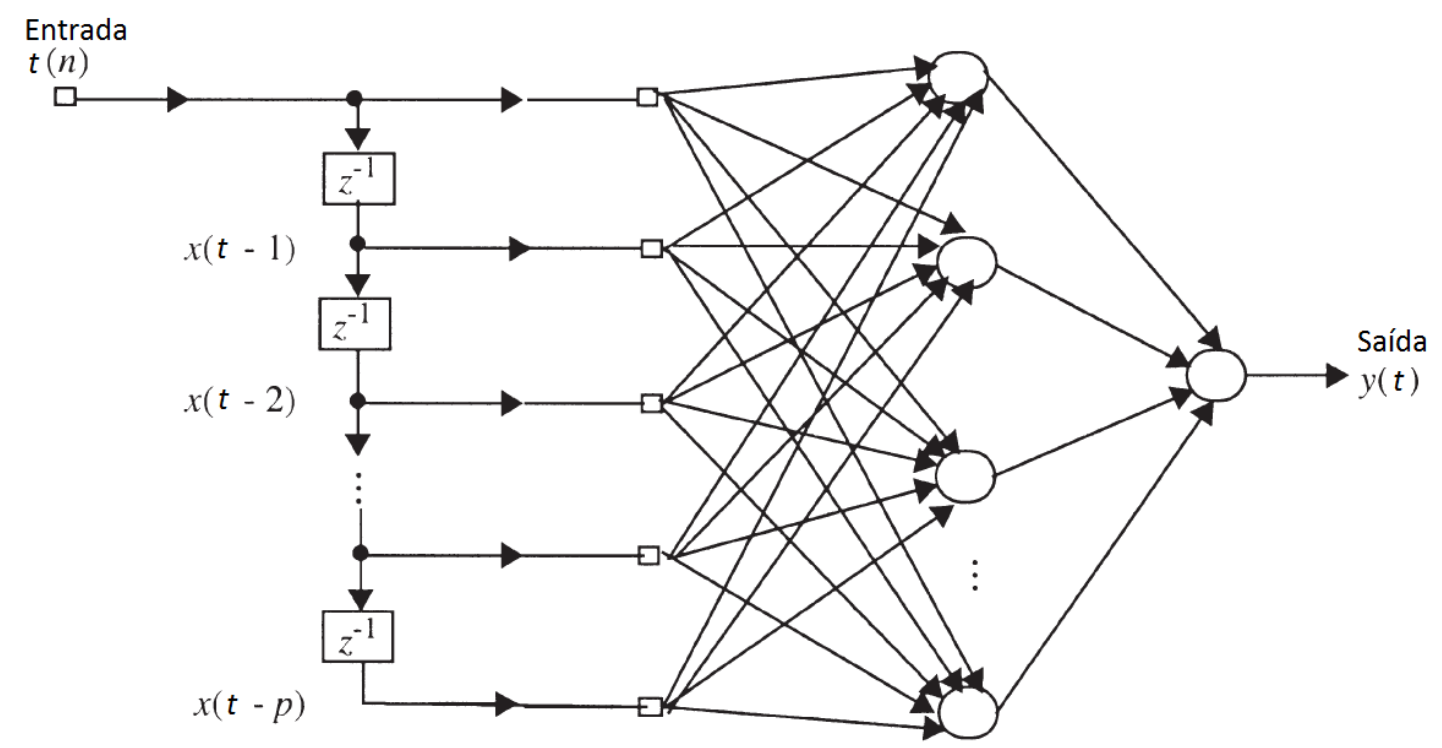

Figura 4.5: Rede neural alimentada adiante focada atrasada no tempo Haykin (1999).

Outro modo importante pelo qual o tempo pode ser incorporado na operação de uma rede neural de maneira implícita é através do uso de realimentação. As redes neurais com um ou mais laços de realimentação são chamadas de redes recorrentes (RNN - Recurrent Neural Network) (Haykin, 1999). Os neurônios artificiais podem ser usados em redes recorrentes pela introdução de um fator temporal na computação. Assumindo que a computação da ativação de cada neurônio consome uma unidade de tempo, se as entradas chegam no tempo $t$, a resposta é emitida no tempo $t+1$.

As redes recorrentes são capazes de propagar dados de estágios de processamento posterior para estágios anteriores. Nessas redes, o estado de 
ativação é uma função do estado de ativação anterior, bem como das entradas atuais. Adicionar realimentação ao passo de ativação anterior introduz uma espécie de memória ao processo. Isso aumenta a capacidade da rede aprender sequências temporais, sem fundamentalmente mudar o processo de treinamento (Mazumdar e Harley, 2008).

Nas redes de Elman, as conexões de todas as camadas se propagam de forma ascendente, exceto uma que possui conexões recorrentes. O sistema tem uma camada de entrada, uma camada oculta e uma camada de saída, as quais são conectadas de modo ascendente. Entretanto, a camada oculta não é apenas conectada para a camada de saída, mas também, em uma simples conexão 1:1, para uma camada extra, chamada camada de contexto. Para formar conexões recorrentes, a saída da camada de contexto se conecta como entrada para a camada oculta. Exceto para as conexões 1:1 da camada oculta para a camada de contexto, para as quais os pesos são fixados em 1 , todas as outras camadas devem ser completamente conectadas e todos os pesos devem ser modificáveis. Além disso, todos os pesos modificáveis pertencem às conexões ascendentes da rede. As conexões recorrentes da camada de contexto fornecem ao sistema uma memória de curto prazo; as unidades ocultas observam não somente a entrada atual, via camada de contexto, mas também obtém informação do seu próprio estado no passo de tempo anterior.

As redes de Jordan são muito semelhantes às redes de Elman. A diferença é que as conexões recorrentes começam da saída, em vez da oculta. Além disso, a camada correspondente ao contexto se resume em uma rede recorrente por si própria, com conexões 1:1 e pesos fixos. Ambas as redes têm a vantagem que apenas pesos nas conexões ascendentes são modificáveis e nenhum método de treinamento especial para redes recorrentes precisa ser introduzido (Cruse, 2009).

\subsection{Considerações Finais}

Nesse capítulo, apresentou-se os principais fundamentos teóricos de Redes Neurais Artificiais. No presente trabalho, as redes neurais possuem um importante papel devido à sua capacidade de processamento paralelo de informações, reconhecimento de padrões e adaptabilidade a mudanças em problemas dinâmicos. Para modelar um método de aprendizado por imitação, descrito no capítulo seguinte, investigou-se as redes neurais RNN, MLP e 
TLFN. 



\section{CAPÍTULO 5 \\ Sistema de Imitação de Expressões Faciais de Emoção}

A extração de características da face é considerada extremamente importante para a tarefa de imitação de expressões faciais que são realizadas por humanos, pois, caso ela não seja bem feita, o sistema de classificação de padrões não conseguirá discenir bem os diversos tipos de expressões faciais. Neste trabalho, é realizada a extração de características de faces humanas, referentes às seguintes emoções: neutra, alegria, raiva, surpresa e tristeza.

Nesse capítulo, é descrito o sistema de imitação de expressões faciais proposto. Este sistema é composto por dois módulos: o módulo de extração automática de características da face e o módulo de reconhecimento e geração de expressões faciais de emoção por parte de uma cabeça robótica. Na Seção 5.1, são descritos dois sistemas para extração de características da face humana. Ora um compõe o módulo de extração automática de características da face, ora outro. Dado o estudo de ambos, cada um é aplicado isoladamente no sistema de imitação proposto. O módulo de reconhecimento e geração de expressões faciais de emoção é descrito na Seção 5.2 detalhando as redes neurais adotadas para a construção de tal módulo. Na Seção 5.3, são dadas as considerações finais. 


\subsection{Módulo de Extração Automática de Características da Face}

Para a construção deste módulo, foram investigados dois sistemas para extrair as características da face humana. O primeiro sistema foi desenvolvido por nós, denominado por Sistema I, que se baseia em estimativas de posicionamento de elementos da face. O segundo foi proposto por e cedido por Saragih et al. (2011), denominado por Sistema II, que usa aproximação não-paramétrica. Estes dois sistemas serão descritos de forma mais detalhada a seguir.

\subsubsection{Sistema I}

O objetivo desse sistema é encontrar pontos característicos da face, os quais são importantes para o reconhecimento de expressões faciais de emoção reproduzidas por um humano. Devido à natureza de tempo real desta aplicação, o tempo de processamento do sistema foi considerado mais relevante do que a acurácia em si, já que este módulo é susceptível para ser executado simultaneamente com o resto das tarefas do sistema. Devido a isso, deu-se preferência por criar regras heurísticas para segmentação da face a usar classificadores de padrões, como feito, por exemplo em Ding e Martinez (2008).

\section{Processamento Inicial da Imagem}

Antes de aplicar o algoritmo de extração, é necessário preprocessar a imagem capturada, como mostrada na Figura 5.1, otimizando-a para todos os procedimentos de extração. Esse processamento envolve os seguintes passos:

- redimensionar e converter a imagem para escala de cinza com profundidade 8-bit,

- equalizar o histograma da imagem,

- aplicar um filtro de borramento Gaussiano 3x3 e

- fazer uma rotação inicial da imagem, baseada no ângulo de inclinação da face estimado anteriormente, para garantir que a face esteja ainda sendo rastreada quando o usuário fizer uma inclinação superior a 10-15 graus. 
A imagem resultante é usada como entrada para todos os passos seguintes para a detecção completa da face, isto é, para a extração de pontos dos olhos, das sobrancelhas, das narinas e da boca. Na Figura 5.2, é mostrada a imagem processada, que será o alvo real dos algoritmos de extração de pontos da face. Em ambas as imagens estão representados os pontos e o ângulo de inclinação, resultantes dos algoritmos de extração que serão explicados a seguir.

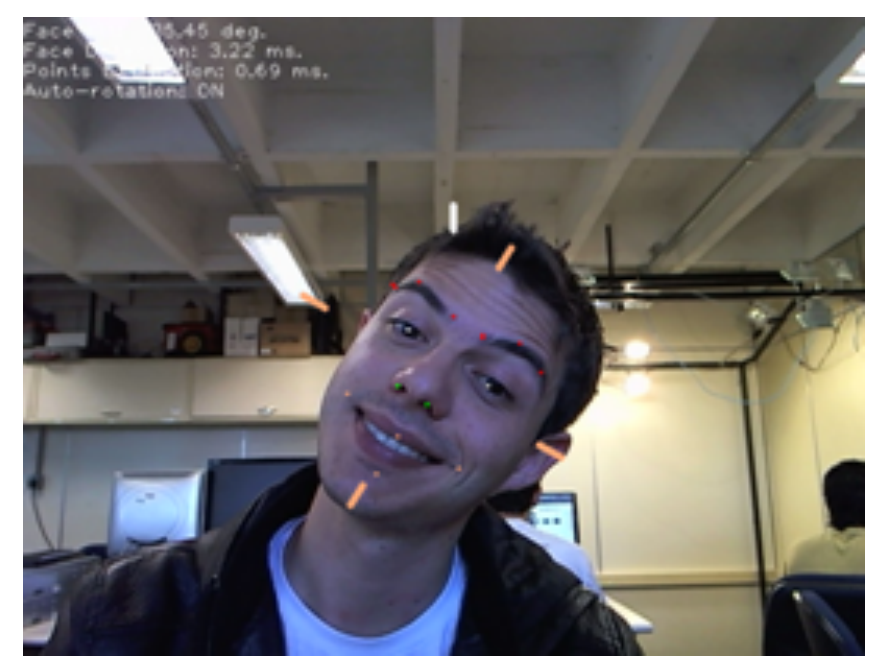

Figura 5.1: Imagem original colorida capturada da câmera com os pontos faciais extraídos marcados em vermelho, branco, verde e laranja, para sobrancelhas, centros dos olhos, narinas e boca, respectivamente. A inclinação da face também é representada.

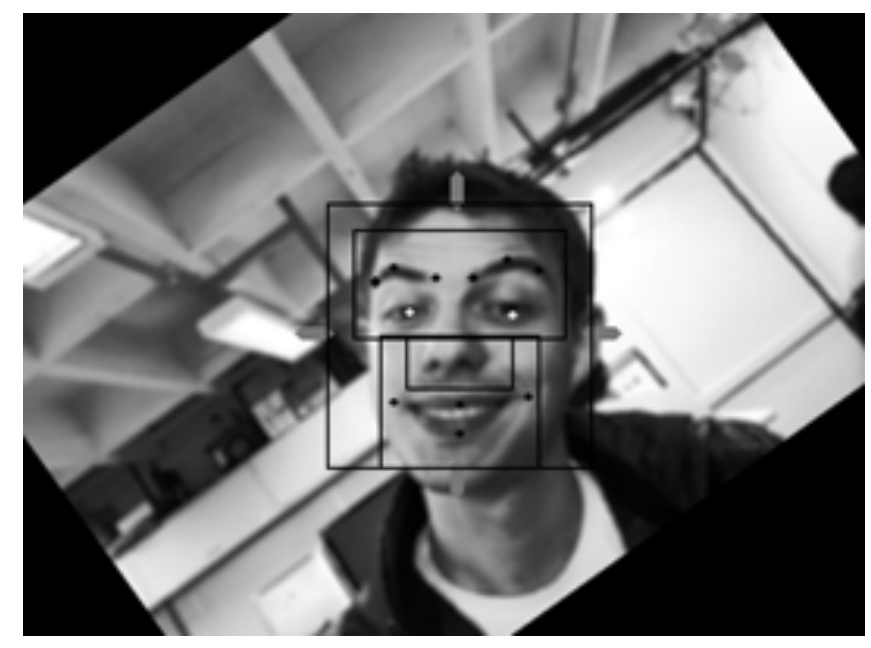

Figura 5.2: Imagem resultante depois da conversão de cores, redimensionamento, rotação e borramento. Os retângulos limitam as diferentes regiões em que a face foi segmentada. 


\section{Detecção da Face}

O próximo passo é encontrar uma face na imagem. Há muitas técnicas para detecção de face. Aqui, foi usada a técnica proposta por Viola em Viola e Jones (2001), que é baseada no algoritmo AdaBoost (Freund e Schapire, 1997). Esta técnica está implementada na biblioteca OpenCV (Bradski, 2000).

Ela é rápida e confiável, mas possui dois principais inconvenientes: é a parte que mais consome tempo no algoritmo de visão computacional e é sensivel à posição da face, mesmo quando o usuário ainda está olhando diretamente para a câmera (que é a posição de interesse).

A parte que consome mais tempo foi reduzida, definindo-se o tamanho mínimo da face para 30x30 pixels, redimensionando-se a imagem capturada para a menor versão possível. Então, com a configuração do computador utilizado, a detecção gastou de 3 a $8 \mathrm{~ms}$, contra 0.3 a $1.0 \mathrm{~ms}$ para o resto de toda extração de características geométricas da face. Isso significa que 7596\% do algoritmo de visão computacional é dedicado apenas para detecção da face.

O problema de inclinação da face foi superado pela introdução de uma rotação automática da imagem capturada, como explicado adiante. Essa rotação é baseada na última estimação da inclinação da face e está vinculada à localização do olho esquerdo do frame anterior.

\section{Detecção da Boca}

O objetivo aqui é extrair os dois cantos da boca e dois pontos localizados nos lábios superior e inferior, centralizados entre os cantos esquerdo e direito da boca.

Para localizar os cantos da boca, os seguintes passos foram necessários:

- Marcar a região da boca para $60 \%$ da largura da face e $50 \%$ da metade inferior da face. Essa região é ilustrada pelos retângulos que aparecem na Figura 5.2.

- Aplicar um filtro Sobel (Gonzalez e Woods, 2001) com um núcleo 3x3, segundo a ordem da derivada "y" e zero no eixo " $x$ "; seguido por um limiar binário médio Gaussiano adaptativo (Gonzalez e Woods, 2001).

- Os pontos limitantes da esquerda e da direita do contorno mais largo, na imagem binária resultante, corresponderão aos cantos esquerdo e direito da boca, respectivamente. 
sendo que a coordenada " $y$ " do lábio superior está localizada no máximo da projeção vertical do contorno mais largo mencionado e a coordenada " $x$ " dos lábios inferior e superior estarão no meio dos cantos da boca.

\section{Detecção das Narinas}

As narinas realmente não são uma parte expressiva da face. Entretanto, suas posições relativas na face são importantes para a definição de características importantes da face. Assim, elas serão uma referência geométrica para a maioria da informação que será usada, tais como ângulos e distâncias.

Os pontos mais escuros das narinas foram extraídos por um algoritmo inspirado no trabalho de Ding e Martinez (2008), sendo que a principal diferença é que não foi usado um classificador para localizar a região do nariz. Ao invés disso, foi considerado que as narinas estarão contidas em $30 \%$ da largura centralizada da face. E, considerando o eixo vertical, é recortado 50\% da parte superior da face. Então, o limite inferior da região do nariz será o ponto mais alto entre $20 \%$ da altura da face e a distância ao ponto do lábio superior extraído anteriormente.

No caso da Figura 5.2, a região do nariz resultou em 20\% do comprimento da metade da face para baixo. Nos casos em que o usuário levanta o queixo, o lábio superior fica dentro da região do nariz. É por isso que nesses casos o comprimento dessa regiao é reduzido pelo algoritmo.

Detecção dos Olhos, Sobrancelhas e Inclinação da Face

Para a detecção dos olhos, sombrancelhas e inclinação da face são extraídos os quatro pontos que definem a região delimitadora de cada sobrancelha, junto com o ponto mais escuro de cada íris do olho. A inclinação da face será o ângulo entre o eixo horizontal da imagem e a linha que passa por ambos os centros das íris.

Para fazer isso, foram necessários os seguintes passos:

- Eliminar os pixels da região superior da face correspondente a $10 \%$ da sua altura, para o início da região do nariz. Ver Figura 5.2.

- Separar essa região em lados esquerdo e direito. Isso tornou o resto do algoritmo mais robusto para a inclinação da face (20-30 graus aproximadamente). Além disso, ajudou a evitar confusão entre as sobrancelhas e as rugas da testa ou cabelo. 
Então, em cada um dos lados da face aplicou-se o filtro Sobel com um núcleo $3 x 3$, segundo a ordem da derivada " $y$ " e zero no eixo " $\mathrm{x}$ ", seguido por um limiar binário. O limiar é dinamicamente definido, usando algoritmo de Otsu (1979) e, em seguida, localizou-se os dois contornos mais escuros e maiores. Isso significa que são considerados os contornos cujos valores dos pixels somam mais no complementar da imagem em níveis de cinza.

O contorno superior será a sobrancelha. Os pontos da região delimitadora serão os pontos característicos da sobrancelha.

O outro contorno conterá, no mínimo, a parte mais escura da íris do olho. Assim, o centro da íris será o pixel mais escuro nesse contorno.

Vale a pena ressaltar que o borramento Gaussiano, aplicado ao processamento inicial da imagem, é um passo fundamental que torna o algoritmo robusto às rugas da testa.

\subsubsection{Sistema II}

O sistema de Saragih et al. (2011) foi desenvolvido como uma estratégia de otimização para ajuste de modelo deformável, baseado em especialista local. Ajuste de modelo deformável é o problema de registrar um modelo de forma parametrizada para uma imagem, tal que seus marcos correspondem às localizações consistentes no objeto de interesse. A partir de um modelo de referência da face, o qual é constituído por vários marcos, para cada nova imagem, o algoritmo tenta fazer um alinhamento dos elementos da face em análise com os vários marcos da face de referência. Esse problema é considerado difícil porque envolve otimização em altas dimensões, em que a aparência pode variar grandemente entre instâncias do objeto, devido às condições de luz, ruído da imagem, resolução e fontes intrínsecas de variabilidade.

A abordagem adotada é baseada no algoritmo de busca de deslocamento pela média, proposto por Fukunaga e Hostetler (1975). A diferença é que a abordagem proposta é aplicada para todos os marcos simultaneamente e também impõe uma prévia global sobre seu movimento de articulação.

O algoritmo começa pelo cálculo dos conjuntos de candidatos de localização para cada marco do modelo de referência, através de uma busca em um região retangular, e, então, é feita uma estimativa não-paramétrica dos mapas de respostas. Depois de realizada a estimativa, o modelo linearizado é encontrado. Em seguida, são calculados os vetores de deslocamento pela média, cujos pontos seguem a direção do aumento 
máximo da função densidade local. Por fim, a atualização dos parâmetros do vetor $\mathbf{p}$ é realizada.

A estratégia proposta se baseia no modelo de distribuição de pontos (point distribution model-PDM), proposto por Cootes e C.J.Taylor (1992). A ideia é realizar uma busca dos parâmetros do vetor $\mathbf{p}$, o vetor de parâmetros PDM, que minimiza o erro de desalinhamento sobre todos os marcos. Os passos do procedimento de ajuste são apresentados no algoritmo 1, denominado Regularized landmark mean-shift.

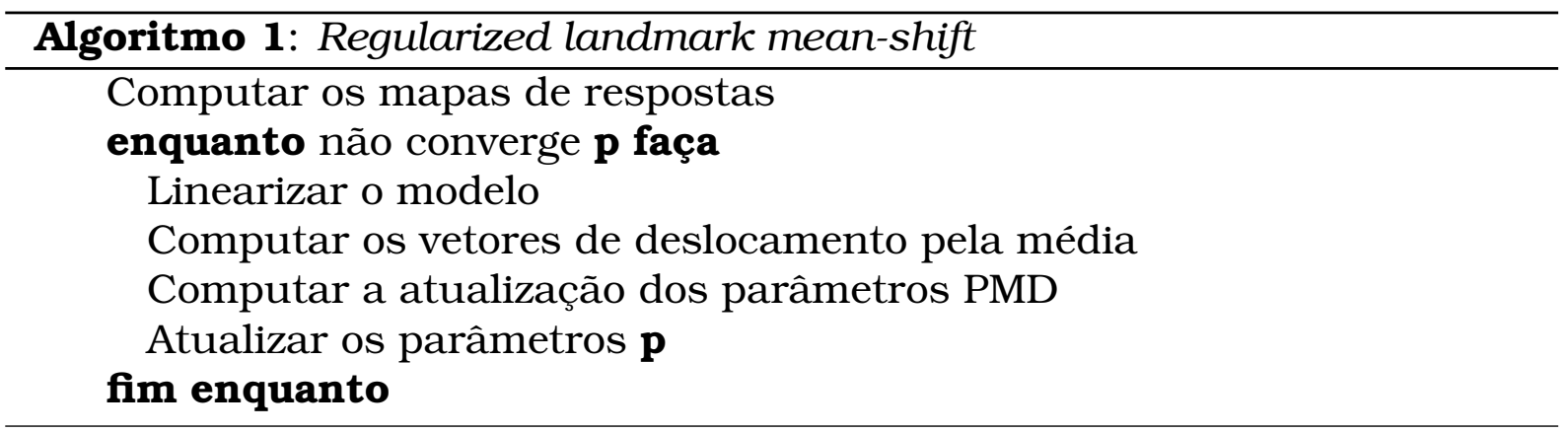

Este algoritmo, segundo os autores, é eficiente e apresentou desempenho superior em relação a algumas abordagens existentes na tarefa de ajustar uma face genérica.

\subsection{Módulo de Reconhecimento e Geração de Expressões Faciais de Emoção}

Como apresentado no Capítulo 3, alguns trabalhos têm utilizado redes neurais artificiais para desenvolver o aprendizado por imitação (Ito e Tani, 2004; Gotoh et al., 2007; Bosse et al., 2009; Boucenna et al., 2010). Baseado nisso, para a cabeça robótica imitar a expressão do usuário de acordo com os pontos obtidos pelo módulo de extração de características, foram investigadas três redes neurais: rede neural recorrente, rede perceptron multicamadas e rede neural alimentada adiante focada atrasada no tempo, descritas no Capítulo 4. As duas primeiras foram usadas na fase de reconhecimento, na qual é feito um mapeamento entre as características do usuário e as capacidades expressivas do robô. A terceira rede foi usada para a geração de expressões, permitindo que a cabeça robótica mude de uma expressão para outra de forma suave. As redes neurais foram implementadas na linguagem de programação Java. 
A seguir são apresentadas a cabeça robótica virtual e a descrição das redes neurais investigadas nesta pesquisa.

\subsubsection{Cabeça Robótica Virtual}

A cabeça robótica virtual usada neste trabalho é a Valerie (nome original), mostrada na figura 5.3. Ela foi primeiramente utilizada no trabalho de Gockley et al. (2005). Segundo os autores, escolher uma face gráfica ao invés de uma mecânica foi uma decisão de projeto significativa. A face em monitor de tela plana oferece várias vantagens sobre uma face mecânica:

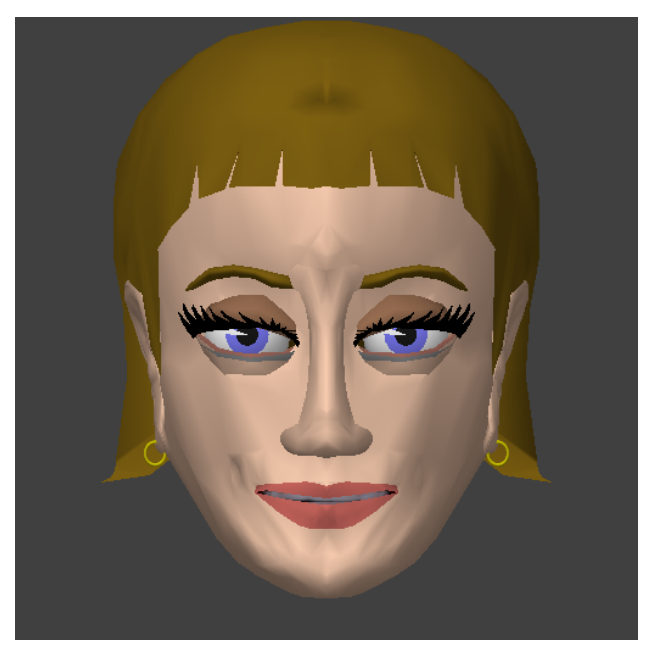

Figura 5.3: Valerie - a cabeça robótica virtual.

- A face gráfica é muito expressiva, com capacidade de mover músculos individuais para gerar uma grande variedade de expressões.

- Uma face mecânica é menos confiável que uma gráfica porque possui muitas partes móveis.

- Mudanças são mais fáceis de serem feitas na face gráfica.

A principal desvantagem da face gráfica é a falta do encorporamento físico de uma face mecânica.

Neste projeto, cinco expressões de emoção foram definidas para a Valerie exibir: neutra, alegria, raiva, surpresa e tristeza, apresentadas nesta ordem na Figura 5.4. Para definir cada expressão, foram atribuídos valores a cinco parâmetros: jaw, smile, brows, sneer e pout, que correspondem ao maxilar, sorriso, sobrancelhas, sarcasmo e careta. Pode-se observar que é possivel alterar a intensidade desse parâmetros, mas não é possível alterar pontos da 
face para exibir novos gestos. Por exemplo, pode-se aumentar ou diminuir a intensidade do sorriso, mas não é possível movimentar a boca só para um lado. Devido a essas limitações de expressão da Valerie, diferente de outros trabalhos encontrados na literatura, que consideram seis expressões básicas, neste trabalho são consideradas cinco.

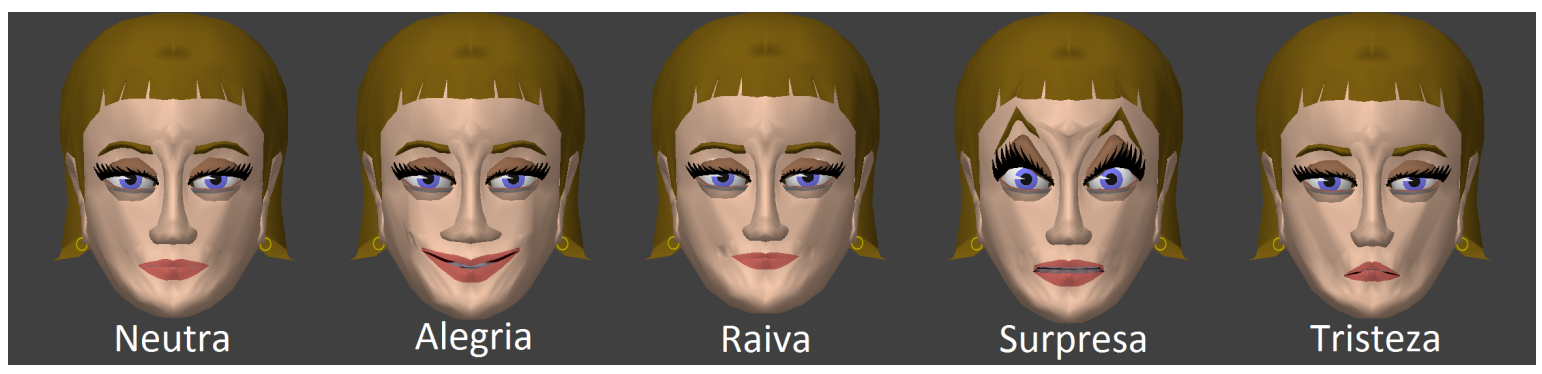

Figura 5.4: Expressões faciais definidas para a Valerie.

\subsubsection{Rede de Jordan com a Utilização do Sistema I}

Baseado no trabalho de Ito e Tani (2004), descrito no capítulo 3, inicialmente foi investigado o uso de uma rede recorrente de Jordan para obter um aprendizado dinâmico.

Na definição das entradas da rede neural, primeiro foram considerados diretamente os pontos extraídos pelo Sistema I. Entretanto, percebeu-se que desse modo havia uma grande dependência da distância do usuário à camera. Assim, decidiu-se usar como entradas os ângulos calculados a partir desses pontos. Os pontos considerados para calcular os ângulos são: narina direita (ND), narina esquerda (NE), lábio direito (LD), lábio esquerdo (LE), lábio superior (LS) and lábio inferior (LI), como mostrado na Figura 5.5. Desse modo, os ângulos formados entre os seguintes pontos são calculados: $a_{1 t}$ (LE e NE); $a_{2 t}$ (LE and LS); $a_{3 t}$ (LD and ND); $a_{4 t}$ (LD and LS), em que $t$ representa o tempo. Os ângulos obtidos são normalizados para estarem entre 0 e 1 , de acordo com a equação (5.1).

$$
a_{j t}^{\prime}=\frac{a_{j t}-\min _{a j}}{\max _{a j}-\min _{a j}}
$$

em que $j$ é a posição do ângulo no vetor $x, \min _{a j}$ é o valor mínimo de $a_{j}$, em todo tempo $t$, e $\max _{a j}$ é o valor máximo de $a_{j}$, em todo tempo $t$.

Para essa rede neural, foram definidos 5 neurônios para a camada de entrada, 20 neurônios para a camada oculta, 5 neurônios para a camada de saída e 5 neurônios para a camada de contexto. As entradas da rede neural 
são 5: os 4 ângulos formados pelos pontos da boca e das narinas (expressão do usuário) mais o parâmetro de intensidade de sorriso da Valerie (expressão do robô). A quantidade de neurônios da camada oculta foi definida experimentalmente, sendo que a quantidade considerada, foi a que gerou o menor valor de erro.
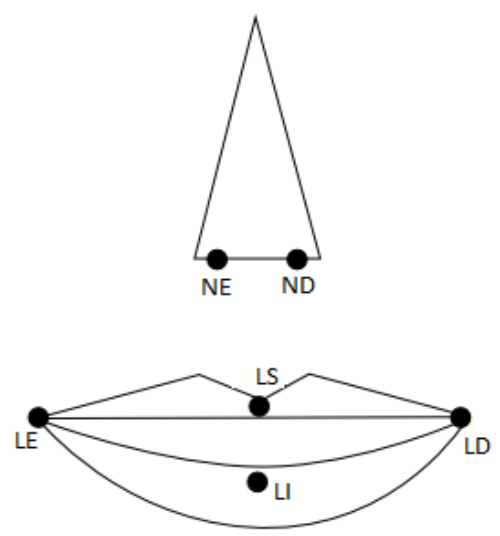

Figura 5.5: Pontos considerados para calcular os ângulos a partir do sistema do Sergio.

A rede foi treinada com o algoritmo padrão de retropropagação, com valor de taxa de aprendizado 0,1 . Na iteração $t=0$, foi definido o valor 0,5 para as entradas dos neurônios da camada de contexto. Nas demais iterações, esses valores são as saídas da camada de saída no tempo anterior. Assim, os sinais de entrada e da camada de contexto se propagam para a camada oculta, e da camada oculta para a camada de saída. As saídas desejadas no tempo $t$ são a expressão do usuário e do robô no tempo $t+1$. O erro gerado pela diferença entre as saídas obtidas e as saídas desejadas é usado para atualizar os pesos sinápticos da rede.

Para o aprendizado desejado, não se obteve a convergência com o uso da rede de Jordan. Mesmo após muitas interações, o valor do erro manteve-se estável. Desse modo, decidiu-se investigar o uso de uma rede TLFN, como explicado na seção a seguir.

\subsubsection{Rede TLFN com a Utilização do Sistema I}

Devido à instabilidade do Sistema I, apenas duas expressões foram consideradas com os pontos obtidos desse sistema: neutra e alegria. Para mapear as expressões faciais entre um humano e a cabeça robótica virtual, foi usada uma rede neural TLFN focada. Essa rede foi utilizada com o objetivo de classificar padrões que variam com o tempo. 
Para a TLFN, foram atribuídas 4 unidades para a camada de entrada, 20 unidades para a camada oculta e 1 unidade para a camada de saída. As entradas são os 4 ângulos calculados a partir dos pontos da boca e das narinas, como feito para a rede de Jordan, na seção anterior. Os ângulos obtidos são normalizados para estarem entre 0 e 1, de acordo com a Equação (5.1).

Aqui, é proposta uma diferente combinação das entradas da TLFN. Ao invés de considerar apenas as $p$ entradas atrasadas no tempo, considera-se as $t$ entradas ponderadas pelos respectivos pesos, almejando ter uma memória de entradas passadas. Assim, o padrão de entrada $x(t)$ é uma combinação dos valores anteriores $x(t-1), \ldots, x(1)$, de acordo com a Equação (5.2).

$$
x(t)=\alpha^{(t-1)} x(1)+\alpha^{(t-2)}(1-\alpha) x(2)+\ldots+\alpha(1-\alpha) x(t-1)+(1-\alpha) x(t)
$$

A quantidade de neurônios da camada oculta foi definida experimentalmente, sendo que a quantidade considerada, foi a que gerou o menor valor de erro. A saída da rede é a intensidade do sorriso do robô.

A TLFN foi treinada pelo algoritmo de retropropagação (Haykin, 1999). Para isso, foram usados vídeos com as expressões humanas neutra e alegria.

\subsubsection{Rede MLP e TLFN com a Utilização do Sistema II}

Com o uso do sistema II foi possivel obter pontos mais precisos e consistentes e fazer imitação de cinco expressões faciais de emoção. As emoções consideradas são: neutra, alegria, tristeza, raiva e surpresa. Para isso, além de considerar os ângulos formados entre os pontos da boca, foram considerados também os ângulos entre os pontos da sobrancelha e do nariz. Os pontos considerados para calcular os ângulos são: sobrancelha esquerda 1 (SE1), sobrancelha esquerda 2 (SE2), sobrancelha esquerda 3 (SE3), sobrancelha direita 1 (SD1), sobrancelha direita 2 (SD2), sobrancelha direita 3 (SD3), nariz superior (NS), nariz inferior (NI), lábio esquerdo (LE), lábio direito (LD), como mostrado na Figura 5.6. Desse modo, os ângulos formados entre os seguintes pontos são calculados: $a_{1 t}$ (SE1 e NS); $a_{2 t}$ (SE2 e NS); $a_{3 t}$ (SE3 e NS); $a_{4 t}$ (SD1 e NS); $a_{5 t}$ (SD2 e NS); $a_{6 t}$ (SD3 e NS); $a_{7 t}$ (LE e NI); $a_{8 t}$ (LD e $\mathrm{NI})$, em que $t$ representa o tempo.

Os valores dos ângulos obtidos são normalizados para o intervalo [0,1], de acordo com a equação (5.1). 


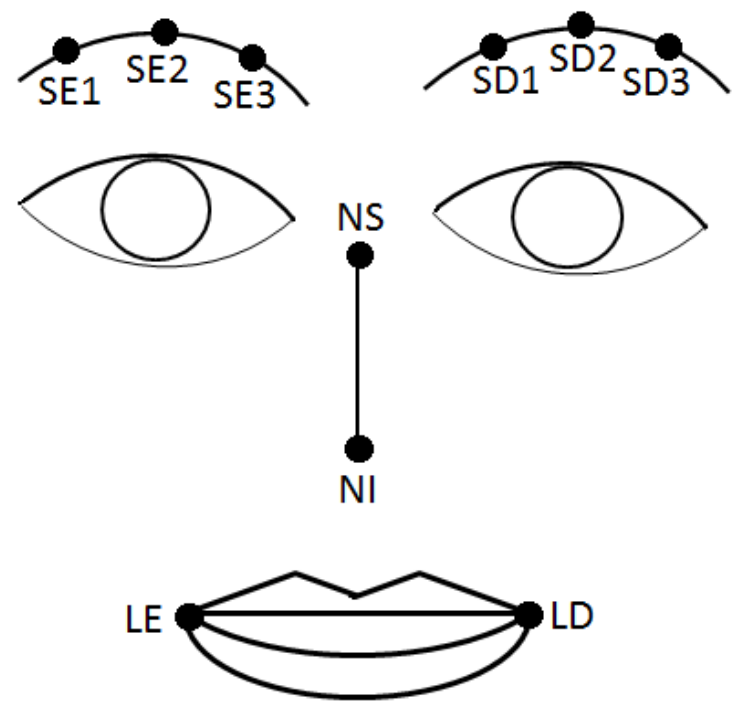

Figura 5.6: Pontos considerados para calcular os ângulos a partir do Sistema II.

Com a base de dados obtida, foi utilizada uma rede MLP para o aprendizado e uma rede TLFN para o momento da interação, para evitar que a Valerie mude de expressão de forma brusca, sendo adicionada à informação atual, informação do tempo anterior. Para a TLFN foi feita uma diferente combinação das entradas, de acordo com a Equação (5.2), explicada na seção anterior.

De acordo com a revisão bibliográfica, é possível fazer a imitação de duas maneiras: através de um mapeamento entre as características de um humano e a respectivas características do robô (Ito e Tani, 2004; Gotoh et al., 2007), e através da classificação das características do usuário e posterior geração da correspondente característica do robô (Boucenna et al., 2010; Ge et al., 2008), tornando o sistema independente do robô utilizado. Desse modo, foram construídas duas redes MLP para as duas formas de aprendizado; a primeira denominada MLP I e a segunda denominada MLP II. Ambas as redes possuem a mesma arquitetura: 8 neurônios na camada de entrada, 15 neurônios na camada intermediária e 5 neurônios na camada de saída. Os sinais de entrada correspondem aos 8 ângulos obtidos das características da face do usuário. A quantidade de neurônios da camada oculta foi definida experimentalmente, com a qual se obteve o menor valor de erro. Os sinais de saída tem função diferente para essas redes, como explicado a seguir.

$\mathrm{Na}$ rede MLP I, as saídas desejadas da rede neural correspondem aos parâmetros definidos paras as expressões da Valerie. A modelagem dessas saídas pode ser observada na Tabela 5.1. Para saber qual emoção a saída da 
rede MLP I representa, outra rede MLP foi treinada, denominada rede Avaliação. A rede Avaliação possui 5 neurônios na camada de entrada, 3 neurônios na camada oculta e 5 neurônios na camada de saída. As entradas são os parâmetros de emoção definidos para a Valerie. As saídas desejadas correspondem às cinco expressões definidas: neutra, alegria, raiva, surpresa e tristeza. Essas saídas foram representadas por vetores da base canônica de dimensão 5. Mais especificamente, o vetor $(10000)^{T}$, denota a primeira emoção considerada, que é neutra, o vetor: $(01000)^{T}$ denota a segunda emoção, que no caso é, alegria e assim por diante.

Na rede MLP II, em que foi feita a classificação da expressão de emoção do usuário para posterior geração da expressão correspondente da Valerie, as saídas desejadas da rede neural correspondem às cinco expressões definidas: neutra, alegria, raiva, surpresa e tristeza. Assim como na rede Avaliação, essas saídas foram representadas por vetores da base canônica de dimensão 5 .

Tabela 5.1: Saídas Desejadas - Valerie

\begin{tabular}{|c|c|c|c|c|c|}
\hline & \multicolumn{5}{|c|}{ Parâmetros da Valerie } \\
\hline Saída & Neutra & Alegria & Raiva & Surpresa & Tristeza \\
\hline Neutra & 0 & 0 & 0 & 0 & 0 \\
\hline Alegria & 1 & 2 & 0 & 0 & 0 \\
\hline Raiva & -0.5 & -0.03 & -0.22 & 0.5 & 0 \\
\hline Surpresa & 2 & 0 & 2 & 0 & 0 \\
\hline Tristeza & 0 & -0.5 & -0.1 & 0 & 0.2 \\
\hline
\end{tabular}

Cada vídeo corresponde a uma expressão facial de emoção de uma pessoa. À medida que em foram extraídas as características do vídeo de determinada expressão, as saídas desejadas correspondentes foram registradas.

Para validar as redes neurais foi usado o método de validação cruzada (Larson, 1931). O método de validação cruzada é um método estatístico de avaliação e comparação de algoritmos de aprendizado que divide os dados em duas partes: uma usada para treinamento e outra para validar o modelo. $\mathrm{Na}$ validação cruzada típica, os conjuntos de treinamento e teste devem ser cruzados em sucessivas rodadas, tal que todos os exemplos dos dados tem uma chance de ser validado. A forma básica de validação cruzada é a $k$-fold cross-validation. Em $k$-fold cross-validation, os dados são particionados em $k$ conjuntos de mesmo tamanho. Em seguida, $k$ iterações de treinamento e teste são executadas, tal que em cada iteração um diferente conjunto dos dados é separado para teste enquanto os restantes $k-1$ são usados para 
treinamento. Outras formas de validação cruzada são casos especiais do $k$-fold cross-validation ou envolve repetidas rodadas dele. O 10-fold cross-validation é o mais comumente utilizado, no qual, em cada rodada, nove conjuntos são usados para treinamento e um é separado para teste. No $5 \times 2$-fold cross-validation, o 2-fold cross-validation é executado cinco vezes, resultando em dez valores de acurácia (Refaeilzadeh et al., 2009), como explicado a seguir:

- Dado um conjunto de $N$ exemplos

- Para i $=1$ até 5 faça

Dividir $\mathrm{N}$ aleatoriamente em duas metades

Usar metade 1 para treinamento e metade 2 para teste

Usar metade 2 para treinamento e metade 1 para teste

Os resultados da validação das redes neurais são apresentados e discutidos no Capítulo 6.

\subsection{Considerações Finais}

Nesse capítulo foi apresentado o sistema de imitação de expressões faciais de emoção proposto. Esse sistema é composto por dois módulos: módulo de extração automática de características da face e módulo de reconhecimento e geração de expressões faciais de emoção. No módulo de extração automática de características da face foram usados dois sistemas, um desenvolvido no nosso grupo de pesquisa e o outro cedido por Saragih et al. (2011). No módulo de reconhecimento e geração de expressões faciais de emoção foram utilizadas três redes neurais: rede de Jordan, MLP e TLFN. Com a primeira a rede de Jordan não foi alcançada a convergência.

No capítulo a seguir são apresentados e discutidos os resultados obtidos com as avaliações experimentais realizadas no sistema de imitação proposto. 


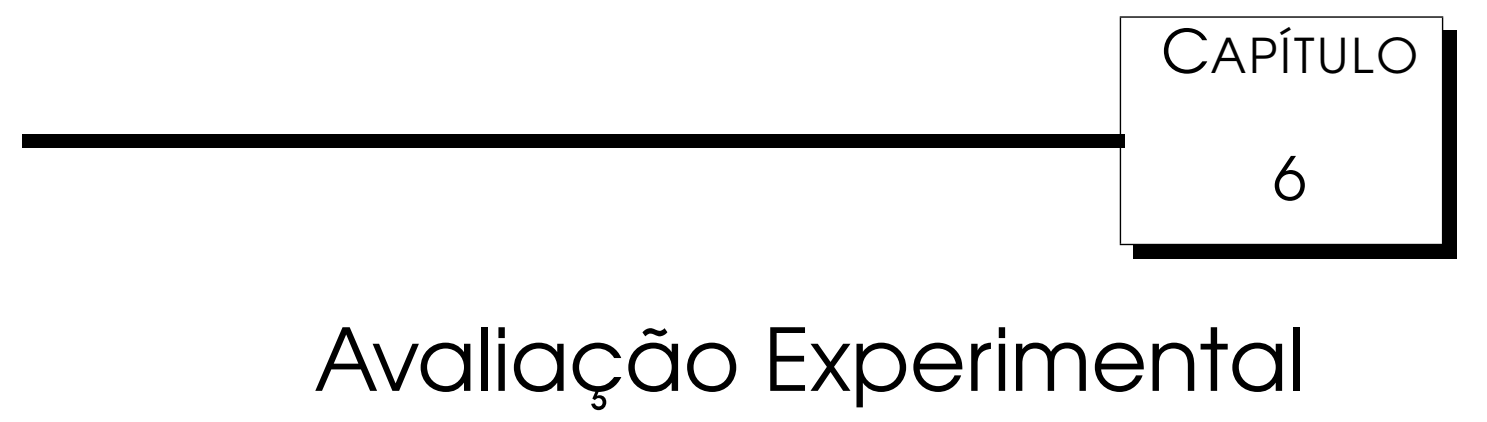

Nesse capítulo, são apresentados e discutidos os experimentos realizados durante a pesquisa. Em particular, na Seção 6.1, são apresentados os resultados obtidos com a rede TLFN a partir dos dados do Sistema I; na Seção 6.2, são apresentados os resultados obtidos com o aprendizado das redes MLP, a partir dos dados do Sistema II; e, por último, é apresentada a geração de expressões pela cabeça robótica com a rede TLFN.

\subsection{Rede TLFN com a Utilização do Sistema I}

A rede neural TLFN foi treinada com os dados obtidos do Sistema I. Esse sistema apresenta tempo de resposta rápido, mas baixa robustez. Distância do usuário à câmera, variações de luz no ambiente e presença de barba no rosto dos homens foram os principais fatores que atrapalharam a detecção dos pontos. Por isso, com os dados obtidos desse sistema, apenas duas expressões foram consideradas: neutra e alegria.

Nessa avaliação foram usados vídeos de 10 pessoas, em que cada pessoa exibiu as expressões neutra e alegria, totalizando 20 vídeos. De cada vídeo, foram extraídos 280 frames de pontos característicos da face do usuário, com os quais foram calculados ângulos que representam as entradas da rede.

Para o treinamento, foram usados frames de vídeos de 4 pessoas, cada uma com as expressões neutra e alegria. As entradas são propagadas para a camada oculta, e da camada oculta para a camada de saída. A saída desejada 
Tabela 6.1: Matriz de Confusão

\begin{tabular}{|c|c|c|}
\hline & \multicolumn{2}{|c|}{ Classe verdadeira } \\
\hline Classe prevista & Normal & Sorriso \\
\hline Normal & 664 & 139 \\
\hline Sorriso & 287 & 920 \\
\hline
\end{tabular}

é a intensidade do sorriso do robô. De acordo com a abordagem padrão de retropropagação (Haykin, 1999), a saída calculada é comparada com a saída desejada e o erro obtido é retropropagado para atualizar os pesos sinápticos.

Para o teste, foram usados vídeos de 3 pessoas (distintas do treinamento), e, na Tabela 6.1 é mostrada a matriz de confusão obtida dos resultados. A partir da matriz, foi calculada a acurácia, cujo valor é $78,8 \%$. Considerando que a rede neural não possui conhecimento sobre as características da face das pessoas usadas no teste e as distorções na detecção de pontos, podese dizer que a acurácia obtida foi satisfatória. Na Figura 6.1 é apresentada a imitação da expressão neutra de uma pessoa do teste e, na Figura 6.2, é apresentada a imitação da expressão alegria da mesma pessoa.

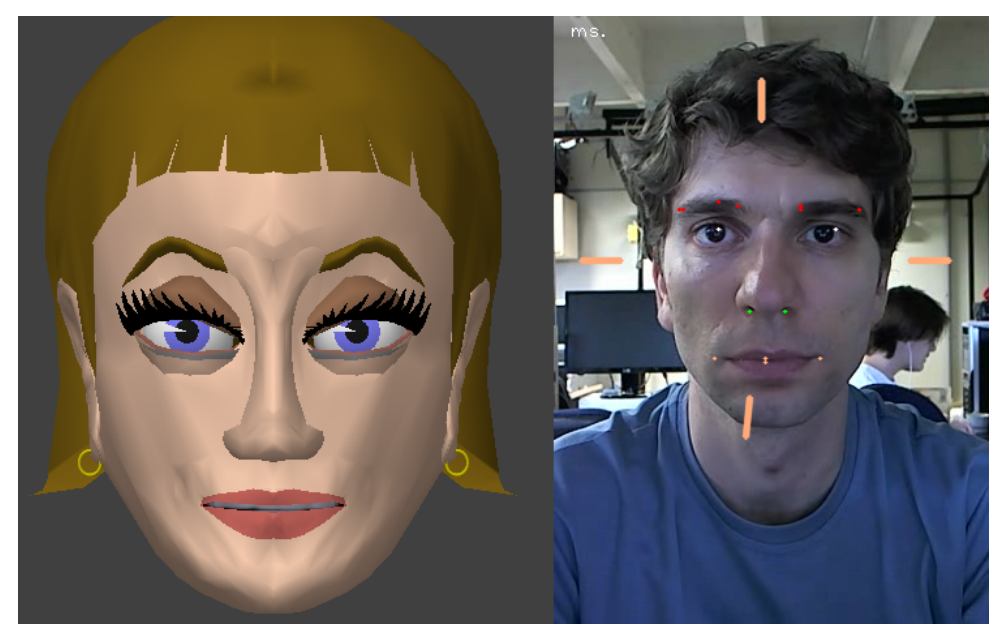

Figura 6.1: Valerie imitando a expressão neutra.

\subsection{Rede MLP e TLFN com a Utilização do Sistema II}

Como descrito no Capítulo 5, com o Sistema II foi possível imitar de cinco expressões faciais. Para isso, foram usadas duas redes MLP: uma para aprender o mapeamento entre as características da face humana e as características da Valerie, rede MLP I, e outra que classifica as características da face humana em uma emoção, rede MLP II. As duas redes possuem a 


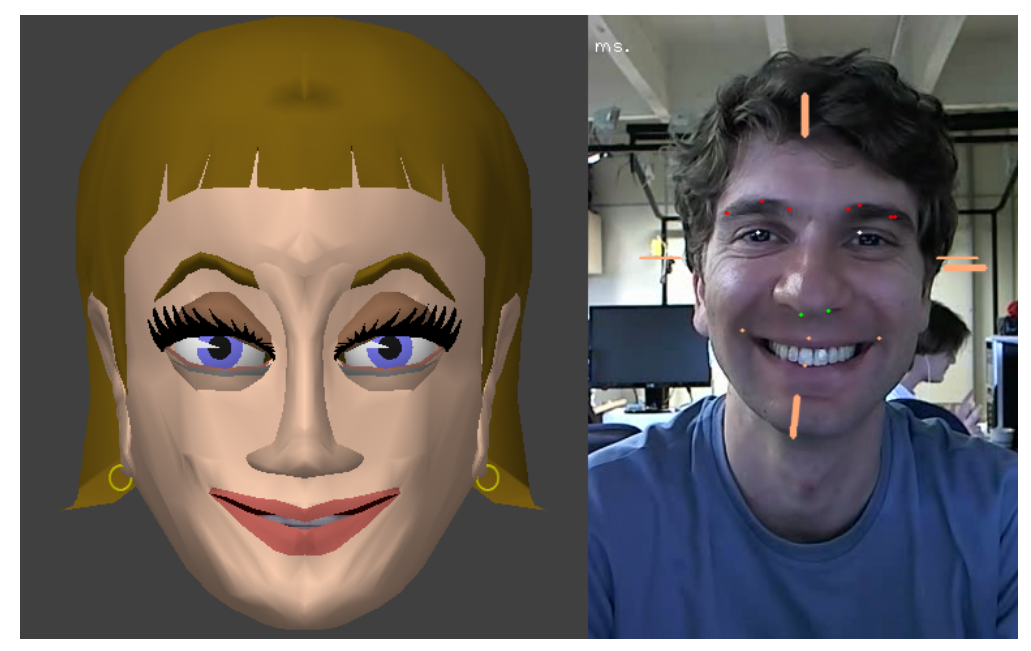

Figura 6.2: Valerie imitando a expressão alegria.

mesma arquitetura: 8 neurônios para a camada de entrada, 15 neurônios para a camada oculta e 5 neurônios para a camada de saída. Na rede MLP I a expressão do robô é mais dependente do usuário. A rede MLP II classifica a expressão do usuário em uma emoção e gera a correspondente expressão definida para o robô. A vantagem da rede MLP I é que ela permite uma imitação mais real da expressão exibida pelo usuário, entretanto o sistema fica dependente do robô. Por outro lado, a rede MLP II fornece uma imitação menos real, mas permite que o sistema utilize outros robôs para a geração da expressão.

Ambas as redes foram treinadas com o algoritmo de retropropagação, com frequência de atualização dos pesos por padrão. $\mathrm{O}$ valor da taxa de aprendizado adotado foi 0,3, e valor de termo momento, 0,4, que foi a combinação de valores que gerou menor erro. Todos os padrões foram apresentados à rede até que o erro atingisse o valor 1 .

Os dados usados para treinamento e teste foram extraídos de vídeos de 10 pessoas, cada uma expressando as cinco emoções consideradas, totalizando 50 vídeos. O primeiro método de avaliação das redes neurais usado foi o teste com dados de pessoas não vistas no treinamento. Nessa avaliação, foram usados dados de quatro pessoas no treinamento e dados de seis pessoas distintas no teste. As saídas da rede MLP I são classificadas em uma emoção pela rede Avaliação, sendo que a emoção é representada pelo maior valor entre as saídas dessa rede. As saídas da MLP II são classificadas em uma emoção da mesma forma que é feita com a rede Avaliação. As matrizes de confusão obtidas dos resultados das redes MLP I e MLP II são apresentadas nas Tabelas 6.2 e 6.3, respectivamente. De acordo com as matrizes, os 
Tabela 6.2: Matriz de confusão obtida dos testes com a rede MLP I, de vídeos de 6 pessoas não vistas no treinamento. As colunas representam as classes verdadeiras e as linhas representam as respostas da rede neural.

\begin{tabular}{|c|c|c|c|c|c|}
\hline & \multicolumn{5}{|c|}{ Classe verdadeira } \\
\hline Classe prevista & Alegria & Neutra & Raiva & Surpresa & Tristeza \\
\hline Alegria & $\mathbf{5}$ & 1 & 1 & 0 & 2 \\
\hline Neutra & 0 & $\mathbf{3}$ & 1 & 0 & 3 \\
\hline Raiva & 0 & 2 & $\mathbf{4}$ & 1 & 0 \\
\hline Surpresa & 1 & 0 & 0 & $\mathbf{5}$ & 0 \\
\hline Tristeza & 0 & 0 & 0 & 0 & $\mathbf{1}$ \\
\hline
\end{tabular}

valores de acurácia obtidos com os testes para a rede MLP I foi $60 \%$ e com a MLP II foi 50\%. Nesses resultados, pode-se observar que as expressões neutra e tristeza são as mais dificeis de aprender em ambas as redes. De fato, nos vídeos, há pouca diferença entre essas expressões exibidas pelos usuários, como o exemplo mostrado na Figura 6.3. Observa-se, ainda, que a rede MLP II classificou a maior parte das expressões de surpresa como raiva. Esse resultado é inesperado, sendo que na expressão de surpresa as sobrancelhas estão levantadas e, na expressão de raiva estão abaixadas.

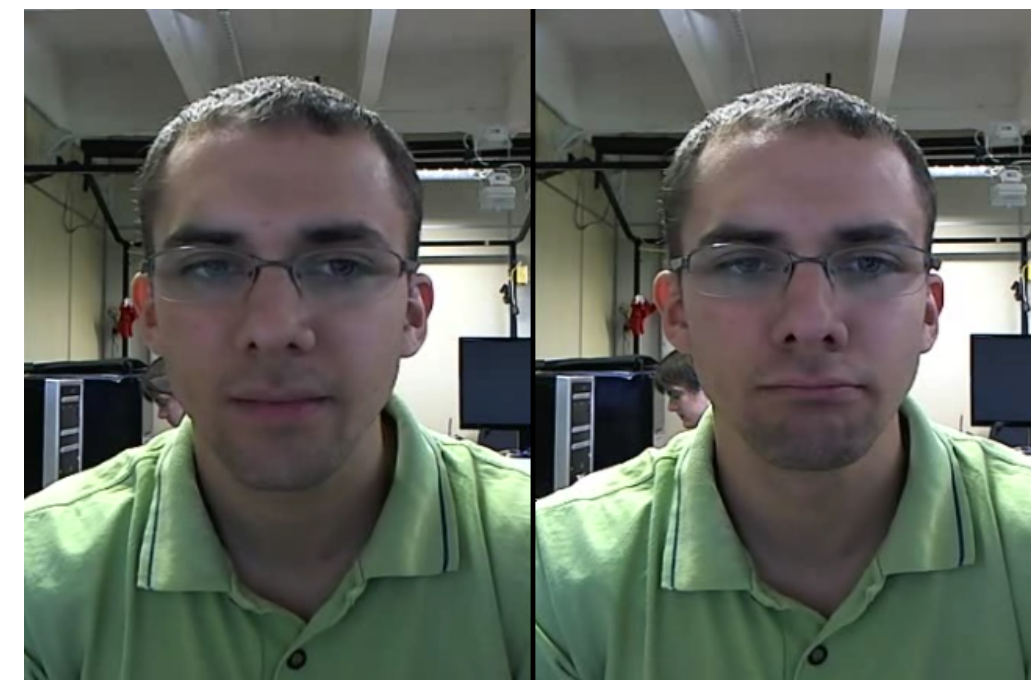

Figura 6.3: Expressões neutra (esquerda) e tristeza (direita) exibidas por um usuário.

Vale ressaltar que em alguns vídeos os pontos não foram detectados corretamente, como no caso mostrado na Figura 6.4, em que as sobrancelhas são confundidas com os cílios. A posição da face do usuário foi outro fator que interferiu significativamente no aprendizado. A Figura 6.5 apresenta um usuário expressando alegria, porém com a cabeça um pouco inclinada. 


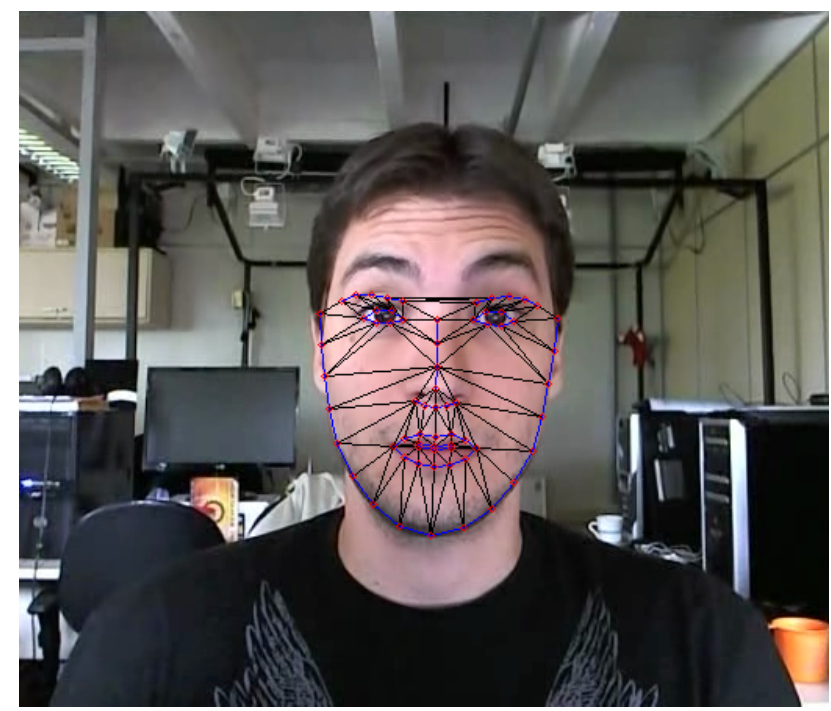

Figura 6.4: Detecção de pontos incorreta com o sistema II. Confusão entre sobrancelhas e cílios.

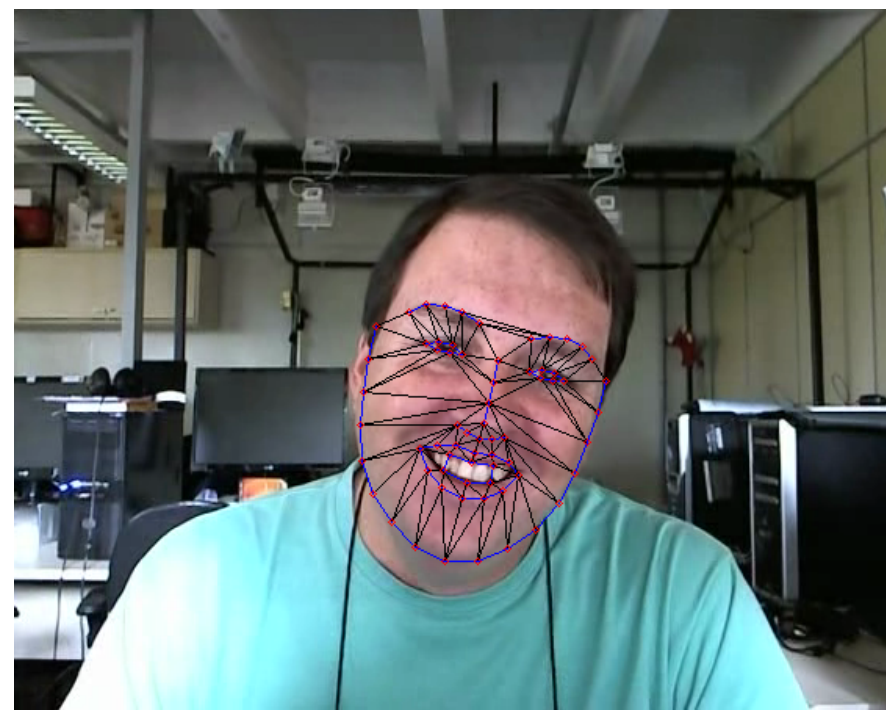

Figura 6.5: Usuário expressando alegria com a face inclinada.

Ainda com objetivo de avaliar a capacidade de aprendizado das redes neurais para expressões faciais de pessoas desconhecidas, foi usado o método de validação cruzada 5-fold. Na validação cruzada 5-fold, os dados foram divididos em cinco conjuntos de mesmo tamanho, sendo que cada conjunto possui informação das cinco expressões faciais de duas pessoas distintas. Assim, cinco iterações de treinamento e teste foram executadas, tal que em cada iteração um conjunto diferente dos dados é separado para validação e os quatro restantes são usados para treinamento.

As matrizes de confusão obtidas de cada experimento com a rede MLP I são 
Tabela 6.3: Matriz de confusão obtida dos testes com a rede MLP II, de vídeos de 6 pessoas não vistas no treinamento. As colunas representam as classes verdadeiras e as linhas representam as respostas da rede neural.

\begin{tabular}{|c|c|c|c|c|c|}
\hline & \multicolumn{5}{|c|}{ Classe verdadeira } \\
\hline Classe prevista & Alegria & Neutra & Raiva & Surpresa & Tristeza \\
\hline Alegria & $\mathbf{5}$ & 3 & 0 & 1 & 1 \\
\hline Neutra & 0 & $\mathbf{1}$ & 0 & 0 & 2 \\
\hline Raiva & 1 & 2 & $\mathbf{6}$ & 4 & 1 \\
\hline Surpresa & 0 & 0 & 0 & $\mathbf{1}$ & 0 \\
\hline Tristeza & 0 & 0 & 0 & 0 & $\mathbf{2}$ \\
\hline
\end{tabular}

Tabela 6.4: Matriz de Confusão - MLP I - Teste 1

\begin{tabular}{|c|c|c|c|c|c|}
\hline & \multicolumn{5}{|c|}{ Classe verdadeira } \\
\hline Classe prevista & Neutra & Alegria & Raiva & Surpresa & Tristeza \\
\hline Neutra & $\mathbf{0}$ & 0 & 0 & 0 & 0 \\
\hline Alegria & 0 & $\mathbf{1}$ & 0 & 0 & 1 \\
\hline Raiva & 2 & 1 & $\mathbf{2}$ & 0 & 0 \\
\hline Surpresa & 0 & 0 & 0 & $\mathbf{2}$ & 0 \\
\hline Tristeza & 0 & 0 & 0 & 0 & $\mathbf{1}$ \\
\hline
\end{tabular}

apresentadas nas Tabelas 6.4 - 6.8. A partir das cinco tabelas, as acurácias calculadas foram de 60\%, 80\%, 60\%, 40\% e 50\%, gerando uma média de acerto de $58 \%$.

De forma análoga, as matrizes de confusão obtidas de cada experimento com a rede MLP II são apresentadas nas Tabelas 6.9 - 6.13. A partir das cinco tabelas, as acurácias calculadas foram de 70\%, 70\%, 30\%, 40\% e 60\%, gerando uma média de acerto de $54 \%$.

Observa-se, então, que nesse conjunto de experimentos as duas redes apresentaram desempenho semelhante. Esse resultado é esperado, visto que ambas as redes apresentam a mesma estrutura, foram treinadas com o mesmo algoritmo de aprendizado e tiveram o mesmo critério de parada, diferenciando-se apenas nas saídas desejadas. Apesar da semelhança, a rede MLP I apresentou desempenho um pouco melhor.

Com os resultados obtidos da primeira avaliação, observou-se a dificuldade de atingir maiores taxas de acerto para pessoas desconhecidas, pois o aprendizado desejado envolve duas variáveis: características da face da pessoa e expressão facial de emoção. Dessa forma, uma segunda avaliação foi feita, sendo que tanto nos dados de treinamento, quanto nos dados de teste foram inseridas informações de todas as pessoas e de todas as expressões faciais de emoção. 
Tabela 6.5: Matriz de Confusão - MLP I - Teste 2

Classe verdadeira

\begin{tabular}{|c|c|c|c|c|c|}
\hline & \multicolumn{5}{|c|}{ Classe verdadeira } \\
\hline Classe prevista & Neutra & Alegria & Raiva & Surpresa & Tristeza \\
\hline Neutra & $\mathbf{1}$ & 0 & 0 & 0 & 1 \\
\hline Alegria & 0 & $\mathbf{2}$ & 0 & 0 & 0 \\
\hline Raiva & 0 & 0 & $\mathbf{2}$ & 0 & 0 \\
\hline Surpresa & 1 & 0 & 0 & $\mathbf{2}$ & 0 \\
\hline Tristeza & 0 & 0 & 0 & 0 & $\mathbf{1}$ \\
\hline
\end{tabular}

Tabela 6.6: Matriz de Confusão - MLP I - Teste 3

\begin{tabular}{|c|c|c|c|c|c|}
\hline & \multicolumn{5}{|c|}{ Classe verdadeira } \\
\hline Classe prevista & Neutra & Alegria & Raiva & Surpresa & Tristeza \\
\hline Neutra & $\mathbf{0}$ & 0 & 0 & 0 & 1 \\
\hline Alegria & 0 & $\mathbf{2}$ & 1 & 0 & 0 \\
\hline Raiva & 1 & 0 & $\mathbf{1}$ & 0 & 0 \\
\hline Surpresa & 0 & 0 & 0 & $\mathbf{2}$ & 0 \\
\hline Tristeza & 1 & 0 & 0 & 0 & $\mathbf{1}$ \\
\hline
\end{tabular}

Tabela 6.7: Matriz de Confusão - MLP I - Teste 4

\begin{tabular}{|c|c|c|c|c|c|}
\hline & \multicolumn{5}{|c|}{ Classe verdadeira } \\
\hline Classe prevista & Neutra & Alegria & Raiva & Surpresa & Tristeza \\
\hline Neutra & $\mathbf{0}$ & 0 & 1 & 0 & 1 \\
\hline Alegria & 0 & $\mathbf{1}$ & 0 & 0 & 0 \\
\hline Raiva & 0 & 0 & $\mathbf{0}$ & 0 & 0 \\
\hline Surpresa & 0 & 1 & 0 & $\mathbf{2}$ & 0 \\
\hline Tristeza & 2 & 0 & 1 & 0 & $\mathbf{1}$ \\
\hline
\end{tabular}

Tabela 6.8: Matriz de Confusão - MLP I - Teste 5

\begin{tabular}{|c|c|c|c|c|c|}
\hline & \multicolumn{5}{|c|}{ Classe verdadeira } \\
\hline Classe prevista & Neutra & Alegria & Raiva & Surpresa & Tristeza \\
\hline Neutra & $\mathbf{2}$ & 0 & 2 & 0 & 1 \\
\hline Alegria & 0 & $\mathbf{2}$ & 0 & 0 & 0 \\
\hline Raiva & 0 & 0 & $\mathbf{0}$ & 1 & 0 \\
\hline Surpresa & 0 & 0 & 0 & $\mathbf{1}$ & 1 \\
\hline Tristeza & 0 & 0 & 0 & 0 & $\mathbf{0}$ \\
\hline
\end{tabular}

Tabela 6.9: Matriz de Confusão - MLP II - Teste 1

\begin{tabular}{|c|c|c|c|c|c|}
\hline & \multicolumn{5}{|c|}{ Classe verdadeira } \\
\hline Classe prevista & Neutra & Alegria & Raiva & Surpresa & Tristeza \\
\hline Neutra & $\mathbf{1}$ & 0 & 0 & 0 & 0 \\
\hline Alegria & 0 & $\mathbf{2}$ & 0 & 0 & 1 \\
\hline Raiva & 1 & 0 & $\mathbf{2}$ & 0 & 1 \\
\hline Surpresa & 0 & 0 & 0 & $\mathbf{2}$ & 0 \\
\hline Tristeza & 0 & 0 & 0 & 0 & $\mathbf{0}$ \\
\hline
\end{tabular}


Tabela 6.10: Matriz de Confusão - MLP II - Teste 2

\begin{tabular}{|c|c|c|c|c|c|}
\hline & \multicolumn{5}{|c|}{ Classe verdadeira } \\
\hline Classe prevista & Neutra & Alegria & Raiva & Surpresa & Tristeza \\
\hline Neutra & $\mathbf{2}$ & 0 & 0 & 0 & 1 \\
\hline Alegria & 0 & $\mathbf{2}$ & 0 & 0 & 0 \\
\hline Raiva & 0 & 0 & $\mathbf{1}$ & 0 & 0 \\
\hline Surpresa & 0 & 0 & 1 & $\mathbf{2}$ & 1 \\
\hline Tristeza & 0 & 0 & 0 & 0 & $\mathbf{0}$ \\
\hline
\end{tabular}

Tabela 6.11: Matriz de Confusão - MLP II - Teste 3

\begin{tabular}{|c|c|c|c|c|c|}
\hline & \multicolumn{5}{|c|}{ Classe verdadeira } \\
\hline Classe prevista & Neutra & Alegria & Raiva & Surpresa & Tristeza \\
\hline Neutra & $\mathbf{0}$ & 0 & 0 & 2 & 0 \\
\hline Alegria & 0 & $\mathbf{2}$ & 1 & 0 & 0 \\
\hline Raiva & 0 & 0 & $\mathbf{0}$ & 0 & 0 \\
\hline Surpresa & 1 & 0 & 1 & $\mathbf{0}$ & 1 \\
\hline Tristeza & 1 & 0 & 0 & 0 & $\mathbf{1}$ \\
\hline
\end{tabular}

Tabela 6.12: Matriz de Confusão - MLP II - Teste 4

\begin{tabular}{|c|c|c|c|c|c|}
\hline & \multicolumn{5}{|c|}{ Classe verdadeira } \\
\hline Classe prevista & Neutra & Alegria & Raiva & Surpresa & Tristeza \\
\hline Neutra & $\mathbf{0}$ & 0 & 0 & 0 & 0 \\
\hline Alegria & 0 & $\mathbf{0}$ & 0 & 0 & 0 \\
\hline Raiva & 0 & 1 & $\mathbf{1}$ & 0 & 0 \\
\hline Surpresa & 0 & 0 & 0 & $\mathbf{1}$ & 0 \\
\hline Tristeza & 2 & 1 & 1 & 1 & $\mathbf{2}$ \\
\hline
\end{tabular}

Tabela 6.13: Matriz de Confusão - MLP II - Teste 5

\begin{tabular}{|c|c|c|c|c|c|}
\hline & \multicolumn{5}{|c|}{ Classe verdadeira } \\
\hline Classe prevista & Neutra & Alegria & Raiva & Surpresa & Tristeza \\
\hline Neutra & $\mathbf{2}$ & 0 & 1 & 0 & 1 \\
\hline Alegria & 0 & $\mathbf{2}$ & 0 & 0 & 0 \\
\hline Raiva & 0 & 0 & $\mathbf{1}$ & 1 & 0 \\
\hline Surpresa & 0 & 0 & 0 & $\mathbf{1}$ & 0 \\
\hline Tristeza & 0 & 0 & 0 & 0 & $\mathbf{1}$ \\
\hline
\end{tabular}


Tabela 6.14: Matriz de Confusão - MLP I - Teste 1

\begin{tabular}{|c|c|c|c|c|c|}
\hline & \multicolumn{5}{|c|}{ Classe verdadeira } \\
\hline Classe prevista - Teste 1 & Neutra & Alegria & Raiva & Surpresa & Tristeza \\
\hline Neutra & $\mathbf{8}$ & 0 & 0 & 0 & 0 \\
\hline Alegria & 0 & $\mathbf{1 0}$ & 0 & 0 & 0 \\
\hline Raiva & 1 & 0 & $\mathbf{1 0}$ & 0 & 0 \\
\hline Surpresa & 0 & 0 & 0 & $\mathbf{1 0}$ & 0 \\
\hline Tristeza & 1 & 0 & 0 & 0 & $\mathbf{1 0}$ \\
\hline
\end{tabular}

Na segunda forma de avaliação, os dados foram organizados da seguinte forma. Com os frames extraídos dos 50 vídeos, foram criadas 6 pastas, cada uma contendo 5 frames distintos de cada vídeo, totalizando 750 instâncias de dados em cada pasta. Distribuindo os dados dessa forma, tanto o treinamento quanto o teste possuem informação sobre as características de todas as pessoas, exibindo todas as expressões.

Inicialmente, tentou-se validar o desempenho das redes neurais com o método típico de validação cruzada 10-fold. Porém, o conjunto de treinamento ficou muito grande, e a convergência, muito lenta. Então, decidiu-se usar o método de validação cruzada 5x2, que divide conjuntos de treinamento e teste em um mesmo tamanho. Nesse teste, a validação cruzada 2-fold é executada 5 vezes, resultando em 10 valores de acurácia.

Nos 10 testes realizados com a rede MLP I, as acurácias obtidas foram de 96\%, 88\%, 88\%, 96\%, 98\%, 88\%, 90\%, 96\%, 86\% e 98\%, gerando uma média de acerto de 92,4\%. As matrizes de confusão obtidas de cada experimento são apresentadas nas Tabelas 6.14 - 6.23. Nessa avaliação, a taxa de acerto obtida foi bem maior do que a obtida na primeira forma de avaliação. $O$ aumento da taxa de acerto deve-se ao conhecimento que a rede obteve das características da face de todas as pessoas. Por essas tabelas, percebe-se mais uma vez a classificação errada entre as expressões neutra e tristeza. Além disso, houve a expressão raiva que foi classificada como neutra, mas somente dois casos: um observado na Tabela 6.20 e outro na Tabela 6.22. As outras expressões, alegria, raiva e surpresa, foram classificadas corretamente em todos os casos. Na Figura 6.6 é apresentada a imitação das expressões faciais de uma pessoa obtida com o treinamento rede MLP I e saídas obtidas pela rede TLFN. Observando a figura, fica clara a dificuldade em distinguir entre as expressões neutra e tristeza.

Nos 10 testes realizados com a rede MLP II, as acurácias obtidas foram de 98\%, 98\%, 98\%, 96\%, 96\%, 100\%, 98\%, 98\%, 96\%, 98\%, gerando uma 
Tabela 6.15: Matriz de Confusão - MLP I - Teste 2

Classe verdadeira

\begin{tabular}{|c|c|c|c|c|c|}
\hline & \multicolumn{5}{|c|}{ Classe verdadeira } \\
\hline Classe prevista - Teste 2 & Neutra & Alegria & Raiva & Surpresa & Tristeza \\
\hline Neutra & $\mathbf{4}$ & 0 & 0 & 0 & 0 \\
\hline Alegria & 0 & $\mathbf{1 0}$ & 0 & 0 & 0 \\
\hline Raiva & 0 & 0 & $\mathbf{1 0}$ & 0 & 0 \\
\hline Surpresa & 1 & 0 & 0 & $\mathbf{1 0}$ & 0 \\
\hline Tristeza & 5 & 0 & 0 & 0 & $\mathbf{1 0}$ \\
\hline
\end{tabular}

Tabela 6.16: Matriz de Confusão - MLP I - Teste 3

\begin{tabular}{|c|c|c|c|c|c|}
\hline & \multicolumn{5}{|c|}{ Classe verdadeira } \\
\hline Classe prevista -Teste 3 & Neutra & Alegria & Raiva & Surpresa & Tristeza \\
\hline Neutra & $\mathbf{5}$ & 0 & 0 & 0 & 1 \\
\hline Alegria & 0 & $\mathbf{1 0}$ & 0 & 0 & 0 \\
\hline Raiva & 0 & 0 & $\mathbf{1 0}$ & 0 & 0 \\
\hline Surpresa & 0 & 0 & 0 & $\mathbf{1 0}$ & 0 \\
\hline Tristeza & 5 & 0 & 0 & 0 & $\mathbf{9}$ \\
\hline
\end{tabular}

Tabela 6.17: Matriz de Confusão - MLP I - Teste 4

\begin{tabular}{|c|c|c|c|c|c|}
\hline & \multicolumn{5}{|c|}{ Classe verdadeira } \\
\hline Classe prevista - Teste 4 & Neutra & Alegria & Raiva & Surpresa & Tristeza \\
\hline Neutra & $\mathbf{8}$ & 0 & 0 & 0 & 0 \\
\hline Alegria & 0 & $\mathbf{1 0}$ & 0 & 0 & 0 \\
\hline Raiva & 0 & 0 & $\mathbf{1 0}$ & 0 & 0 \\
\hline Surpresa & 0 & 0 & 0 & $\mathbf{1 0}$ & 0 \\
\hline Tristeza & 2 & 0 & 0 & 0 & $\mathbf{1 0}$ \\
\hline
\end{tabular}

Tabela 6.18: Matriz de Confusão - MLP I - Teste 5

\begin{tabular}{|c|c|c|c|c|c|}
\hline & \multicolumn{5}{|c|}{ Classe verdadeira } \\
\hline Classe prevista - Teste 5 & Neutra & Alegria & Raiva & Surpresa & Tristeza \\
\hline Neutra & $\mathbf{9}$ & 0 & 0 & 0 & 0 \\
\hline Alegria & 0 & $\mathbf{1 0}$ & 0 & 0 & 0 \\
\hline Raiva & 0 & 0 & $\mathbf{1 0}$ & 0 & 0 \\
\hline Surpresa & 0 & 0 & 0 & $\mathbf{1 0}$ & 0 \\
\hline Tristeza & 1 & 0 & 0 & 0 & $\mathbf{1 0}$ \\
\hline
\end{tabular}

Tabela 6.19: Matriz de Confusão - MLP I - Teste 6

\begin{tabular}{|c|c|c|c|c|c|}
\hline & \multicolumn{5}{|c|}{ Classe verdadeira } \\
\hline Classe prevista - Teste 6 & Neutra & Alegria & Raiva & Surpresa & Tristeza \\
\hline Neutra & $\mathbf{4}$ & 0 & 0 & 0 & 0 \\
\hline Alegria & 0 & $\mathbf{1 0}$ & 0 & 0 & 0 \\
\hline Raiva & 0 & 0 & $\mathbf{1 0}$ & 0 & 0 \\
\hline Surpresa & 0 & 0 & 0 & $\mathbf{1 0}$ & 0 \\
\hline Tristeza & 6 & 0 & 0 & 0 & $\mathbf{1 0}$ \\
\hline
\end{tabular}


Tabela 6.20: Matriz de Confusão - MLP I - Teste 7

\begin{tabular}{|c|c|c|c|c|c|}
\hline & \multicolumn{5}{|c|}{ Classe verdadeira } \\
\hline Classe prevista & Neutra & Alegria & Raiva & Surpresa & Tristeza \\
\hline Neutra & $\mathbf{6}$ & 0 & 1 & 0 & 0 \\
\hline Alegria & 0 & $\mathbf{1 0}$ & 0 & 0 & 0 \\
\hline Raiva & 1 & 0 & $\mathbf{9}$ & 0 & 0 \\
\hline Surpresa & 0 & 0 & 0 & $\mathbf{1 0}$ & 0 \\
\hline Tristeza & 3 & 0 & 0 & 0 & $\mathbf{1 0}$ \\
\hline
\end{tabular}

Tabela 6.21: Matriz de Confusão - MLP I - Teste 8

\begin{tabular}{|c|c|c|c|c|c|}
\hline & \multicolumn{5}{|c|}{ Classe verdadeira } \\
\hline Classe prevista & Neutra & Alegria & Raiva & Surpresa & Tristeza \\
\hline Neutra & $\mathbf{9}$ & 0 & 0 & 0 & 1 \\
\hline Alegria & 0 & $\mathbf{1 0}$ & 0 & 0 & 0 \\
\hline Raiva & 0 & 0 & $\mathbf{1 0}$ & 0 & 0 \\
\hline Surpresa & 1 & 0 & 0 & $\mathbf{1 0}$ & 0 \\
\hline Tristeza & 0 & 0 & 0 & 0 & $\mathbf{9}$ \\
\hline
\end{tabular}

Tabela 6.22: Matriz de Confusão - MLP I - Teste 9

\begin{tabular}{|c|c|c|c|c|c|}
\hline & \multicolumn{5}{|c|}{ Classe verdadeira } \\
\hline Classe prevista & Neutra & Alegria & Raiva & Surpresa & Tristeza \\
\hline Neutra & $\mathbf{6}$ & 0 & 1 & 0 & 0 \\
\hline Alegria & 0 & $\mathbf{1 0}$ & 0 & 0 & 0 \\
\hline Raiva & 0 & 0 & $\mathbf{9}$ & 0 & 1 \\
\hline Surpresa & 0 & 0 & 0 & $\mathbf{1 0}$ & 0 \\
\hline Tristeza & 4 & 0 & 0 & 0 & $\mathbf{9}$ \\
\hline
\end{tabular}

Tabela 6.23: Matriz de Confusão - MLP I - Teste 10 Classe verdadeira

\begin{tabular}{|c|c|c|c|c|c|}
\hline & \multicolumn{5}{|c|}{ Classe verdadeira } \\
\hline Classe prevista & Neutra & Alegria & Raiva & Surpresa & Tristeza \\
\hline Neutra & $\mathbf{9}$ & 0 & 0 & 0 & 0 \\
\hline Alegria & 0 & $\mathbf{1 0}$ & 0 & 0 & 0 \\
\hline Raiva & 0 & 0 & $\mathbf{1 0}$ & 0 & 0 \\
\hline Surpresa & 0 & 0 & 0 & $\mathbf{1 0}$ & 0 \\
\hline Tristeza & 1 & 0 & 0 & 0 & $\mathbf{1 0}$ \\
\hline
\end{tabular}




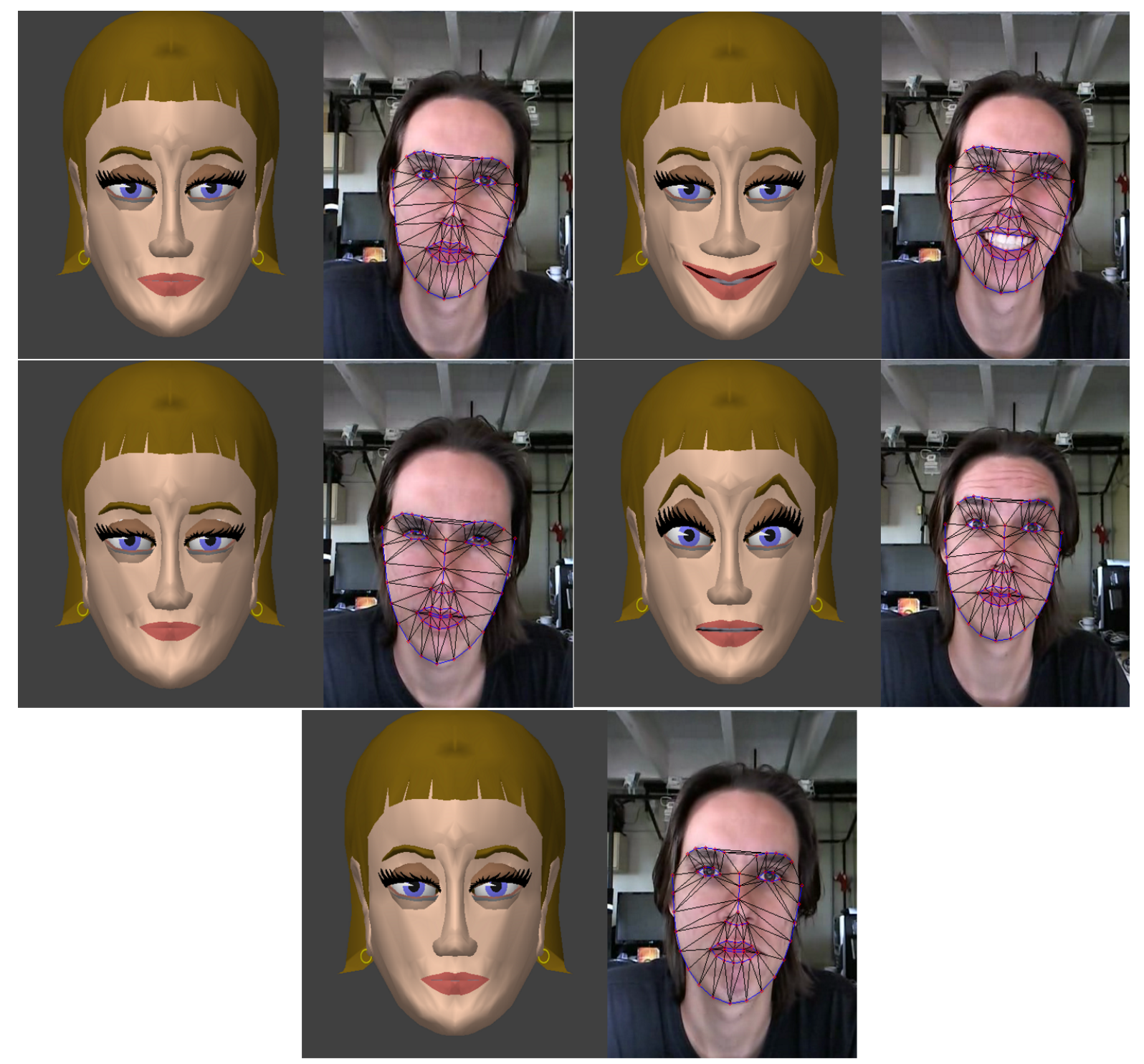

Figura 6.6: Imitação das expressões faciais de um usuário durante uma interação social, obtida com o uso da rede MLP I.

média de acerto de 97,6\%. As matrizes de confusão obtidas de cada experimento são apresentadas nas Tabelas 6.24 - 6.33. A taxa de acerto obtida nesses experimentos foi excelente. A rede foi capaz de diferenciar bem todas as expressões. Observa-se que os erros cometidos foram entre as expressões neutra e tristeza (Tabelas 6.17 e 6.20), raiva e neutra (Tabelas 6.18), tristeza e neutra (Tabelas 6.21, 6.22 e 6.23). Na Figura 6.7 é apresentada a imitação das expressões faciais de uma pessoa obtida com o treinamento rede MLP II e saídas obtidas pela rede TLFN, em que se observa uma imitação perfeita. 
Tabela 6.24: Matriz de Confusão - MLP II - Teste 1

Classe verdadeira

\begin{tabular}{|c|c|c|c|c|c|}
\hline & \multicolumn{5}{|c|}{ Classe verdadeira } \\
\hline Classe prevista & Neutra & Alegria & Raiva & Surpresa & Tristeza \\
\hline Neutra & $\mathbf{1 0}$ & 0 & 0 & 1 & 0 \\
\hline Alegria & 0 & $\mathbf{1 0}$ & 0 & 0 & 0 \\
\hline Raiva & 0 & 0 & $\mathbf{1 0}$ & 0 & 0 \\
\hline Surpresa & 0 & 0 & 0 & $\mathbf{9}$ & 0 \\
\hline Tristeza & 0 & 0 & 0 & 0 & $\mathbf{1 0}$ \\
\hline
\end{tabular}

Tabela 6.25: Matriz de Confusão - MLP II - Teste 2

\begin{tabular}{|c|c|c|c|c|c|}
\hline & \multicolumn{5}{|c|}{ Classe verdadeira } \\
\hline Classe prevista & Neutra & Alegria & Raiva & Surpresa & Tristeza \\
\hline Neutra & $\mathbf{1 0}$ & 0 & 0 & 0 & 0 \\
\hline Alegria & 0 & $\mathbf{1 0}$ & 0 & 0 & 0 \\
\hline Raiva & 0 & 0 & $\mathbf{1 0}$ & 1 & 0 \\
\hline Surpresa & 0 & 0 & 0 & $\mathbf{9}$ & 0 \\
\hline Tristeza & 0 & 0 & 0 & 0 & $\mathbf{1 0}$ \\
\hline
\end{tabular}

Tabela 6.26: Matriz de Confusão - MLP II - Teste 3

\begin{tabular}{|c|c|c|c|c|c|}
\hline & \multicolumn{5}{|c|}{ Classe verdadeira } \\
\hline Classe prevista & Neutra & Alegria & Raiva & Surpresa & Tristeza \\
\hline Neutra & $\mathbf{1 0}$ & 0 & 0 & 1 & 0 \\
\hline Alegria & 0 & $\mathbf{1 0}$ & 0 & 0 & 0 \\
\hline Raiva & 0 & 0 & $\mathbf{1 0}$ & 0 & 0 \\
\hline Surpresa & 0 & 0 & 0 & $\mathbf{9}$ & 0 \\
\hline Tristeza & 0 & 0 & 0 & 0 & $\mathbf{1 0}$ \\
\hline
\end{tabular}

Tabela 6.27: Matriz de Confusão - MLP II - Teste 4

\begin{tabular}{|c|c|c|c|c|c|}
\hline & \multicolumn{5}{|c|}{ Classe verdadeira } \\
\hline Classe prevista & Neutra & Alegria & Raiva & Surpresa & Tristeza \\
\hline Neutra & $\mathbf{9}$ & 0 & 0 & 0 & 0 \\
\hline Alegria & 0 & $\mathbf{1 0}$ & 0 & 0 & 0 \\
\hline Raiva & 0 & 0 & $\mathbf{1 0}$ & 1 & 0 \\
\hline Surpresa & 0 & 0 & 0 & $\mathbf{9}$ & 0 \\
\hline Tristeza & 1 & 0 & 0 & 0 & $\mathbf{1 0}$ \\
\hline
\end{tabular}

Tabela 6.28: Matriz de Confusão - MLP II - Teste 5

\begin{tabular}{|c|c|c|c|c|c|}
\hline & \multicolumn{5}{|c|}{ Classe verdadeira } \\
\hline Classe prevista & Neutra & Alegria & Raiva & Surpresa & Tristeza \\
\hline Neutra & $\mathbf{1 0}$ & 0 & 1 & 0 & 0 \\
\hline Alegria & 0 & $\mathbf{1 0}$ & 0 & 0 & 0 \\
\hline Raiva & 0 & 0 & $\mathbf{9}$ & 1 & 0 \\
\hline Surpresa & 0 & 0 & 0 & $\mathbf{9}$ & 0 \\
\hline Tristeza & 0 & 0 & 0 & 0 & $\mathbf{1 0}$ \\
\hline
\end{tabular}



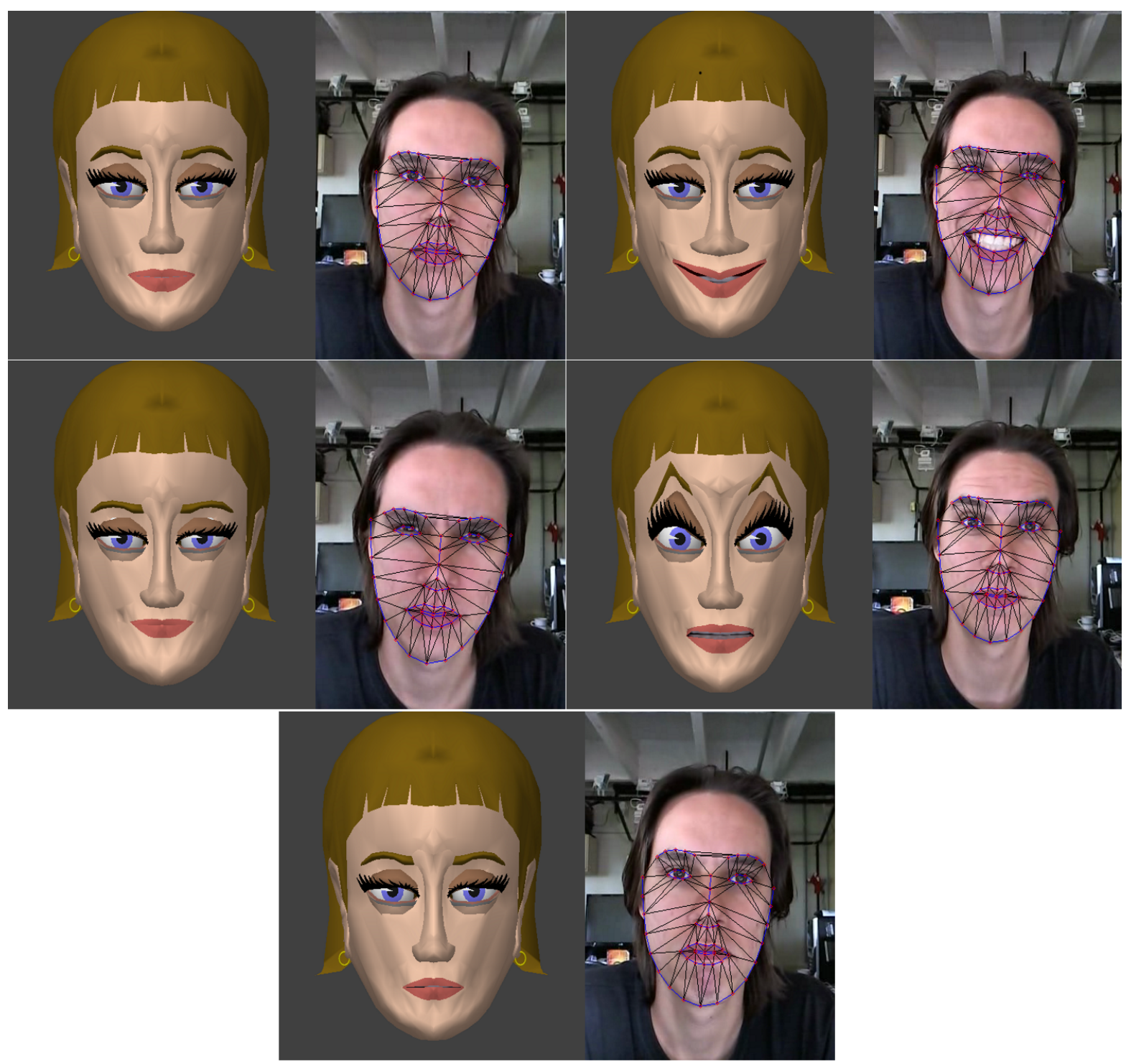

Figura 6.7: Imitação das expressões faciais de um usuário durante uma interação social, obtida com o uso da rede MLP II. 
Tabela 6.29: Matriz de Confusão - MLP II - Teste 6 Classe verdadeira

\begin{tabular}{|c|c|c|c|c|c|}
\hline Classe prevista & Neutra & Alegria & Raiva & Surpresa & Tristeza \\
\hline Neutra & $\mathbf{1 0}$ & 0 & 0 & 0 & 0 \\
\hline Alegria & 0 & $\mathbf{1 0}$ & 0 & 0 & 0 \\
\hline Raiva & 0 & 0 & $\mathbf{1 0}$ & 0 & 0 \\
\hline Surpresa & 0 & 0 & 0 & $\mathbf{1 0}$ & 0 \\
\hline Tristeza & 0 & 0 & 0 & 0 & $\mathbf{1 0}$ \\
\hline
\end{tabular}

Tabela 6.30: Matriz de Confusão - MLP II - Teste 7

\begin{tabular}{|c|c|c|c|c|c|}
\hline & \multicolumn{5}{|c|}{ Classe verdadeira } \\
\hline Classe prevista & Neutra & Alegria & Raiva & Surpresa & Tristeza \\
\hline Neutra & $\mathbf{9}$ & 0 & 0 & 0 & 0 \\
\hline Alegria & 0 & $\mathbf{1 0}$ & 0 & 0 & 0 \\
\hline Raiva & 0 & 0 & $\mathbf{1 0}$ & 0 & 0 \\
\hline Surpresa & 0 & 0 & 0 & $\mathbf{1 0}$ & 0 \\
\hline Tristeza & 1 & 0 & 0 & 0 & $\mathbf{1 0}$ \\
\hline
\end{tabular}

\subsection{Considerações Finais}

Nesse capítulo foram apresentados os resultados do sistema de imitação de expressões faciais de emoção proposto. Esse sistema é composto por dois módulos: módulo de extração automática de características da face e módulo de reconhecimento e geração de expressões faciais de emoção. No módulo de extração automática de características da face foram usados dois sistemas, o I e o II. O sistema I apresenta baixo tempo de resposta, porém a acurácia do sistema foi penalizada. O sistema II mostrou-se bastante robusto em relação ao sistema I, porém o tempo de resposta é mais lento, interferindo no atraso da geração da expressão emocional pela cabeça robótica. No módulo de reconhecimento e geração de expressões faciais de emoção, diferentes redes neurais foram investigadas e diferentes formas de avaliação foram realizadas até se obter a imitação mais adequada para esta pesquisa. 
Tabela 6.31: Matriz de Confusão - MLP II - Teste 8 Classe verdadeira

\begin{tabular}{|c|c|c|c|c|c|}
\hline & \multicolumn{5}{|c|}{ Classe verdadeira } \\
\hline Classe prevista & Neutra & Alegria & Raiva & Surpresa & Tristeza \\
\hline Neutra & $\mathbf{1 0}$ & 0 & 0 & 0 & 1 \\
\hline Alegria & 0 & $\mathbf{1 0}$ & 0 & 0 & 0 \\
\hline Raiva & 0 & 0 & $\mathbf{1 0}$ & 0 & 0 \\
\hline Surpresa & 0 & 0 & 0 & $\mathbf{1 0}$ & 0 \\
\hline Tristeza & 0 & 0 & 0 & 0 & $\mathbf{9}$ \\
\hline
\end{tabular}

Tabela 6.32: Matriz de Confusão - MLP II - Teste 9

\begin{tabular}{|c|c|c|c|c|c|}
\hline & \multicolumn{5}{|c|}{ Classe verdadeira } \\
\hline Classe prevista & Neutra & Alegria & Raiva & Surpresa & Tristeza \\
\hline Neutra & $\mathbf{9}$ & 0 & 0 & 0 & 1 \\
\hline Alegria & 0 & $\mathbf{1 0}$ & 0 & 0 & 0 \\
\hline Raiva & 0 & 0 & $\mathbf{1 0}$ & 0 & 0 \\
\hline Surpresa & 0 & 0 & 0 & $\mathbf{1 0}$ & 0 \\
\hline Tristeza & 1 & 0 & 0 & 0 & $\mathbf{9}$ \\
\hline
\end{tabular}

Tabela 6.33: Matriz de Confusão - MLP II - Teste 10

\begin{tabular}{|c|c|c|c|c|c|}
\hline & \multicolumn{5}{|c|}{ Classe verdadeira } \\
\hline Classe prevista & Neutra & Alegria & Raiva & Surpresa & Tristeza \\
\hline Neutra & $\mathbf{1 0}$ & 0 & 0 & 0 & 1 \\
\hline Alegria & 0 & $\mathbf{1 0}$ & 0 & 0 & 0 \\
\hline Raiva & 0 & 0 & $\mathbf{1 0}$ & 0 & 0 \\
\hline Surpresa & 0 & 0 & 0 & $\mathbf{1 0}$ & 0 \\
\hline Tristeza & 0 & 0 & 0 & 0 & $\mathbf{9}$ \\
\hline
\end{tabular}




\section{$-y$ \\ Conclusão e Trabalhos Futuros}

\subsection{Conclusão}

Uma das maneiras de tornar a interação entre um robô e um humano mais realística é dotá-lo de capacidades de expressões faciais de emoção. O objetivo desse trabalho é fornecer capacidade de imitação de expressões faciais de emoção a uma cabeça robótica virtual, a partir das expressões fornecidas por um humano, em uma interação social. A imitação envolve dois processos: reconhecer a expressão fornecida pelo usuário e gerar, através do robô, a expressão correspondente. Para isso, foi desenvolvido um sistema composto por dois módulos: módulo de extração automática de características da face e módulo de reconhecimento e geração de expressões faciais de emoção.

No módulo de extração automática de características da face foram usados dois sistemas, o I e o II. O sistema I foi desenvolvido no LAR/USP e o sistema II foi cedido por Jason (Saragih et al., 2011). O sistema I foi desenvolvido com o objetivo de extrair as características da face consumindo pouco tempo, pois o foco é usar esse sistema em tempo real. Contudo, a acurácia do sistema foi penalizada. O sistema II mostrou-se bastante robusto em relação ao sistema I, porém o tempo de resposta é mais lento, interferindo no atraso da geração da expressão emocional pela cabeça robótica.

Para desenvolver o módulo de reconhecimento e geração de expressões faciais de emoção, diferentes redes neurais foram investigadas até se obter a mais adequada para o objetivo desta pesquisa. Inicialmente, para permitir 
um aprendizado dinâmico e uma imitação mais realística, foi investigado o uso de uma rede neural recorrente de Jordan, com a qual não se obteve sucesso. Depois, foi utilizada uma rede TLFN para classificar os padrões agregando informação temporal. Entretanto, percebeu-se que não há necessidade de agregar o tempo durante o treinamento da rede. Assim, decidiu-se utilizar uma rede MLP para o aprendizado da classificação dos padrões e a TLFN para a geração da expressão da cabeça robótica no momento da interação com o usuário.

A avaliação do método proposto foi feita através de validação cruzada. A primeira forma de avaliação separou para teste informações de pessoas não vistas no treinamento das redes neurais. O objetivo dessa avaliação é medir a capacidade da rede neural em imitar pessoas desconhecidas. Entretanto, a acurácia obtida com essa avaliação não foi satisfatória, pois é difícil para a rede neural aprender a expressão do usuário sem conhecer alguma informação sobre ele. Com o objetivo de obter uma acurácia melhor, foi realizada a segunda forma de avaliação, que agrega informação de todos os usuários e de todas as expressões no treinamento e no teste, com a qual se obteve uma acurácia bastante satisfatória.

Este trabalho é o primeiro que investiga o aprendizado por imitação no nosso grupo de pesquisa. Por isso, diferentes redes neurais foram implementadas e diferentes formas de combinação dos dados foram realizadas para alcançar uma imitação satisfatória.

No nosso grupo há o projeto de usar a Valerie para atuar como um robô recepcionista no ICMC/USP dando informações básicas aos usuários, como por exemplo, a localização de uma sala. Este trabalho colabora nesse projeto, permitindo que a Valerie imite a expressão do usuário, tornando a interação mais amigável.

\subsection{Trabalhos Futuros}

Como continuidade deste trabalho, pretende-se melhorar o sistema de extração de características, denominado Sistema I. Com esse sistema, o tempo de resposta foi adequado para a interação, mas a precisão da detecção de pontos não foi. Assim, pretende-se obter um sistema cujo tempo de resposta seja aceitável em uma interação, mas que também seja capaz de detectar com precisão os pontos característicos da face, que são importantes para classificar a emoção. 
Além de melhorar o sistema de extração de características desenvolvido, pretende-se utilizar o sistema FACS (Facial Action Coding System) (Ekman e Friesen, 1978), que mede o movimento facial em termos de ações de músculos observáveis parcialmente para sistematicamente categorizar as expressões físicas de emoções. Segundo Gotoh et al. (2007), com o FACS, uma expressão humana observada é decomposta em uma ou mais de 44 unidades de ação, que representa a atividade muscular que produz mudanças momentâneas na aparência facial. Assim, com o uso desse sistema espera-se obter mais características da face humana e, assim, poder distinguir melhor as diferentes expressões faciais.

Inicialmente, pretendia-se adaptar o trabalho de Ito e Tani (2004) para o aprendizado por imitação. Desse modo, foi desenvolvido um código próprio em linguagem Java, para ter mais liberdade na alteração do modo de aprendizado. Como não se obteve a convergência dessa rede, a partir do código desenvolvido foram implementadas as demais redes utilizadas neste trabalho. Nos treinamentos realizados, o tempo para alcançar a convergência foi grande; alguns demoraram três dias para finalizar. Assim, como trabalho futuro, pretende-se utilizar uma ferramenta para organizar os dados de forma automática e mais eficaz.

$\mathrm{Na}$ avaliação, o modo que apresentou melhor acurácia foi aquele que insere informação de todos usuários no treinamente e no teste da rede neural. Entretanto, pretende-se utilizar esse sistemas em interações reais, para as quais não é possível obter informações das características da face de todos os usuários. Desse modo, será feita a avaliação do treinamento que considerou as características da face de todos os usuários disponíveis com usuários desconhecidos. Além disso, será investigado um modo para a rede neural aprender as expressões faciais de forma mais independente das características específicas dos usuários. Uma possibilidade é usar informações de uma quantidade maior de usuários para o treinamento e que possuam um variedade maior de características da face, como cor da pele e espessura dos lábios. Além disso, pode-se variar a intensidade de luz do ambiente no qual os vídeos são gravados e variar a postura da face dos usuários. Também será investigado o uso de outras abordagens inteligentes, tais como a pesquisa neuro fuzzy com aprendizado supervisionado (ANFIS) (Jang, 1992). 



\section{Referências Bibliográficas}

Alejandro e Govea (2010). Hidden markov models. In Incremental Learning for Motion Prediction of Pedestrians and Vehicles, volume 64 of Springer Tracts in Advanced Robotics, páginas 45-68. Springer Berlin / Heidelberg. Citado na página 17.

Argall, B. D., Chernova, S., Veloso, M., e Browning, B. (2009). A survey of robot learning from demonstration. Robotics and Autonomous Systems, 57(5):469483. Citado na página 16.

Billard, A., Calinon, S., e Guenter, F. (2006). Discriminative and adaptive imitation in uni-manual and bi-manual tasks. Robotics and Autonomous Systems, 54(5):370-384. Citado nas páginas 16 e 17.

Billard, A., Epars, Y., Calinon, S., Cheng, G., e Schaal, S. (2004). Discovering optimal imitation strategies. Robotics and Autonomous Systems, 47(2-3):6977. Citado na página 16.

Bjoorne, P. e Balkenius, C. (2005). A model of attentional impairments in autism: first steps toward a computational theory. Cognitive Systems Research, 6(3):193-204. Citado na página 1.

Bombini, G., Mauro, G. D., Basile, N., Ferilli, T. M. A., e Esposito, S. (2009). Relational learning by imitation. Agent and Multi-Agent Systems: Technologies and Applications, páginas 273-282. Citado na página 2.

Bosse, T., Memon, Z. A., e Treur, J. (2009). An adaptive agent model for emotion reading by mirroring body states and hebbian learning. In Proceedings of the 12th International Conference on Principles of Practice in Multi-Agent Systems, PRIMA '09, páginas 552-562, Berlin, Heidelberg. Springer-Verlag. Citado nas páginas 28, 29, e 51. 
Boucenna, S., Gaussier, P., Andry, P., e Hafemeister, L. (2010). Imitation as a communication tool for online facial expression learning and recognition. International Conference on Intelligent Robots and Systems. Citado nas páginas 26, 51, e 56 .

Bradski, G. (2000). The opencv library. Dr. Dobb's Journal of Software Tools. Citado na página 48.

Breazeal, C. (2000). Sociable Machines: Expressive Social Interaction Between Human and Robots. Tese de Doutorado, MIT Department of Electrical Engineering and Computer Science, Cambridge, MA. Citado na página 2.

Breazeal, C. (2002). Designing Sociable Robots. The MIT Press. Citado nas páginas 1,6 , e 10 .

Breazeal, C. (2003). Emotion and sociable humanoid robots. International Journal of Human-Computer Studies, 59:119-155. Citado nas páginas 11 e 23.

Breazeal, C. (2003b). Toward sociable robots. Robotics and Autonomous Systems, 42(3-4):167-175. Citado na página 10.

Calinon, S. (2009). Robot Programming by Demonstration: A Probabilistic Approach. EPFL/CRC Press. Citado nas páginas 15 e 16.

Calinon, S. e Billard, A. (2005). Learning of Gestures by Imitation in a Humanoid Robot. Cambridge University Press. Citado na página 15.

Casacuberta, D. (2000). Que es una emocion? Ed Critica. Citado nas páginas 9 e 10.

Cootes, T. e C.J.Taylor (1992). Active shape models - smart snakes. In In British Machine Vision Conference, páginas 266-275. Springer-Verlag. Citado na página 51.

Cruse, H. (2009). Neural networks as cybernetic systems - 3rd and revised edition. Brains, Minds and Media, (3). Citado na página 42.

da Silva, I. N., Spatti, D. H., e Flauzino, R. A. (2010). Redes Neurais Artificiais: para engenharia e ciencias aplicadas. Artliber Editora. Citado na página 32.

Damasio, A. (1994). Descartes' error: Emotion, reason, and the human brain. Picador, Londres. Citado na página 8. 
Dautenhahn, K., Ogden, B., e Quick, T. (2002). From embodied to socially embedded agents-implications for interactionaware robots. Cognitive Systems Research, 3(3). Citado na página 2.

Ding, L. e Martinez, A. (2008). Precise detailed detection of faces and facial features. In Computer Vision and Pattern Recognition, 2008. CVPR 2008. IEEE Conference on, páginas 1 -7. Citado nas páginas 46 e 49.

Dominguez, S., Casanova, E. Z., Garcia-Bermejo, J. G., e Pulido, J. (2006). Robot learning in a social robot. In $S A B$, páginas 691-702. Citado nas páginas 10 e 11 .

Duffy, B. R., Rooney, C., O'Hare, G., e O'Donoghue, R. (1999). What is a Social Robot? In 10th Irish Conf. on Artificial Intelligence and Cognitive Science, UCC, Ireland. Citado na página 5.

Ekman, P. e Friesen, W. V. (1978). Facial action coding system. Consulting Psychologists Press. Citado nas páginas 25 e 77.

Freund, Y. e Schapire, R. E. (1997). A decision-theoretic generalization of on-line learning and an application to boosting. Journal of Computer and System Sciences, 55(1):119-139. Citado na página 48.

Frith, C. (2009). Role of facial expressions in social interactions. Philosophical Transactions of the Royal Society B-Biological Sciences, 364(1535):34533458. Citado na página 8.

Fukunaga, K. e Hostetler, L. (1975). The estimation of the gradient of a density function, with applications in pattern recognition. Information Theory, IEEE Transactions on, 21(1):32-40. Citado na página 50.

Ge, S. S., Wang, C., e Hang, C. C. (2008). Facial expression imitation in human robot interaction. In 17th IEEE International Symposium on Robot and Human Interactive Communication, páginas 213-218, Munich, Germany. Citado nas páginas 8, 24, e 56.

Geman, S., Bienenstock, E., e Doursat, R. (1992). Neural networks and the bias/variance dilemma. Neural Computation, (4):1 - 58. Citado na página 39.

Gockley, R., Bruce, A., Forlizzi, J., Michalowski, M., Mundell, A., Rosenthal, S., Sellner, B., Simmons, R., Snipes, K., Schultz, A. C., e Wang, J. (2005). 
Designing robots for long-term social interaction. In Intelligent Robots and Systems, 2005. (IROS 2005). 2005 IEEE/RSJ International Conference on, páginas 1338-1343. Citado na página 52.

Gockley, R., Forlizzi, J., e Simmons, R. (2007). Natural person-following behavior for social robots. In Proceedings of the ACM/IEEE international conference on Human-robot interaction, páginas 17-24, New York, NY, USA. Citado nas páginas 6 e 8 .

Gonzalez, R. C. e Woods, R. E. (2001). Digital Image Processing. AddisonWesley Longman Publishing Co., Inc., Boston, MA, USA, 2ndł edição. Citado na página 48.

Gotoh, M., Kanoh, M., Kato, S., e Itoh, H. (2007). A neural-based approach to facial expression mapping between human and robot. In Proceedings of the 11th international conference, KES 2007 and XVII Italian workshop on neural networks conference on Knowledge-based intelligent information and engineering systems: Part III, páginas 194-201, Berlin, Heidelberg. SpringerVerlag. Citado nas páginas 25, 51, 56, e 77.

Gouaillier, D., Hugel, V., Blazevic, P., Kilner, C., Monceaux, J., Lafourcade, P., Marnier, B., Serre, J., e Maisonnier, B. (2009). Mechatronic design of nao humanoid. In Proceedings of the 2009 IEEE international conference on Robotics and Automation, ICRA'09, páginas 2124-2129, Piscataway, NJ, USA. IEEE Press. Citado na página 24.

Grimes, D. B. e Rao, R. P. N. (2009). Learning actions through imitation and exploration: Towards humanoid robots that learn from humans. Creating Brain-Like Intelligence: from Basic Principles to Complex Intelligent Systems, 5436:103-138. Citado na página 18.

Haykin, S. (1999). Neural Networks: A Comprehensive Foundation. Prentice Hall, Upper Saddle River, NJ. 2nd edition. Citado nas páginas 32, 40, 41, 55 , e 60.

Iacoboni, M. (2005). Neural mechanisms of imitation. Curr. Opin. Neurobiol., 15:632-637. Citado na página 23.

Ito, M. e Tani, J. (2004). On-line imitative interaction with a humanoid robot using a dynamic neural network model of a mirror system. Adaptive Behavior, 12(2):93-115. Citado nas páginas 18, 19, 51, 53, 56, e 77. 
James, W. (1884). What is an emotion? Mind, 9(34):pp. 188-205. Citado na página 9 .

Jang, R. (1992). Neuro-Fuzzy Modeling: Architectures, Analyses and Applications. Tese de Doutorado, University of California, Berkeley. Citado na página 77 .

Kanda, T., Sata, R., Saiwaki, N., e Ishiguro, H. (2004). Friendly social robot that understands human's friendly relationships. IEEE/RSJ International Conference on Intelligent Robots and Systems, páginas 2215-2222. Citado na página 6.

Kato, S., Ohshiro, S., Itoh, H., e Kimura, K. (2004). Development of a communication robot ifbot. In Robotics and Automation, 2004. Proceedings. ICRA '04. 2004 IEEE International Conference on. Citado na página 25.

Kirby, R., Forlizzi, J., e Simmons, R. (2010). Affective social robots. Robotics and Autonomous Systems, 58(3):322-332. Citado na página 11.

Larson, S. C. (1931). The shrinkage of the coefficient of multiple correlation. Journal of Educational Psychology, 22:45-55. Citado na página 57.

Lee, D. e Nakamura, Y. (2010). Mimesis model from partial observations for a humanoid robot. Int. J. Rob. Res., 29:60-80. Citado na página 22.

Masayoshi Kanoh, Shohei Kato, H. I. (2004). Facial expressions using emotional space in sensitivity communication robot "ifbot". In IEEE/RSJ International Conference on Intelligent Robots and Systems, páginas 15861591, Sendai, Japan. Citado na página 25.

Mazumdar, J. e Harley, R. (2008). Recurrent neural networks trained with backpropagation through time algorithm to estimate nonlinear load harmonic currents. Industrial Electronics, IEEE Transactions on, 55(9):3484 -3491. Citado na página 42.

Michaud, F., Pirjanian, P., Audet, J., e Letourneau, F. (2000). Artificial emotion and social robotics. In International Symposium on Distributed Autonomous Robotic Systems. Citado na página 10.

Monceaux, J., Becker, J., Boudier, C., e Mazel, A. (2009). Demonstration: first steps in emotional expression of the humanoid robot nao. In Proceedings of the 2009 international conference on Multimodal interfaces, ICMI-MLMI '09, páginas 235-236, New York, NY, USA. ACM. Citado na página 24. 
Oatley, K., Keltner, D., e Jenkins, J. M. (1996). Understanding Emotions. Blackwell. Citado na página 9.

Otsu, N. (1979). A threshold selection method from gray-level histograms. IEEE Transactions on Systems, Man and Cybernetics, 9(1):62-66. Citado na página 50.

Oztop, E., Kawato, M., e Arbib, M. (2006). Mirror neurons and imitation: A computationally guided review. Neural Networks, 19(3):254-271. Citado na página 18.

Policastro, C., Pais, G., Munhoz, V., Romero, R., Zuliani, G., e Pizzolato, E. (2008). Applying learning by tutelage and multimodal interface to sociable robots. In Seventh International Conference on Machine Learning and Applications, páginas 792-795, Washington, DC, USA. Citado nas páginas 6 e 9 .

Policastro, C., Zuliani, G., e Romero, R. (2007). Robotic architecture inspired on behavior analysis. In IEEE International Joint Conference on Neural Network, páginas 1482-1487, Orlando, Florida, USA. Citado nas páginas 6 e 9 .

Refaeilzadeh, P., Tang, L., e Liu, H. (2009). Cross-validation. In Liu, L. e Ozsu, M. T., editors, Encyclopedia of Database Systems, páginas 532-538. Springer US. Citado na página 58.

Richert, W., Scheller, U., Koch, M., Kleinjohann, B., e Stern, C. (2009). Integrating sporadic imitation in reinforcement learning robots. In IEEE International Symposium on Approximate Dynamic Programming and Reinforcement Learning (ADPRL'O9). Citado na página 21.

Robins, B., Dickerson, P., Stribling, P., e Dautenhahn (2004). Robot-mediated joint attention in children with autism: A case study in robot-human interaction. Interaction Studies, 5(2):161-198. Citado na página 1.

Rosemblatt, F. (1958). The perceptron: a probabilistic model for information storage and organization in the brain. In Phychological Review, páginas 386-408. Citado na página 39.

Rumelhart, D. E., Hinton, G. E., e Willians, R. J. (1986a). Learning representations of back-propagation errors. Nature, páginas 536 - 553 . Citado na página 36. 
Rumelhart, D. E., Hinton, G. E., e Willians, R. J. (1986b). Learning representations of backpropagation errors. In Nature, páginas 536-553. Citado na página 39.

Sakoe, H. e Chiba, S. (1978). Dynamic programming algorithm optimization for spoken word recognition. IEEE Transactions on Acoustics, Speech and Signal Processing, 26(1):43-49. Citado na página 21.

Salichs, M., Barber, R., Khamis, A., Malfaz, M., Gorostiza, J., Pacheco, R., Rivas, R., Corrales, A., e E. Delgado, E. (2006). Maggie: A robotic platform for human-robot social interaction. In IEEE International Conference on Robotics, Automation and Mechatronics, Bangkok, Thailand. Citado nas páginas 6,7 , e 9 .

Saragih, J., Lucey, S., e Cohn, J. (2011). Deformable Model Fitting by Regularized Landmark Mean-Shift. International Journal of Computer Vision, 91(2):200-215. Citado nas páginas 46, 50, 58, e 75.

Sidner, C., Lee, C., Kidd, C., Lesh, N., e Rich, C. (2005). Explorations in engagement for humans and robots. Artificial Intelligence, 166(1-2):181186. Citado na página 6.

Thobbi, A. e Sheng, W. (2010). Imitation learning of hand gestures and its evaluation for humanoid robots. páginas 60-65. Citado na página 20.

Viola, P. e Jones, M. (2001). Rapid object detection using a boosted cascade of simple features. páginas 511-518. Citado na página 48.

Webb, B. (2000). What does robotics offer animal behaviour? Animal Behaviour, 60(5):545-558. Citado na página 1.

Widrow, B. e Hoff., M. (1960). Adaptive switching circuits. 1960 IRE WESCON Convention Record, Part 4, páginas 96 - 104. Citado na página 36. 